CONDIÇÕES OPERACIONAIS . DE TURBOATOMIZADORES NA DISTRIBUIÇÃO E DEPOSIÇÃO DA PULVERIZAÇÃO EM CITROS

CARLOS GILBERTO RAETANO

Engenheiro Agrônomo

Orientador: Prof. Dr. TOMOMASSA MATUO

Tese apresentada à Escola Superior de Agricultura "Luiz de Queiroz", da Universidade de São Paulo, para obtenção do título de Doutor em Ciências, Área de Concentração: Entomologia.

P I R A C I C A B A

Estado de São Paulo - Brasil

Novembro - 1996 
Dados Internacionais de Catalogação na Publicação (CIP)

DIVISÃO DE BIBLIOTECA E DOCUMENTAÇÃO - Campus "Luiz de Queiroz"/USP

Raetano, Carlos Gilberto

Condiçōes operacionais de turboatomizadores na distribuiçāo e deposiçāo da pulverizaçăo em citros / Carlos Gilberto Raetano. - . Piracicaba, 1996

93 p. : il.

Tese (doutorado) -- Escola Superior de Agricultura Luiz de Queiroz, 1997. Bibliografia.

1. Acaricida 2. Ácaro - Controle 3. Laranja valência 4. Pulverizador - Avaliaçāo I. Titulo

CDD 632.951

632.6542 
CONDIÇÕES OPERACIONAIS DE TURBOATOMIZADORES NA DISTRIBUIÇÃO E DEPOSIÇÃO DA PULVERIZAÇÃO EM CITROS

Aprovada em : 17.02.1997

Comissão Julgadora :

Prof. Dr. Tomomassa Matuo

ESALQ/USP

Prof. Dr. Octávio Nakano

ESALQ/USP

Prof. Dr. Luiz Gonzaga Chiavegato

FCA/UNESP

Prof. Dr. Carlos Amadeu Leite de Oliveira

FCAVJ/UNESP

Prof. Dr. Joaquim Gonçalves Machado Neto

FCAVJ/UNESP

$\frac{\text { Prof. Dr. TOMOMASSA MATUO }}{\text { Tmò }}$

Orientador 
Aos meus pais

e irmãs

\section{OFEREÇO}

À minha esposa. pela paciência.

amor e dedicação

DEDICO 


\section{AGRADECIMENTOS}

Ao Prof. Dr. Tomomassa Matuo, pela amizade e orientação na execução desta pesquisa;

Aos professores do Departamento de Entomologia da ESALQ/ USP, pelos ensinamentos transmitidos e atenção dispensada, em especial ao Prof. Dr. Evôneo Berti Filho, pelas sugestões apresentadas;

À Máquinas Agrícolas Jacto S.A., pelo equipamento e material fornecidos para o desenvolvimento deste trabalho, com especial referência aos engenheiros agrônomos Alberto Honda, Affonso Celso Ribeiro Filho e Fabio Pernassi Torres;

Ao Sr. Lázaro Boschiero pelas condições e facilidades oferecidas para a realização do trabalho;

À Coordenação de Aperfeiçoamento Pessoal de Nível Superior (CAPES) pela bolsa de estudos concedida durante a realização do curso;

Aos professores do Departamento de Defesa Fitossanitária da FCA/UNESP - "Campus" de Botucatu, em especial aos professores Dr. Wilson Badiali Crocomo e Dr. Luiz Gonzaga Chiavegato, pelas sugestões e apoio dispensados durante o desenvolvimento deste trabalho;

Ao Prof. Dr. Edivaldo Domingues Velini da FCA/UNESP, pela orientação na determinação e análise dos depósitos foliar;

Aos professores do Departamento de Estatística da ESALQ/USP, pelo auxílio na análise dos dados, em especial ao Prof. Dr. Décio Barbin; 
Aos funcionários da Biblioteca Central da ESALQ/USP, pela colaboração e obtenção das referências bibliográficas;

À Sra. Rita de Cássia Colombara Gasparini pelos serviços de digitação;

E a todos que, direta e indiretamente, contribuíram para a realização deste trabalho. 
Página

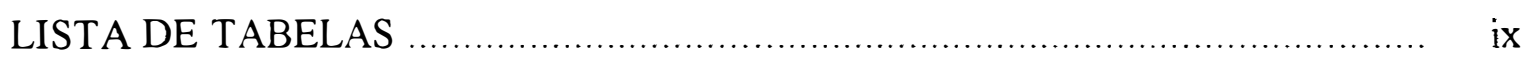

LISTA DE FIGURAS _..................................................................... xvi

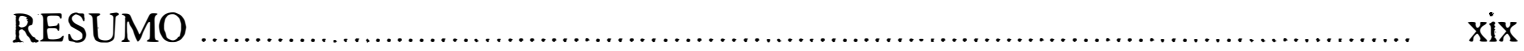

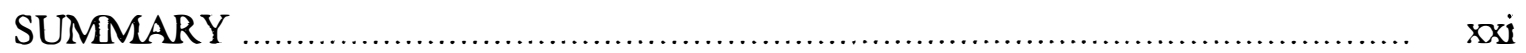

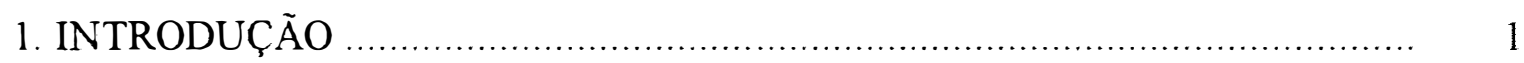

2. REVISÃO DE LITERATURA …............................................................ 4

2.1. Técnicas de pulverização ........................................................................ 4

2.2. Emprego de aditivos no estudo da deposição ................................................ 10

3. MATERIAL E MÉTODOS _.................................................................... 12

3.1. Distribuição e deposição das pulverizações ……………………................... 12

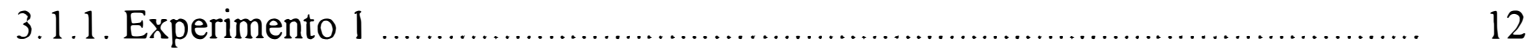

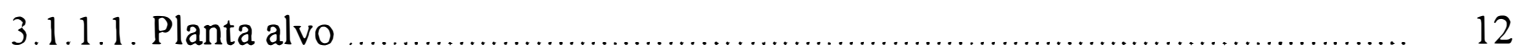

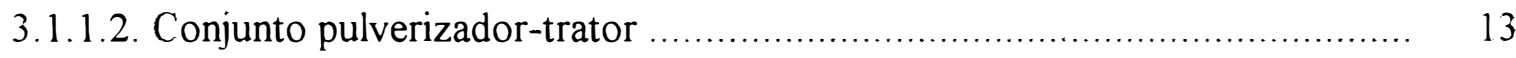

3.1.1.3. Bicos de pulverização ................................................................... 13

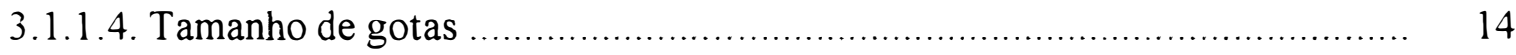

3.1.1.5. Seleção, caracterização e aplicação do pigmento fluorescente …............... 16

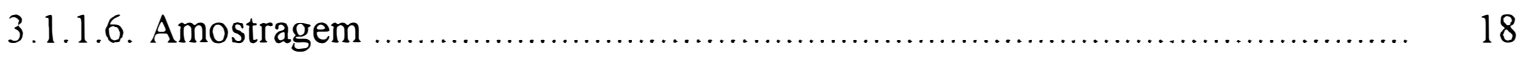

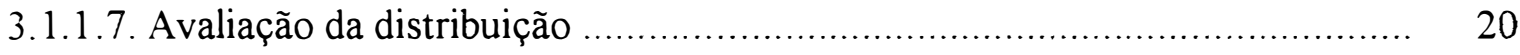

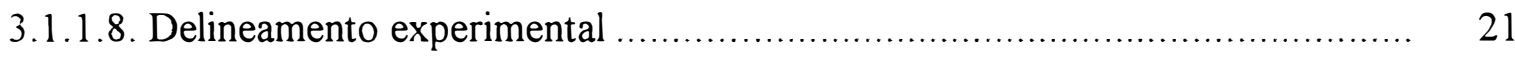

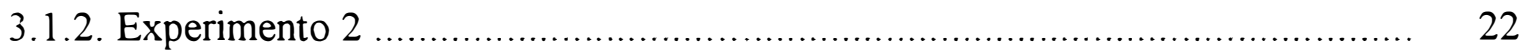

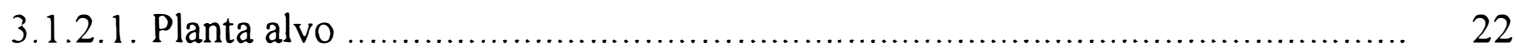

3.1.2.2. Delineamento experimental e tratamentos ......................................... 22 
3.1.2.3. Amostragem

3.1.2.4. Determinação da área foliar ............................................................... 23

3.1.2.5. Quantificação dos depósitos ........................................................... 24

3.2. Efeito da distribuição e deposição das pulverizações no controle de ácaros ....... 25

3.2.1. Experimento 3 - Controle do ácaro purpúreo $P$. citri .............................. 25

3.2.1.1. Avaliação da população de $P$. citri ....................................................... 26

3.2.1.2. Delineamento experimental ............................................................ 27

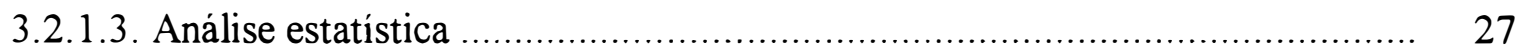

3.2.2. Experimento 4 - Controle do ácaro da leprose B. phoenicis _................... 28

3.2.2.1. Avaliação da população de $B$. phoenicis ................................................. 28

3.2.2.2. Delineamento experimental ........................................................... 29

3.2.2.3. Análise estatística ......................................................................... 29

3.2.3. Experimento 5 - Controle do ácaro da falsa ferrugem $P$. oleivora ............. 30

3.2.3.1. Avaliação da população de $P$. oleivora ……......................................... 31

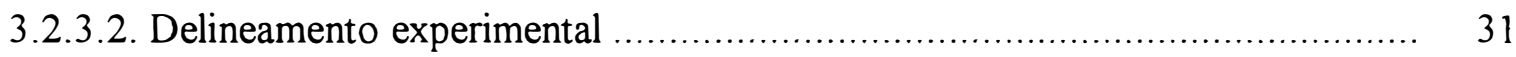

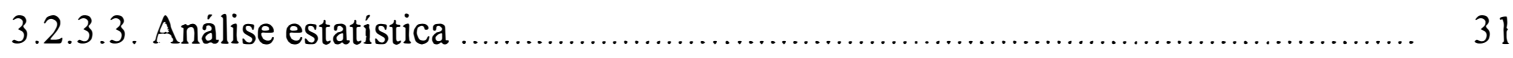

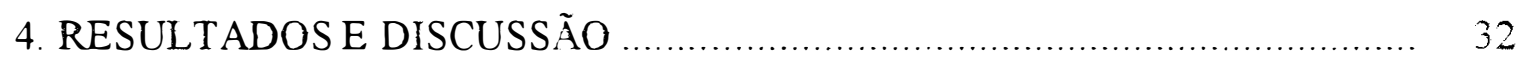

4.1. Distribuição e deposição das pulverizações .................................................. 32

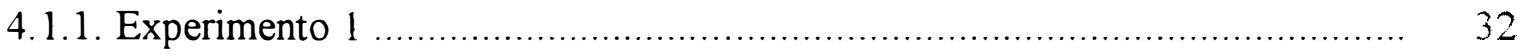

4.1.1.1. Vazão e volume de aplicação ......................................................... 32

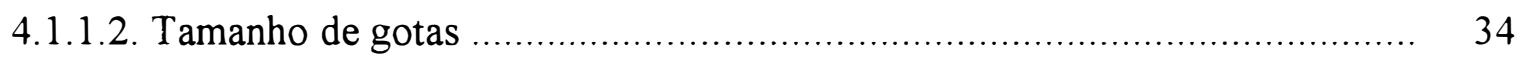

4.1.1.3. Cobertura da pulverização ............................................................. 36

4.1.1.3.1. Quadrante I - Superficie adaxial da folha ........................................ 37

4.1.1.3.2. Quadrante I - Superficie abaxial da folha ........................................ 41

4.1.1.3.3. Quadrante II - Superficie adaxial da folha ........................................ 44

4.1.1.3.4. Quadrante II - Superficie abaxial da folha ....................................... 47

4.1.1.3.5. Quadrante III - Superficie adaxial da folha ...................................... 50 
4.1.1.3.6. Quadrante III - Superficie abaxial da folha ........................................ 53

4.1.1.3.7. Quadrante IV - Superficie adaxial da folha ........................................ 57

4.1.1.3.8. Quadrante IV - Superficie abaxial da folha ...................................... 60

4.1.1.3.9. Comparação entre os fatores arranjo de bicos, pressão e velocidade nos

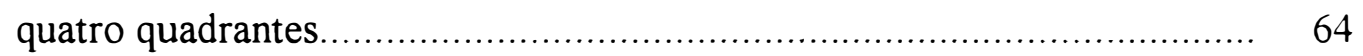

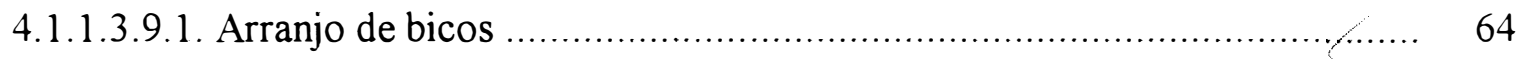

4.1.1.3.9.2. Pressão ....................................................................................... 65

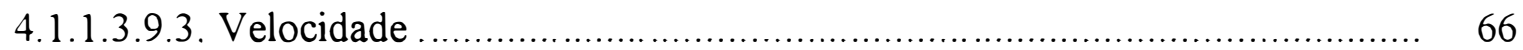

4.1.1.4. Penetração da pulverização ............................................................... 66

4.1.1.4.1. Índice médio de penetração da pulverização e frequència (\%) de notas

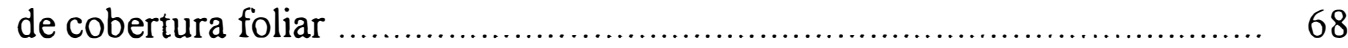

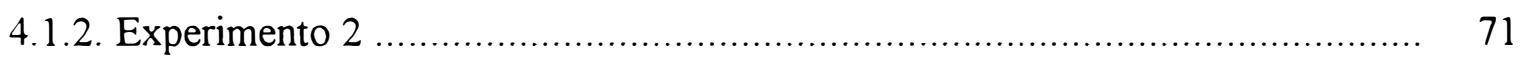

4.1.2.1. Quantificação dos depósitos da solução de $\mathrm{KCl}$ nas folhas ....................... 72

4.2. Efeito da distribuição e depósito de pulverizações no controle de ácaros ......... 75

4.2.1. Experimento 3 - Controle do ácaro purpúreo (P. citri) ............................ 75

4.2.2. Experimento 4 - Controle do ácaro da leprose (B. phoenicis) .................... 78

4.2.3. Experimento 5 - Controle do ácaro da falsa ferrugem (P. oleivora) ............ 80

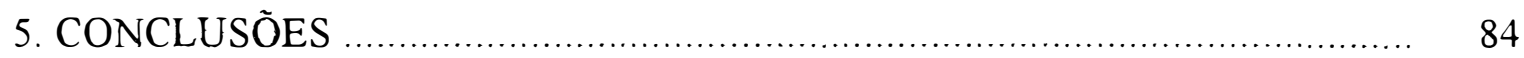

REFERÊNCIAS BIBLIOGRÁFICAS _......................................................... 86 


\section{LISTA DE TABELAS}

TABELA

Página

1 Arranjo, distribuição, tipo e vazão média ( litros/min.) dos bicos nos ramais de pulverização para os turboatomizadores Arbus 2000 / Export $\left(\mathrm{M}_{1}\right)$ e Arbus $2000 / 850\left(\mathrm{M}_{2}\right)$ pulverizando à $200\left(\mathrm{P}_{1}\right)$ e $300\left(\mathrm{P}_{2}\right)$ $\mathrm{lbf} / \mathrm{pol}^{2}$

2 Tratamentos estabelecidos na aplicação de $\mathrm{KCl}(3 \%)$ em pulverização com o turboatomizador Arbus 2000/Export, especificando a velocidade de deslocamento $(\mathrm{km} / \mathrm{h})$, pressão $\left(\mathrm{lbf} / \mathrm{pol}^{2}\right)$, arranjo de bicos e volume de aplicação (litros/hectare)

3 Tratamentos com diferentes equipamentos, arranjo de bicos e dosagens do produto azociclotin no controle de Panonychus citri.

4 Tratamentos empregados no controle de Brevipalpus phoenicis com o acaricida azociclotin, aplicado por turboatomizadores equipados com diferentes arranjos de bicos de pulverização

5 Tratamentos selecionados na aplicação do acaricida azociclotin visando o controle de Phyllocoptruta oleivora especificando-se modelo de turboatomizador, arranjo de bicos, velocidade de deslocamento e volume de aplicação

6 Vazão total nos ramais de pulverização para os respectivos arranjos, em um dos lados dos turboatomizadores Arbus 2000 / Export $\left(\mathrm{M}_{1}\right)$ e Arbus $2000 / 850\left(\mathrm{M}_{2}\right)$, em diferentes pressões 
7 Volume de aplicação, por planta, nas diferentes combinações de arranjo de bicos, pressão $\left(\mathrm{lbf} / \mathrm{pol}^{2}\right)$ e velocidade com os turboatomizadores Arbus 2000 / Export $\left(\mathrm{M}_{1}\right)$ e Arbus $2000 / 850\left(\mathrm{M}_{2}\right)$

8 Diâmetro mediano volumétrico $(\mathrm{dmv})$, diâmetro mediano numérico (dmn) e coeficiente de dispersão ( $r$ ) das gotas produzidas por diferentes bicos de pulverização em dois níveis de pressão

9 Efeito do arranjo de bicos, pressão e velocidade de trabalho na cobertura da superficie adaxial das folhas, nas posições alta externa (AE) e interna (AI); média externa (ME) e interna (MI) e baixa externa (BE) e interna (BI) do quadrante $\mathrm{I}$

9A Médias das notas de cobertura da pulverização na superficie adaxial das folhas para as interações: Arranjo de bicos x pressão; arranjo de bicos $x$ velocidade e pressão $x$ velocidade, nas posições alta externa ( $\mathrm{AE}$ ) e interna ( $\mathrm{AI})$; média externa (ME) e interna (MI) e baixa externa (BE) e interna (BI) do quadrante I

10 Efeito do arranjo de bicos, pressão e velocidade de trabalho na cobertura da superficie abaxial das folhas nas posições alta externa (AE) e interna (AI); média externa (ME) e interna (MI) e baixa externa (BE) e interna (BI) do quadrante I 
10A Médias das notas de cobertura da pulverização na superficie abaxial das folhas para as interações: Arranjo de bicos x pressão; arranjo de bicos $\mathrm{x}$ velocidade e pressão $\mathrm{x}$ velocidade, nas posições alta externa (AE) e interna ( $\mathrm{AI})$; média externa (ME) e interna (MI) e baixa externa (BE) e interna (BI) do quadrante I

11 Efeito do arranjo de bicos, pressão e velocidade de trabalho na cobertura da superficie adaxial das folhas nas posições alta externa (AE) e interna (AI); média externa (ME) e interna (MI) e baixa externa (BE) e interna (BI) do quadrante II

$11 \mathrm{~A}$ Médias das notas de cobertura da pulverização na superficie adaxial das folhas para as interações: Arranjo de bicos x pressão; arranjo de bicos $x$ velocidade e pressão $x$ velocidade, nas posições alta externa (AE) e interna ( $\mathrm{AI})$; média externa (ME) e interna (MI) e baixa externa (BE) e interna (BI) do quadrante II

12 Efeito do arranjo de bicos, pressão e velocidade de trabalho na cobertura da superficie abaxial das folhas nas posições alta externa (AE) e interna ( $\mathrm{AI})$; média externa (ME) e interna (MI) e baixa externa (BE) e interna (BI) do quadrante II

12A Médias das notas de cobertura da pulverização na superficie abaxial das folhas para as interações: Arranjo de bicos x pressão; arranjo de bicos $\mathrm{x}$ velocidade e pressão $\mathrm{x}$ velocidade, nas posições alta externa (AE) e interna (AI); média externa (ME) e interna (MI) e baixa externa (BE) e interna (BI) do quadrante II 
13 Efeito do arranjo de bicos, pressão e velocidade de trabalho na cobertura da superficie adaxial das folhas nas posições alta externa $(\mathrm{AE})$ e interna $(\mathrm{AI})$; média externa $(\mathrm{ME})$ e interna $(\mathrm{MI})$ e baixa externa (BE) e interna (BI) do quadrante III

13A Médias das notas de cobertura da pulverização na superficie adaxial das folhas para as interações: Arranjo de bicos x pressão; arranjo de bicos $\mathrm{x}$ velocidade e pressão $\mathrm{x}$ velocidade, nas posições alta externa ( $\mathrm{AE})$ e interna ( $\mathrm{AI})$; média externa $(\mathrm{ME})$ e interna $(\mathrm{MI})$ e baixa externa (BE) e interna (BI) do quadrante III

14 Efeito do arranjo de bicos, pressão e velocidade de trabalho na cobertura da superficie abaxial das folhas nas posições alta externa $(\mathrm{AE})$ e interna $(\mathrm{AI})$; média externa $(\mathrm{ME})$ e interna $(\mathrm{MI})$ e baixa externa (BE) e interna (BI) do quadrante III

14A Médias das notas de cobertura da pulverização na superficie abaxial das folhas para as interações: Arranjo de bicos x pressão; arranjo de bicos $x$ velocidade e pressão $x$ velocidade, nas posições alta externa $(\mathrm{AE})$ e interna ( $\mathrm{AI})$; média externa $(\mathrm{ME})$ e interna $(\mathrm{MI})$ e baixa externa (BE) e interna (BI) do quadrante III

15 Efeito do arranjo de bicos, pressão e velocidade de trabalho na cobertura da superficie adaxial das folhas nas posições alta externa $(\mathrm{AE})$ e interna $(\mathrm{AI})$; média externa $(\mathrm{ME})$ e interna $(\mathrm{MI})$ e baixa externa (BE) e interna (BI) do quadrante IV 
15A Médias das notas de cobertura da pulverização na superficie adaxial das folhas para as interações: Arranjo de bicos x pressão; arranjo de bicos $\mathrm{x}$ velocidade e pressão $\mathrm{x}$ velocidade, nas posições alta externa (AE) e interna (AI); média externa (ME) e interna (MI) e baixa externa (BE) e interna (BI) do quadrante IV

16 Efeito do arranjo de bicos, pressão e velocidade de trabalho na cobertura da superficie abaxial das folhas nas posições alta externa $(\mathrm{AE})$ e interna ( $\mathrm{AI}$ ); média externa (ME) e interna (MI) e baixa externa (BE) e interna (BI) do quadrante IV

16A Médias das notas de cobertura da pulverização na superficie abaxial das folhas para as interações: Arranjo de bicos x pressão; arranjo de bicos $x$ velocidade e pressão $x$ velocidade, nas posições alta externa (AE) e interna ( $\mathrm{AI})$; média externa (ME) e interna (MI) e baixa externa $(\mathrm{BE})$ e interna $(\mathrm{BI})$ do quadrante IV

17 Índice de penetração para a relação entre cobertura foliar interna (I) e externa (E) na parte baixa (B), média (M) e alta (A) da planta, em diferentes arranjos de bicos, pressões e velocidades nas superficies adaxial e abaxial da folha nos respectivos quadrantes

18 Índices médios de penetração da pulverização para as superficies adaxial e abaxial das folhas e volume de aplicação nos respectivos tratamentos envolvendo diferentes arranjos de bicos $\left(A_{2}, A_{3}, A_{4}, A_{5}\right.$ e $\left.A_{6}\right)$, pressões $\left(P_{1}=200 \mathrm{lbf} / \mathrm{pol}^{2}\right.$ e $\left.P_{2}=300 \mathrm{lbf} / \mathrm{pol}^{2}\right)$ e velocidades $\left(\mathrm{V}_{1}=3,6 \mathrm{~km} / \mathrm{h} \mathrm{e} \mathrm{V}_{2}=5,1 \mathrm{~km} / \mathrm{h}\right)$ 
19 Número médio de Panonychus citri, em 25 folhas, antes (-) e após (+) a pulverização do acaricida azociclotin em diferentes dosagens. São Pedro, SP. Novembro /1994 76

20 Eficiência média (\%) dos diferentes tratamentos no controle de Panonychus citri após a aplicação do acaricida azociclotin em diferentes dosagens. São Pedro, SP. Novembro/1994

21 Número médio de Brevipalpus phoenicis, por fruto, antes (-) e após $(+)$ a aplicação do acaricida azociclotin nos diferentes tratamentos. São Pedro, SP. Março a maio/1995.

22 Eficiência média (\%) de controle de Brevipalpus phoenicis após a aplicação do acaricida azociclotin por turboatomizadores trabalhando sob diferentes condições operacionais. São Pedro, SP. Março a maio/1995

23 Número médio de Phyllocoptruta oleivora na superficie adaxial das folhas antes (-) e após (+) a aplicação do acaricida azociclotin com o turboatomizador Arbus 2000 / Export sob diferentes condições operacionais. São Pedro, SP. Agosto a outubro/1995

24 Número médio de Phyllocoptruta oleivora na superficie abaxial das folhas antes (-) e após (+) a aplicação do acaricida azociclotin com o turboatomizador Arbus 2000 / Export sob diferentes condições operacionais. São Pedro, SP. Agosto a outubro/1995 
TABELA

Página

25 Eficiência média (\%) de controle de Phyllocoptruta oleivora, nas superficies adaxial e abaxial das folhas, até 56 dias da aplicação do produto azociclotin. São Pedro, SP. Agosto a outubro/1995 ............ 


\section{LISTA DE FIGURAS}

FIGURA

Página

1 Distribuição dos bicos de pulverização: 13 bicos num único ramal no turboatomizador Arbus 2000/850 (A); 21 (B) ou 35 (C) bicos em ramais superior e inferior no turboatomizador Arbus 2000/ Export

2 Anteparo triangular deslisante com abertura simultânea lateral, com destaque para a disposição das lâminas em seu interior

3 Pulverização do traçador fluorescente no pomar com o turboatomiza dor Arbus 2000 / Export

4 Representação esquemática dos 24 setores de amostragem na copa da planta pulverizada. Quadrantes I, II, III e IV = posição em relação à pulverização; $\mathrm{B}, \mathrm{M}$ e A = Baixa (até $1,20 \mathrm{~m})$, média $(1,20 \mathrm{a}$ $2,40 \mathrm{~m}$ ) e alta (superior a $2,40 \mathrm{~m}$ ); E e I = posição em relação à profundidade: externa (até $0,40 \mathrm{~m}$ da periferia), interna (além de $0,40 \mathrm{~m}$ da periferia

5 Escala de notas referencial para a avaliação da cobertura da pulverização em citros (var. Valência)

6 Freqüência (\%) de notas pares (cobertura em toda a superficie foliar) nos diferentes tratamentos envolvendo os arranjos de bicos $A_{2}$, $\mathrm{A}_{3}, \mathrm{~A}_{4}, \mathrm{~A}_{5}$ e $\mathrm{A}_{6}$, sob pressões de $200\left(\mathrm{P}_{1}\right)$ ou $300 \mathrm{lbf} / \mathrm{pol}^{2}\left(\mathrm{P}_{2}\right)$ nas velocidades de $3,6\left(\mathrm{~V}_{1}\right)$ ou $5,1 \mathrm{~km} / \mathrm{h}\left(\mathrm{V}_{2}\right)$ 
FIGURA

7 Frequiência ( $\%$ ) de notas ímpares (cobertura em segmentos da superficie foliar) nos diferentes tratamentos envolvendo os arranjos de bicos $A_{2}, A_{3}, A_{4}, A_{5}$ e $A_{6}$, sob pressões de $200\left(P_{1}\right)$ ou $300 \mathrm{lbf}$ $/ \mathrm{pol}^{2}\left(\mathrm{P}_{2}\right)$ nas velocidades de $3,6\left(\mathrm{~V}_{1}\right)$ ou $5,1 \mathrm{~km} / \mathrm{h}\left(\mathrm{V}_{2}\right)$

8 Depósito médio de calda $\left(\mu \mathrm{l} / \mathrm{cm}^{2}\right)$ nas folhas externas da parte alta, média e baixa da copa aplicado em diferentes condições operacionais, avaliado através da condutividade elétrica do $\mathrm{KCl}$ em água....

9 Depósito médio de calda $\left(\mu 1 / \mathrm{cm}^{2}\right)$ nas folhas internas da parte alta, média e baixa da copa aplicado em diferentes condições operacionais, avaliado através da condutividade elétrica do $\mathrm{KCl}$ em água....

10 Depósito médio de calda $\left(\mu \mathrm{l} / \mathrm{cm}^{2}\right)$ nas folhas externas da copa posicionadas a $0^{\circ}, 90^{\circ} \mathrm{e} 180^{\circ}$ em relação à pulverização realizada sob diferentes condições operacionais, avaliado através da condutividade elétrica do $\mathrm{KCl}$ em água

11 Depósito médio de calda $\left(\mu \mathrm{l} / \mathrm{cm}^{2}\right)$ nas folhas internas da copa posicionadas a $0^{\circ}, 90^{\circ}$ e $180^{\circ}$ em relação à pulverização realizada sob diferentes condições operacionais, avaliado através da condutividade elétrica do $\mathrm{KCl}$ em água 
12 Número médio de Panonychus citri antes (-) e após (+) a aplicação nos diferentes tratamentos: $\mathrm{M}_{2} / \mathrm{A}_{5} / 100$ - turboatomizador $\mathrm{Ar}-$ bus $2000 / 850 \mathrm{com}$ arranjo $\mathrm{A}_{5}$ pulverizando $100 \mathrm{~g}$ p.c. $/ 100 \mathrm{li}-$ tros d'água; $\mathrm{M}_{1} / \mathrm{A}_{3} / 50,75$ e 100 - turboatomizador Arbus 2000 / Export com arranjo $\mathrm{A}_{3}$ pulverizando 50, 75 e 100g p.c. / 100 litros d'água, respectivamente e testemunha 


\title{
CONDIÇÕES OPERACIONAIS DE TURBOATOMIZADORES NA DISTRIBUIÇÃO E DEPOSIÇÃO DA PULVERIZAÇÃO EM CITROS
}

\author{
Autor: CARLOS GILBERTO RAETANO \\ Orientador : PROF. DR. TOMOMASSA MATUO
}

\section{RESUMO}

Visando estudar a distribuição e a deposição das gotas nas pulverizações com turboatomizadores no controle de ácaros, foram instalados cinco experimentos em um pomar de citros (var. Valência) empregando-se os turboatomizadores Arbus 2000/Export e Arbus 2000/850. Na avaliação da distribuição das pulverizações trabalhou-se com 3 arranjos de bicos, 3 velocidades, 2 pressões e mais 4 tratamentos adicionais, em 4 repetições. A avaliação foi realizada aplicando-se um traçador fluorescente às folhas examinadas sob luz ultra-violeta, em laboratório, utilizando-se uma escala de notas para diferentes niveis de cobertura. Pulverizações com cloreto de potássio (3\%) foram realizadas para a determinação dos depósitos de calda nas folhas $\left(\mu \mathrm{l} / \mathrm{cm}^{2}\right)$. Amostras, com 5 folhas cada, foram lavadas em água deionizada e medida a condutividade $(\mu \mathrm{S} / \mathrm{cm})$ da solução. Os ácaros da leprose (Brevipalpus phoenicis), da falsa ferrugem (Phyllocoptruta oleivora) e purpúreo (Panonychus citri) foram utilizados como indicadores biológicos na avaliação da eficácia da distribuição e dos depósitos do produto azociclotin. Constatou-se uma cobertura de pulverização superior nas folhas da parte externa da copa em relação às localizadas internamente, quando posicionadas frontalmente e lateralmente à pulverização. A melhor cobertura das folhas situadas na parte interna da copa foi obtida com pulverizações à $300 \mathrm{lbf} / \mathrm{pol}^{2} \operatorname{com} 14$ bicos de pulverização do tipo JA-2 (Jacto) no ramal superior e 21 no inferior. Menores velocidades de deslocamento $(3,6$ e $5,1 \mathrm{~km} / \mathrm{h})$ e maior pressão (300lbf/pol $\left.{ }^{2}\right)$ 
proporcionaram maiores niveis de cobertura foliar. O arranjo de bicos $\mathrm{A}_{3}$ (35 bicos JA-2) possibilitou a obtenção de maiores índices médios de penetração da pulverização na copa com menores volumes de aplicação, em menor velocidade e maior pressão. Constatou-se uma relação diretamente proporcional entre o volume de calda aplicado e o nível de depósito nas folhas posicionadas externamente à copa que, independentemente da altura, apresentaram depósitos superiores aos verificados na parte interna da copa. As combinações envolvendo os arranjos de bicos $\mathrm{A}_{2}$ (21 bicos J5-2) à 200lbf/pol e $\mathrm{A}_{3}$ (35 bicos JA-2) à $300 \mathrm{lbf} / \mathrm{pol}^{2}$ na menor velocidade $(3,6 \mathrm{~km} / \mathrm{h})$ proporcionaram maiores niveis de depósitos, independentemente da localização na planta. $\mathrm{O}$ acaricida azociclotin na dosagem $25 \mathrm{~g}$ i.a./100l d'água foi eficiente por 30 dias no controle de $B$. phoenicis e $P$. oleivora. Variações nas condições operacionais dos turboatomizadores Arbus 2000/Export e Arbus 2000/850 não influenciaram no controle dos ácaros pragas. O produto azociclotin pulverizado a $75 \%$ da dosagem comercial com 35 bicos do tipo JA-2, à $3,6 \mathrm{~km} / \mathrm{h}$ e na pressão de $300 \mathrm{lbf} / \mathrm{pol}^{2}$ proporcionou níveis de controle equivalentes aos obtidos com $100 \%$ da dosagem comercialmente recomendada desse acaricida, quando aplicado convencionalmente no controle do ácaro purpúreo. 


\title{
OPERATIONAL CONDITIONS OF AIRBLAST SPRAYERS IN THE SPRAY DISTRIBUTION AND DEPOSITION ON CITRUS TREES
}

\author{
Author: CARLOS GILBERTO RAETANO \\ Adviser: DR. TOMOMASSA MATUO
}

\section{SUMMARY}

The spray distribution and deposition from airblast ground sprayers to different operational conditions were studied in mite control. Five experiments were set in a 'Valencia' commercial citrus orchard using the Arbus 2000/Export and Arbus 2000/850 airblast sprayers. A completely randomized experiment with 3 nozzle arrangements, 3 ground speeds, 2 working pressures and four additional treatments was set to evaluate the spray distribution. Samples of leaves were collected and examined under an ultraviolet lamp, after a tracer pigment was sprayed in one side of orange trees. This technique permitted the establishment of a grade scale for different coverage levels. A second completely randomized field experiment was conducted for the evaluation of deposits $\left(\mu \mathrm{l} / \mathrm{cm}^{2}\right)$ of potassium chloride solution $(3 \%)$ on orange trees. Samples of 5 leaves each were washed in deionized water and potassium chloride deposition was measured by conductivity $(\mu \mathrm{S} / \mathrm{cm})$. The efficacy of spray distribution and deposits of azocyclotin were evaluated on citrus rust mite (Phyllocoptruta oleivora), leprosis mite (Brevipalpus phoenicis) and red spider mite (Panonychus citri). The spray coverage of external canopy was greater than in the inner leaves, when positioned in front of spraying. The $\mathrm{A}_{3}$ nozzle arrangements (thirty five JA-2 nozzles) at 300psi showed the highest coverage in leaf samples picked from the inner. The slower ground speeds $(3.6$ and $5.1 \mathrm{~km} / \mathrm{h}$ ) and higher working pressure $(300 \mathrm{psi})$ resulted in higher levels of leaf coverage. These experimental conditions allowed highest spray penetration into the tree canopies with lower application rates. Spray volume had a significant effect on 
deposition, but the effect varied according to different canopy locations. The deposit levels and application volume were positively correlated in outer portions of the canopy and greater than those of inner leaves. The greatest deposit levels were obtained with $\mathrm{A}_{2}$ (twenty one J5-2 nozzles) and $\mathrm{A}_{3}$ (thirty five JA-2 nozzles) nozzle arrangements at 200 and $300 \mathrm{psi}$, respectively in slower speed $(3.6 \mathrm{~km} / \mathrm{h})$. The dosage of $25 \mathrm{~g}$ a.i.of azocyclotin per 100 litre of water was efficient during thirty days after spraying on the control of mites $B$. phoenicis and P. oleivora. Different operational conditions did not permit to identify significative differences between treatments on the initial mite control. The spraying of azocyclotin at $75 \%$ of commercial dosage with thirty five JA-2 nozzles type at $3.6 \mathrm{~km} / \mathrm{h}$ and $300 \mathrm{psi}$ of working pressure showed equivalent control levels when compared $100 \%$ of conventional dosage used for red spider mite control. 


\section{INTRODUCÃO}

A necessidade de se efetuar aplicações de defensivos, várias vezes ao ano, na tentativa de solucionar inúmeros problemas fitossanitários da citricultura têm contribuído significativamente para o aumento do custo de produção.

Na Flórida (EUA), o custo das pulverizações (material e aplicação) na citricultura é bastante significativo, sendo da ordem de um terço do custo total da produção para o mercado de frutos frescos (MURARO et al., 1988). Valor semelhante ao relatado por MATUO (1988) em nosso pais, nas condições da região citrícola da Divisão Regional Agrícola de Ribeirão Preto, Estado de São Paulo, onde o custo dos tratamentos fitossanitários do pomar de citros, já formado, atinge $26 \%$ do total do custo de produção.

$\mathrm{Na}$ maioria das regiões citrícolas do mundo o método de pulverização praticado é predominantemente o de volume alto, com o emprego basicamente de dois tipos de equipamentos: os pulverizadores de pistola e os atomizadores (MATUO, 1984). $\mathrm{O}$ uso desses equipamentos terrestres tem resultado em substanciais perdas por ocasião da aplicação em pomares. Estas perdas podem ocorrer entre plantas, por escorrimento e ou deriva, totalizando em mais de um terço do volume pulverizado (CARMAN et al., 1977; MORGAN, 1981).

A eficácia no controle de pragas e doenças está intimamente relacionada 
com a uniformidade de distribuição do produto químico sobre a superficie (SHARP, 1973), tamanho de gotas e grau de cobertura da pulverização (SALYANI \& McCOY, 1989), volume de aplicação (McCOY \& SALYANI, 1989) e estrutura da planta (CARMAN, 1975). Por essas razões, a planta cítrica constitui-se num dos alvos mais dificeis de serem cobertos pela pulverização devido à densa distribuição de folhas na parte externa da copa, o que dificulta a penetração das gotas para o seu interior (CARMAN \& JEPPSON, 1974).

Dada às dificuldades de cobertura das partes internas da copa dessas plantas, maiores volumes de calda e equipamentos com ventiladores de maior potência para o transporte de gotas até o interior da copa vêm sendo utilizados na citricultura, determinando maciças aplicações de produtos em relação ao que a planta consegue reter e, dessa forma, ocasionando desperdícios e baixa eficiência de aplicação (MATUO, 1988).

O uso de defensivos, em grandes quantidades, e o alto custo de investimento na produção agrícola criam a necessidade de aplicações mais precisas e eficientes, por razões de ordem econômica e ambiental (CARPENTER et al., 1983).

As pesquisas visando ao melhor desempenho dos pulverizadores de jato arrastado, denominados comumente de turboatomizadores (MATUO, 1990), em pomares, sob diferentes condições operacionais são incipientes e realizadas em maior número na Inglaterra e Estados Unidos da América, com destaque às realizadas por CARPENTER et al. (1983), SALYANI \& WHITNEY (1990) e TRAVIS et al. (1987b).

No Brasil, os estudos sobre a pulverização de plantas cítricas e macieiras, através de uso de turboatomizadores em diferentes condições operacionais (arranjo de bicos x velocidade x pressão) foram iniciados por PALLADINI (1990; 1991). Entretanto, este pesquisador não fez considerações biológicas para os diferentes graus de cobertura obtidos com o uso de pulverizador de jato arrastado, marca Jacto, modelo ARBUS 2000/850 nas culturas mencionadas anteriormente.

Segundo STAFFORD et al. (1970), o mesmo grau de cobertura foliar por uma pulverização pode ser eficiente para o controle de um inseto praga, mas inadequado a outro. Portanto, a escassez de informações relativa ao desempenho destes 
equipamentos (turboatomizadores) na citricultura, a necessidade de aperfeiçoá-los para propiciarem maior uniformidade na distribuição com menores volumes de aplicação e, também, a falta de conhecimento entre a cobertura foliar por uma pulverização e a eficácia de controle dos ácaros-pragas nesta cultura, constituem motivos suficientes para a realização deste estudo.

Assim, o presente trabalho teve por objetivos:

a) Estudar a distribuição e a deposição das gotas nas pulverizações realizadas com os turboatomizadores Arbus 2000/Export e Arbus 2000/850 sob diferentes condições operacionais, em citros;

b) Avaliar a eficiência da cobertura da pulverização com estes turboatomizadores no controle dos ácaros-pragas Panonychus citri (McGregor, 1916), Brevipalpus phoenicis (Geijskes, 1939) e Phyllocoptruta oleivora (Ashmead, 1879), em plantas cítricas. 


\section{REVISÃO DE LITERATURA}

\subsection{Técnicas de pulverização}

Em pomares, as pulverizações normalmente praticadas e conhecidas como "pulverizações convencionais", são aquelas efetuadas até que ocorra escorrimento na planta (MATUO, 1988). Geralmente, nessas aplicações são empregados altos volumes de calda, existindo referências de até 15000 litros/hectare, na citricultura (WHITNEY et al., 1978; PEREGRINE et al., 1986).

Atualmente. o uso de pulverizações a "alto volume" tèm sido bastante questionado, pois o èxito no controle dos agentes fitossanitários não depende somente do volume aplicado, mas também da forma como é distribuído sobre a superficie das plantas. HALL et al. (1981) compararam níveis de deposição de uma aplicação de volume alto (3972 litros/hectare), com aplicações de volumes mais reduzidos: 718, 301 e 167 litros/hectare, em diferentes cultivares de maçãs com altura variando de 4,2 a 5,2 metros. Os autores observaram que o emprego de 301 e 718 litros/hectare proporcionaram mesmo nível de deposição que a aplicação de alto volume, mas a 167 litros/hectare, a deposição foi ligeiramente menor.

FRANKEL et al. (1976) e SARTORI \& HONDA (s.d.), visando reduzir o volume de líquido a ser pulverizado, respectivamente, com um pulverizador periférico e um atomizador com bocal oscilante verificaram que o uso de baixos volumes associado a 
estes equipamentos podem substituir com vantagens o processo de aplicação convencional (pistola de pulverização) no controle de cochonilha e ácaro da falsa ferrugem, em citros. Entretanto, CROSS \& BERRIE (1990) constataram que em pomares de maçãs a diferença na eficácia, variando-se o volume aplicado, está intimamente ligada à ação de contato do defensivo e ou grau de movimentação do alvo a ser controlado. Em citros, este fato pode assumir grande importância no controle de ácaros, pois movimentam-se ativamente sobre superficies tratadas (CARMAN, 1975).

VAN EE et al. (1985) obtiveram melhor distribuição de líquido em plantas cítricas (altura superior a 3,6 metros) aplicando 160 litros/hectare com um atomizador desenvolvido para aplicações de baixo volume, comparativamente ao convencional, aplicando 2340 litros/hectare.

Segundo BYERS (1987), a deposição e distribuição de produtos químicos dependem de fatores como: tamanho de planta, densidade da copa, deriva, tamanho de gota, volume d'água pulverizado, forma e volume de planta, velocidade de deslocamento do pulverizador, vento, tipo de equipamento utilizado, combinação de bicos no pulverizador em relação à planta, volume de saída de ar do pulverizador, velocidade do ar e distância do pulverizador até o alvo.

A importància da estrutura e densidade foliar na deposição e distribuição de defensivos já foram reconhecidos por BYASS (1968), quando construiu um modelo geométrico para macieiras em crescimento na tentativa de se definir a planta mais adequada como alvo. O efeito da densidade da copa na deposição e distribuição de defensivos, também foi avaliado por TRAVIS et al. (1987a) em macieiras utilizando-se um pulverizador "speed sprayer" FMC, modelo E 200 TR, com velocidade de deslocamento de $54 \mathrm{~m} / \mathrm{min}$ e regulado para aplicar 617 litros/hectare. Os autores constataram que plantas de tamanhos médio ( 4,1 metros de altura) e pequena $(3,1$ metros de altura) com menores densidades foliares apresentaram maiores depósitos e uniformidade na distribuição dos defensivos.

SALYANI (1987) avaliou o efeito do tamanho de gotas na eficiência de deposição de uma pulverização, em citros. Variando-se o tamanho das gotas, distância ao alvo, velocidade de deslocamento, superfície foliar e surfactantes, concluiu que o 
tamanho ótimo das gotas para uma pulverização em plantas cítricas deve estar compreendido entre 240-340 micrometros ( $\mu \mathrm{m})$.

A distribuição da pulverização proveniente de nove equipamentos aplicando baixo volume (446 a 614 litros/hectare) sobre laranjeiras 'Valência' foram avaliadas por CARMAN \& JEPPSON (1974). Os pulverizadores Kinkelder, modelo Royal, "speed sprayer" E 757 CPCD e RSM - 4 "spout" proporcionaram, em média, maiores porcentagens de distribuição de gotas na superfície total dessas plantas comparativamente aos demais equipamentos em teste.

A eficiência do equipamento na deposição da pulverização, em plantas cítricas, também foi avaliado por WHITNEY \& SALYANI (1991). O atomizador de jato arrastado, designado como convencional, apresentou maior deposição em relação ao atomizador de cortina de ar, ambos operando na velocidade de $2,4 \mathrm{~km} / \mathrm{h}$, regulados para aplicar 233 litros/hectare e com fluxos de ar de 25 e $14,8 \mathrm{~m}^{3} / \mathrm{s}$ em apenas um dos lados, respectivamente.

Embora existam inúmeros fatores influenciando a deposição e distribuição dos defensivos, poucos trabalhos relatam a ação conjunta desses fatores em pomares. RANDALL (1971) comparou o depósito da pulverização, em folhas de macieiras, resultante da combinação de diferentes fluxos de ar e velocidades de deslocamento produzidos por um atomizador modificado. Maior uniformidade do deposito foi obtida com menor velocidade de deslocamento em maior fluxo de ar.

A influência da pressão, velocidade de deslocamento e arranjo de bicos sobre a distribuição dos depósitos da pulverização proveniente de um turboatomizador FMC, modelo 12-RC foram avaliados por CARPENTER et al. (1983), em condições de campo. Avaliações realizadas a diferentes alturas da planta mostraram maior uniformidade dos depósitos a 0,31 metro do nível do solo utilizando-se bicos de baixas vazões, em velocidade de $3,2 \mathrm{~km} / \mathrm{h}$ e pressões de 100 a $400 \mathrm{lbf} / \mathrm{pol}^{2}$. Nessa mesma altura, maiores depósitos foram obtidos com o aumento da distância do pulverizador ao alvo, sendo máximo à 5,5 metros. Este fato, não foi observado a 1,22 metros de altura, onde o depósito decresceu rapidamente com o aumento da distância do pulverizador ao alvo. 
PALLADINI (1990) avaliou o efeito dos mesmos parâmetros estudados por CARPENTER et al. (1983) sobre plantas citricas, em diferentes alturas e posições, utilizando-se um turboatomizador marca Jacto, modelo Arbus 2000/850 Golden S. A melhor cobertura foi obtida com arranjo de bicos liberando 50:50\% do volume aplicado nas partes superior e inferior do equipamento, respectivamente. Maiores deposições foram obtidas nas velocidades de deslocamento de 3,0 e $5,3 \mathrm{~km} / \mathrm{h}$ e na parte baixa das plantas. A utilização deste equipamento, sob diferentes condições operacionais, em macieiras mostrou que a velocidade de deslocamento de $2,5 \mathrm{~km} / \mathrm{h}$ proporcionou maior cobertura foliar (PALLADINI, 1991).

TRAVIS et al. (1987b) estudaram o efeito da velocidade de deslocamento, volume de aplicação e arranjo de bicos na deposição de produtos químicos em macieiras utilizando-se um pulverizador "speed sprayer" FMC John Bean, modelo E 200 TR. Os resultados de maior deposição e menor variação na deposição foram obtidos com velocidade de $54 \mathrm{~m} / \mathrm{min}(3,2 \mathrm{~km} / \mathrm{h})$ e volume de aplicação de 617 litros/hectare, com arranjos de bicos liberando $66: 34 \%$ do volume aplicado, respectivamente nas partes alta e baixa de plantas consideradas de tamanho médio, e com arranjo liberando 50:50\% do volume, respectivamente para as partes alta e baixa de plantas consideradas pequenas.

SALYANI \& WHITNEY (1990) avaliaram o efeito da velocidade de deslocamento $(1,6 ; 2,8 ; 4,0$ e $6,4 \mathrm{~km} / \mathrm{h}$ ) no depósito de uma solução cúprica (720 ppm de cobre metálico), em citros, aplicada por turboatomizadores FMC, modelos $1087 \mathrm{e}$ 9100 , com fluxos de ar de $50 \mathrm{~m} \% / \mathrm{s}$ e regulados para aplicar 2340 e 4680 litros/hectare, respectivamente liberando dois terços do volume na parte superior e um terço na inferior da planta. Através dos resultados, os pesquisadores constataram que o aumento da velocidade de deslocamento não necessariamente reduz a deposição, porém aumenta sua variabilidade.

Os resultados apresentados por SALYANI \& WHITNEY (1990) discordam dos obtidos por TRAVIS et al. (1987b), onde obtiveram maiores depósitos com menores velocidades de deslocamento. Entretanto, ambos concordam que o aumento na velocidade de deslocamento reflete em maior variabilidade dos depósitos. 
A deposição ideal dos produtos sobre as plantas seria, naturalmente, estarem em quantidades suficientes e uniformes em toda a copa. No entanto, avaliações da distribuição dos defensivos têm mostrado que as partes internas e mais altas das plantas recebem quantidades insuficientes de produto químico, enquanto partes externas e baixas são super-pulverizadas (MORGAN, 1981).

A presença de depósitos, em quantidades duas vezes maior na parte externa, em relação ao interior da copa, foi constatada por MATUO (1988) para aplicações convencionais com pistola e turboatomizadores em citros. Por outro lado, a densa distribuição de folhas na parte externa dificultando a penetração das gotas no interior da copa dessas plantas (CARMAN \& JEPPSON, 1974) implica em excesso de liquido (acima da capacidade de retenção da planta) ocasionando perdas estimadas entre $25-40 \%$ do volume aplicado (CARMAN et al., 1977).

$\mathrm{O}$ aumento na eficiência da aplicação e economia podem ser obtidos com turboatomizadores convencionais modificados para pulverização em UBV (volume ultra baixo) substituindo bicos hidráulicos, normalmente empregados em pulverização, por bicos rotativos e/ou sistemas fechados re-circulantes (MORGAN, 1981).

ANTONIN et al. (1987) avaliaram o espectro de gotas produzidos por um turbodifusor, modelo Fischer 780, equipado com 10 bicos de jato cônico (Fischer Jet 09; 400 litros/hectare; 323lbf/pol ${ }^{2}$ ) e oito bicos rotativos (Micron Sprayers x.1; 100 litros/hectare; $54 \mathrm{lbf} / \mathrm{pol}^{2}$ ) e seu efeito no controle de pragas e doenças em pomares. Os bicos rotativos apresentaram um espectro de gotas mais homogêneo e volumes menores foram mais eficientes no controle de pragas e doenças, exceto para Panonychus uimi, onde observaram-se um maior número de formas móveis, comparativamente à 400 litros/hectare com bicos de jato cônico.

O desenvolvimento de sistemas que forneçam informações sobre o alvo a 
ser controlado, acoplados aos turboatomizadores, tem proporcionado uma substancial economia no volume a ser aplicado. GILES et al. (1989) obtiveram uma economia de 28 a 52\% utilizando sistemas ultrasônicos, quando comparados ao convencional.

GILES et al. (1987), também constataram economias da ordem de 28 a $35 \%$ e de 36 a $52 \%$ em pessegueiros e macieiras, respectivamente, quando turboatomizadores foram adaptados para operar com este sistema. Os autores, ainda relataram que a simples intermitência no sistema resultou em economias de 10 a $17 \%$ em pessegueiros e de 21 a $28 \%$ em macieiras.

Uma economia de 43 a $50 \%$ do volume aplicado com um pulverizador intermitente, operado fotoeletricamente no tratamento de pomares cítricos, também foi constatada por MATUO (1988).

A necessidade em melhorar a deposição e penetração dos produtos químicos na copa das plantas, em pomares cítricos levou alguns pesquisadores a estudar o efeito de ar oscilante nos turboatomizadores. Entretanto, alguns citricultores da Flórida (EUA) tem questionado a melhoria da cobertura de pulverização utilizando-se o ar oscilante na aplicação com estes equipamentos. Baseando-se neste fato, SALYANI \& WHITNEY (1991) avaliaram a deposição de uma solução cúprica (240 ppm de Cu) na cultura de citros utilizando-se um turboatomizador, modelo FMC 9100, com placas oscilantes em um dos lados em funcionamento e, do outro, imóveis e posicionadas paralelamente á direção do fluxo de ar. Os autores verificaram que o depósito foi em média 10,2\% maior na ausência de osciladores em relação a presença deles.

A avaliação de um pulverizador requer um método de medição da quantidade e distribuição da pulverização sobre um determinado alvo e, o uso de aditivos fluorescentes no líquido a ser aplicado têm-se constituído numa metodologia bastante conveniente para este propósito (SHARP, 1973). 


\subsection{Emprego de aditivos no estudo da deposição}

O emprego de aditivos nas aplicações de formulações do tipo pó sêco ou ao líquido a ser pulverizado, como forma de avaliação qualitativa e quantitativa dos depósitos é bastante antigo. Inicialmente, os compostos cúpricos foram muito utilizados com esta finalidade, conforme relatos de EDWARDS et al. (1961). Em busca de outros métodos de avaliação, estes pesquisadores adicionaram suspensões de pigmentos fluorescentes ao produto a ser aplicado nas plantas, substâncias que se destacam facilmente sob luz ultra-violeta pela sua fluorescência.

Entre os traçadores fluorescentes, o "Phosphor 2283" foi empregado com êxito em avaliações da distribuição de líquidos sobre folhas por EDWARDS et al. (1961) e BULLOCK et al. (1968).

Os pigmentos fluorescentes "Saturn Yellow", na concentração de $0,4 \%$ (peso/volume) e "Poliglow SLY", na concentração de 0,075\%, ambos solúveis em água, também têm sido usados com sucesso em avaliações no desempenho de pulverizadores em pomares por SHARP (1973) e PALLADINI (1990), respectivamente.

A utilização desses materiais fluorescentes apresenta vantagens pois, sendo invisíveis nas folhas, diminui a tendência de escolha na colheita das amostras, além dos depósitos serem facilmente determinados em presença de luz ultra-violeta (BLB15). Já o uso de produtos cúpricos, como marcadores, além de exigir equipamentos e técnicas mais sofisticadas, a presença desse elemento como constituinte foliar pode super-estimar os depósitos por ocasião de sua extração nesse substrato.

O critério, normalmente adotado, para a avaliação dos depósitos empregando-se traçadores fluorescentes tem sido uma escala de notas, variável em função da porcentagem ou intensidade de cobertura, conforme descrita por BULLOCK 
et al. (1968); PALLADINI (1990; 1991) e DERKSEN \& BRETH (1994). Este critério de avaliação(escala de notas), também foi utilizado por ANTUNIASSI et al. (1996) na estimativa da porcentagem de cobertura de pulverização em folhas de pessegueiros, após a aplicação de um traçador fluorescente à $0,7 \%$ (peso/volume).

Materiais radioativos como ${ }^{152} \mathrm{Eu}$ (MORIYA \& SHIBUYA, 1984) e compostos cúpricos junto a reagentes capazes de exibir diferentes colorações (JUSTE et al., 1990), também estão sendo utilizados para se determinar os níveis dos depósitos e sua distribuição em superficies vegetais ou artificiais.

Diferentes técnicas como a colorimétrica (SALYANI \& WHITNEY, 1988), fluorimétrica ( HIMEL, 1969; NORBDO, 1992) e espectrofotométrica (DERKSEN \& GRAY, 1995) têm sido empregadas na quantificação dos depósitos em superficies alvo.

Recentemente, VELINI et al. (1995) desenvolveram um novo método para se estimar o depósito de pulverizações em diferentes superficies alvo, utilizando-se da condutividade elétrica das soluções. Neste método de quantificação são utilizados como traçantes, ou indicadores do depósito da calda, sais com grande capacidade de modificar a condutividade elétrica de soluções aquosas $(\mathrm{NaCl}, \mathrm{KCl})$. Os pesquisadores, utilizando um condutivímetro com compensação de temperatura, relataram a possibilidade de se detectar concentrações da ordem de 0,0001\% para o cloreto de potássio, com erro máximo de $2 \%$ na concentração indicada.

ANTUNIASSI et al. (1996) utilizaram essa metodologia para a avaliação da deposição e deriva em pessegueiros pulverizados sob diferentes condições operacionais. O uso da condutividade elétrica, na avaliação da uniformidade de deposição e perdas de calda na utilização de um pulverizador, também foi relatado por NOGUEIRA (1996). 


\section{MATERIAL E MÉTODOS}

\subsection{Distribuição e deposição das pulverizações}

Com o objetivo de avaliar a deposição e a distribuição das pulverizações realizadas por turboatomizadores sob diferentes condições operacionais, em plantas cítricas, foram instalados dois experimentos em pomar comercial de citros $(7 \times 6 \mathrm{~m}) \mathrm{da}$ Fazenda São José, localizado no Município de São Pedro, SP.

\subsubsection{Experimento 1}

\subsubsection{Planta alvo}

Plantas cítricas da variedade Valência, com aproximadamente 16 anos de idade, altura média de 4,0 metros e diâmetro médio de copa na base da planta de 5,4 metros foram previamente selecionadas como alvo e devidamente marcadas, com fitas plásticas coloridas, antecedendo às pulverizações.

A uniformidade, bem como a ausência de clareiras na copa foram fatores que auxiliaram na seleção das plantas, procurando, assim, reduzir a interferência de fatores relacionados a desuniformidade das plantas na análise dos resultados. 


\subsubsection{Conjunto pulverizador-trator}

As pulverizações foram realizadas com turboatomizadores da marca Jacto, modelos Arbus 2000/850 e Arbus 2000/Export, sendo este último equipado com defletor unilateral tipo "camarão" e cardã grande angular. Também, estavam equipados com tanques de fibra de vidro com capacidade de 2000 litros, bomba hidráulica JP - 150 com capacidade de recalque de 150 litros/minuto a $540 \mathrm{rpm}$ na tomada de potência e ventiladores de $850 \mathrm{~mm}$ de diâmetro, capazes de produzir $19,5 \mathrm{~m}^{3}$ de ar / segundo com velocidade de $112 \mathrm{~km} / \mathrm{h}$ à $2050 \mathrm{rpm}$, conforme especificações técnicas do fabricante.

O trator utilizado no tracionamento dos pulverizadores foi da marca Massey - Ferguson, modelo 290 com rodagem 18.4 / 15-34 e acionado a 1900 rpm para proporcionar $540 \mathrm{rpm}$ na tomada de potência.

\subsubsection{Bicos de pulverização}

A identificação e distribuição dos bicos de pulverização em seus respectivos arranjos são mostrados na Tabela 1. A determinação do volume líquido a ser aplicado em cada tratamento foi realizada medindo-se as vazões dos bicos individualmente, nos diferentes níveis de pressão a serem testados, mantendo-se o ventilador desligado.

A uniformidade da vazão entre bicos permitiu selecioná-los e enumerá-los, mantendo-os assim, sempre na mesma posição quando colocados nos ramais de pulverização. Os bicos de pulverização foram distribuídos num único ramal de pulverização (A) ou em ramais duplos, com 8 bicos no ramal superior e 13 no inferior (B) ou 14 no ramal superior e 21 no inferior (C), conforme apresentados respectivamente na Figura 1.

As pulverizações foram realizadas utilizando-se apenas um lado dos turboatomizadores Arbus 2000/850 e Arbus 2000/Export e, em apenas um dos lados das plantas. Para a obtenção do volume pulverizado em cada planta multiplicou-se por dois o 
volume aplicado em apenas um lado da planta. $\mathrm{Na}$ ocasião das pulverizações, os turboatomizadores sempre foram posicionados no quadrante I.

Tabela 1. Arranjo, distribuição, tipo e vazão média (litros/min.) dos bicos nos ramais de pulverização para os turboatomizadores Arbus 2000/Export $\left(M_{1}\right)$ e Arbus 2000/850 ( $\left(\mathrm{M}_{2}\right)$ pulverizando à $200\left(\mathrm{P}_{1}\right)$ e $300\left(\mathrm{P}_{2}\right) \mathrm{lbf} / \mathrm{pol}^{2}$.

\begin{tabular}{|c|c|c|c|cc|}
\hline Turboatom. & $\begin{array}{c}\text { Arranjo de } \\
\text { bicos }\end{array}$ & $\begin{array}{c}\text { Distribuição dos bicos nos } \\
\text { ramais de pulverização }\end{array}$ & Tipo de & \multicolumn{2}{|c|}{ Vazão média } \\
\hline $\mathrm{M}_{1}$ & $\mathrm{~A}_{1}{ }^{*}$ & 13 no inferior / 8 no superior & $\mathrm{APT}$ & 1,94 & 2,59 \\
$\mathrm{M}_{1}$ & $\mathrm{~A}_{2}{ }^{*}$ & 13 no inferior / 8 no superior & $\mathrm{J} 5-2$ & 2,23 & 2,96 \\
$\mathrm{M}_{1}$ & $\mathrm{~A}_{3}{ }^{*}$ & 21 no inferior /14 no superior & $\mathrm{JA}-2$ & 1,05 & 1,38 \\
$\mathrm{M}_{1}$ & $\mathrm{~A}_{4}{ }^{* *}$ & 21 no inferior /14 no superior & $\mathrm{J} 5-2$ & 2,23 & 2,96 \\
\hline $\mathrm{M}_{2}$ & $\mathrm{~A}_{5}{ }^{* *}$ & $13(7+6)$ intercalados num & $\mathrm{J} 5-2 \mathrm{e}$ & 2,42 & 2,84 \\
& & único ramal & $\mathrm{J} 4-3$ & 2,74 & 3,12 \\
\hline $\mathrm{M}_{2}$ & $\mathrm{~A}_{6}{ }^{* *}$ & 13 num unico ramal & $\mathrm{J} 5-3$ & 4,44 & 5,21 \\
\hline
\end{tabular}

* arranjos envolvidos no esquema fatorial.

** arranjos dos tratamentos adicionais (extras).

\subsubsection{Tamanho de gotas}

A determinação do tamanho das gotas, para os diferentes bicos de pulverização e níveis de pressão em teste, deu-se em superficie com óxido de magnésio (MgO) segundo metodologia utilizada por MATTHEWS (1975). Em campo, com o ventilador do turboatomizador desligado, colocou-se o ramal de pulverização em posição horizontal e a 1 metro do solo, fixando-se sua extremidade em um suporte de altura regulável e, assim, mantendo-o em nível e conectado ao circuito hidráulico do turboatomizador. Para a amostragem das gotas utilizou-se um anteparo em forma de triângulo, com rodas na base e regulagem de abertura no vértice superior para, assim, limitar a passagem do jato pulverizado (Figura 2). 

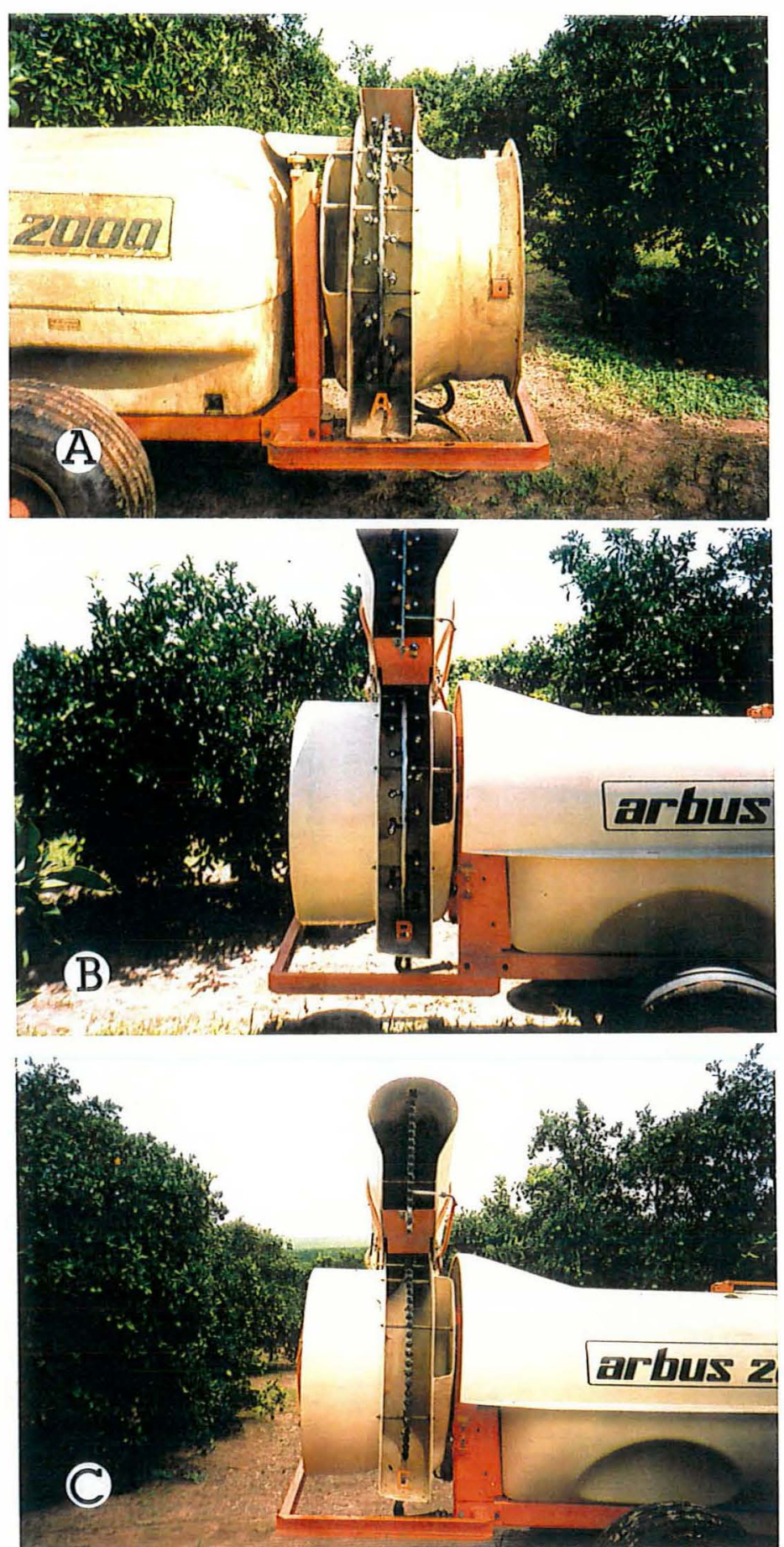

Figura 1. Distribuição dos bicos de pulverização: 13 bicos num único ramal no turboatomizador Arbus 2000 /850 (A); 21 (B) ou 35 (C) bicos em ramais superior e inferior no turboatomizador Arbus 2000/Export. 
O anteparo, posicionado perpendicularmente ao ramal, foi tracionado manualmente na mesma direção e sentido em relação ao posicionamento do turboatomizador, possibilitando a sua passagem sob a pulverização.

No interior do anteparo foram distribuídas oito lâminas de vidro impregnadas com $\mathrm{MgO}$ (superficies para amostragem de gotas) sobre um suporte, montado na base dessa estrutura triangular, de largura idêntica à das lâminas e de menor comprimento em relação ao do anteparo. Com a passagem dessa estrutura sob os bicos de pulverização as superficies de amostragem exibiram marcas, decorrentes do impacto das gotas no óxido de magnésio. As duas primeiras lâminas de cada extremidade foram descartadas, pois impossibilitavam a visualização de marcas individualizadas nas superficies com $\mathrm{MgO}$.

O diâmetro das gotas foi determinado com o auxílio da escala de Porton G12 adaptada a ocular do microscópio. Para cada tipo de bico de pulverização e nível de pressão foram selecionadas 800 gotas em 4 amostras de 200 .

\subsubsection{Seleção, caracterização e aplicação do pigmento fluorescente}

Testes preliminares com diferentes pigmentos fluorescentes foram realizados na tentativa de selecionar um produto que exibisse boa fluorescência em presença de luz ultravioleta (TB 15BLB) para avaliação visual dos depósitos e distribuição sobre a superficie foliar. Os pigmentos "Fluorescent Tracer Stardust" (CIBA - GEIGY) solúvel em água; Luxcor AML 100 (DATIQUIM); Poliglow 830, 840 e 1010 YLS (AKZO) e Fluoresceína VT200 foram diluídos em água, nas concentrações de 0,05; 0,$08 ; 0,1$ e $0,2 \mathrm{~g} / 100 \mathrm{ml}$ com a adição do espalhante-adesivo Extravon na proporção de $50 \mathrm{ml}$ do espalhante para cada $100 \mathrm{~g}$ dos respectivos pigmentos e pulverizados com o turboatomizador Arbus 2000/Export (3,6km/h; bicos J5-2 à 200lbf/pol ${ }^{2}$ ) sobre plantas cítricas.

O produto selecionado como traçador fluorescente (Poliglow 830) na forma de pó e cor amarela necessita para sua mistura em água da adição de um espalhante-adesivo, até a formação de uma pasta densa. Espalhantes com poliglicol-éter 
em sua composição (Extravon) apresentam melhor desempenho na diluição deste pigmento, quando utilizado na proporção de $50 \mathrm{ml}$ para cada $100 \mathrm{~g}$ do traçador. Após a realização da pré-mistura, utilizando-se o produto a $0,08 \%$ em água e o espalhanteadesivo Extravon na proporção anteriormente mencionada, transferiu-se o conteúdo para o tanque do turboatomizador.

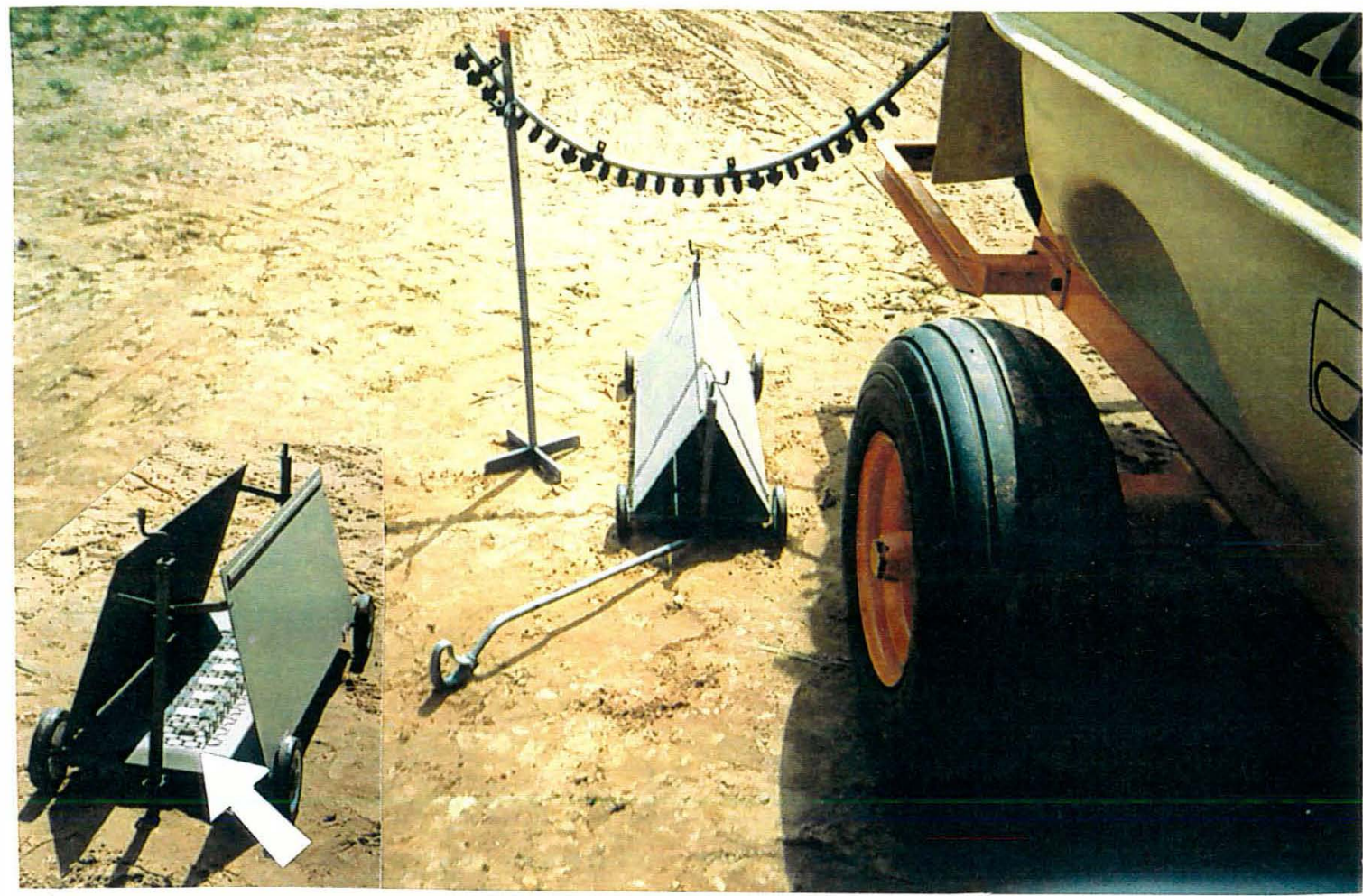

Figura 2. Anteparo triangular deslisante com abertura simultânea lateral, com destaque para a disposição das lâminas em seu interior.

As pulverizações com este traçador foram realizadas entre 10/06 a 26/07/94 e, sempre no período da manhã (Figura 3). As condições ambientais por ocasião das aplicações apresentaram-se relativamente estáveis com temperatura e umidade relativa médias de $21,5^{\circ} \mathrm{C}$ e $58,2 \%$, registradas num termo-higrômetro digital e velocidade média do vento de $2,37 \mathrm{~km} / \mathrm{h}$, medida através de anemômetro mecânico instalado a 4,0 metros de altura do solo. 
As velocidades de deslocamento do conjunto trator-turboatomizador nas aplicações foram 3,6 $\left(\mathrm{V}_{1}\right) ; 5,1\left(\mathrm{~V}_{2}\right)$ e 7,2 $\left(\mathrm{V}_{3}\right) \mathrm{km} / \mathrm{h}$, correspondendo à $3^{\mathrm{a}}$. marcha reduzida, $1^{\mathrm{a}}$. e $2^{\mathrm{a}}$. marchas simples, respectivamente. Também foram usados dois níveis de pressão: $200\left(\mathbf{P}_{1}\right)$ e $300\left(\mathbf{P}_{2}\right)$ lbf/pol ${ }^{2}$; para diferentes arranjos de bicos, conforme mostrados na Tabela 1 .

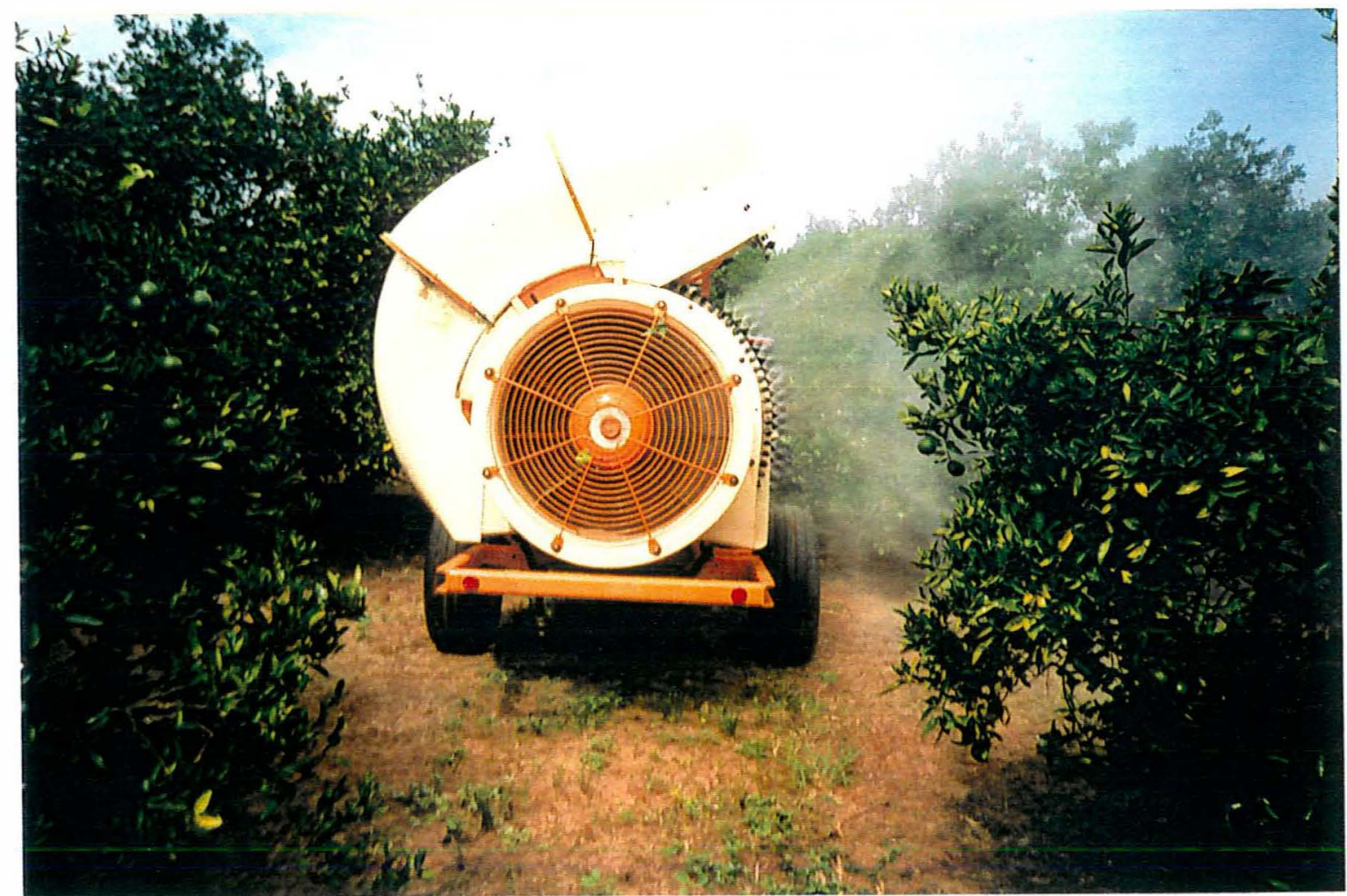

Figura 3. Pulverização do traçador fluorescente no pomar com o turboatomizador Arbus 2000 / Export.

\subsubsection{Amostragem}

Para a avaliação da distribuição do produto fluorescente na copa, as plantas foram divididas em 24 setores de amostragem. Estes setores foram distribuídos em três alturas: baixo (B), até $1,20 \mathrm{~m}$ de altura, médio (M) de 1,20 a 2,40m e alto (A) superior a 2,40m; horizontalmente, em quatro quadrantes: frontal ( I ), laterais (II e IV) e oposto (III) à pulverização e em duas profundidades, externa (E) até $0,40 \mathrm{~m}$ para o interior da copa a partir da periferia, e interna ( I ) além de 0,40m, conforme 
estabelecidos por PALLADINI (1990). A combinação de altura, quadrante e profundidade $(3 \times 4 \times 2)$, originaram 24 setores representados esquematicamente na Figura 4.

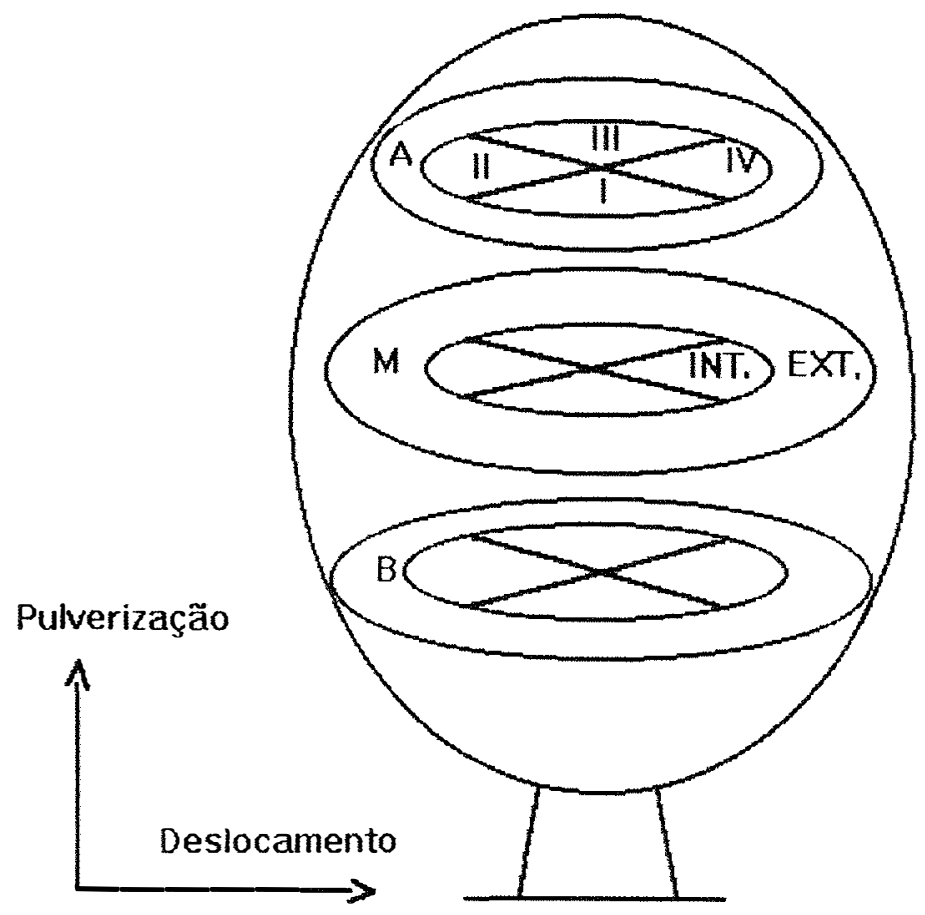

Figura 4. Representação esquemática dos 24 setores de amostragem na copa da planta pulverizada. Quadrantes I, II, III e IV = posição em relação a pulverização; B, $\mathrm{M}$ e $\mathrm{A}=\mathrm{Baixa}$ (até $1,20 \mathrm{~m}$ ), média $(1,20$ a $2,40 \mathrm{~m}$ ) e alta (superior a $2,40 \mathrm{~m}) ; \mathrm{E}$ e I = posição em relação à profundidade: externa (até $0,40 \mathrm{~m}$ da periferia), interna (além de $0,40 \mathrm{~m}$ da periferia).

Após o secamento da calda aplicada, amostras constituidas por 10 folhas cada, foram retiradas dos 24 setores da copa pelo pecíolo sem serem tocadas, para não descaracterizar a deposição do traçador na superfície foliar. As amostras foram embaladas em sacos de papel devidamente identificados e, estes envoltos por sacos plásticos, evitando assim, o enrolamento das folhas. Posteriormente, os sacos plásticos foram acondicionados em recipientes com isolamento térmico (isopor) e transportados ao laboratório para proceder a avaliação da cobertura. 


\subsubsection{Avaliação da distribuição}

Para a avaliação da distribuição do traçador nas superficies abaxial e adaxial das folhas foi construida uma câmara escura, dotada de lâmpadas BL 15 BLB, deixando-se uma abertura para a visualização da fluorescência emitida pelo traçador.

O critério de avaliação foi comparar a cobertura de pulverização nas folhas com uma escala de notas referencial, montada previamente e estabelecida em função de diferentes graus de cobertura, já utilizada por PALLADINI (1990), porém acrescida da nota 9 que representa o máximo de retenção foliar (ponto de escorrimento) e densidade de gotas(número de gotas por $\mathrm{cm}^{2}$ ). Os valores da escala de notas (0 a 9) variam em função da densidade de gotas e distribuição do material depositado na superfície foliar (Figura 5).

Apesar desta escala ser contínua, as notas pares e a nota 9 foram atribuidas a diferentes niveis de deposição em toda a superficie foliar e as impares, exceto a nota 9 , para diferentes niveis de deposição em frações da superfície foliar, como pode ser constatado pela escala descritiva de notas.

Escala descritiva de notas atribuidas a diferentes niveis de deposição na superficie foliar, modificada da proposta por PALLADINI (1990):

0 - sem deposição (ausência de gotas)

1 - traços de deposição (até 10 gotas $/ \mathrm{cm}^{2}$ )

2 - pequena deposição sobre a folha ( 10 a 20 gotas $\left./ \mathrm{cm}^{2}\right)$

3 - deposição leve em uma pequena parte da folha $\left(20\right.$ a 50 gotas $\left./ \mathrm{cm}^{2}\right)$

4 - deposição leve em toda a folha (20 a 50 gotas $/ \mathrm{cm}^{2}$ )

5 - deposição média em metade da folha (50 a 120 gotas $/ \mathrm{cm}^{2}$ )

6 - deposição média em toda a folha (50 a 120 gotas $\left./ \mathrm{cm}^{2}\right)$

7 - deposição pesada em pelo menos $2 / 3$ da folha (acima de 120 gotas $/ \mathrm{cm}^{2}$ )

8 - deposição pesada em toda a folha (acima de 120 gotas $/ \mathrm{cm}^{2}$ )

9 - máxima deposição (ponto de escorrimento) 


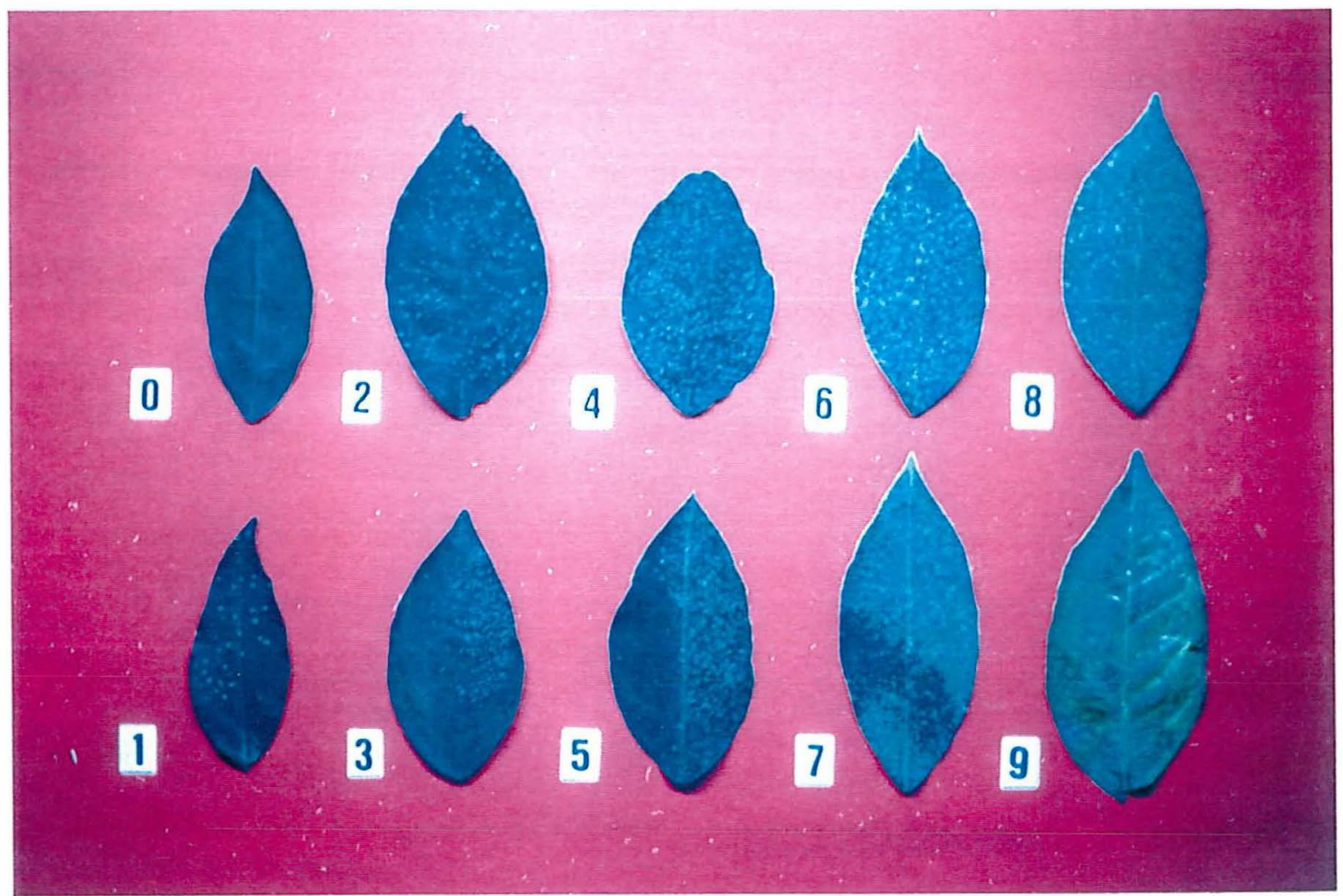

Trigura 5. Escala de notas referencial para a avaliação da cobertura da pulverização em citros (var. Valência).

\subsubsection{Delineamento experimental}

$\mathrm{O}$ delineamento adotado foi o inteiramente casualizado, com esquema fatorial $3 \times 3 \times 2$, sendo 3 arranjos de bicos, 3 velocidades e 2 pressões, mais 4 tratamentos adicionais (extras). Os tratamentos adicionais constituiram-se das seguintes combinações entre arranjo de bicos, velocidade e pressão: $A_{4} / V_{1} / P_{1} ; A_{4} / V_{1} / P_{2} ; A_{5} / V_{1} / P_{2} e$ $\mathrm{A}_{6} / \mathrm{V}_{2} / \mathrm{P}_{1}$. As unidades experimentais foram constituídas por uma planta, com quatro repetições, totalizando 88 plantas avaliadas.

Para as análises estatísticas utilizou-se os testes $\mathrm{F}$, para a análise de variância, e o teste de Tukey ao nível de $5 \%$ de probabilidade, para a comparação das médias. 


\subsubsection{Experimento 2}

\subsubsection{Planta alvo}

Com o propósito de estudar os depósitos de pulverizações sobre plantas cítricas instalou-se o presente ensaio num pomar comercial de laranja (var. Valência), com 14 anos de idade, localizado na mesma propriedade, no período de 22 a 26/06 de 1996. A altura média das plantas e o diâmetro médio de copa foram respectivamente de 3,8 e 4,8 metros e, nesta ocasião, as plantas estavam com frutos maduros.

\subsubsection{Delineamento experimental e tratamentos}

O delineamento experimental adotado foi inteiramente casualizado constituído por 5 tratamentos e 4 repetições. Para a caracterização dos depósitos nas folhas foi pulverizado cloreto de potássio $(\mathrm{KCl})$ em água, na concentração de $3 \%$ mais o espalhante-adesivo Extravon a $0,04 \%$ em apenas um lado da planta, com 0 turboatomizador Arbus 2000/ Export, em diferentes condições operacionais (Tabela 2).

Tabela 2. Tratamentos estabelecidos na aplicação de $\mathrm{KCl}(3 \%)$ em pulverização com o turboatomizador Arbus 2000/Export, especificando a velocidade de deslocamento $(\mathrm{km} / \mathrm{h})$, pressão $\left(\mathrm{lbf} / \mathrm{pol}^{2}\right)$, arranjo de bicos e volume de aplicação (litros/hectare).

\begin{tabular}{|c|c|c|c|c|}
\hline Trat. & Veloc. $(\mathbf{k m} / \mathbf{h})$ & Pressão (lbf/pol $\left.{ }^{2}\right)$ & Arranjo & Vol. de aplic. (I/ha) \\
\hline 1 & 3,6 & 200 & $\mathrm{~A}_{2}(13+8) *$ & 2017 \\
2 & 5,1 & 200 & $\mathrm{~A}_{2}(13+8) *$ & 1424 \\
3 & 3,6 & 300 & $\mathrm{~A}_{3}(21+14) *$ & 1839 \\
4 & 5,1 & 300 & $\mathrm{~A}_{3}(21+14) *$ & 1298 \\
5 & 3,6 & 200 & $\mathrm{~A}_{5}(7+6)^{* *}$ & 1595 \\
\hline
\end{tabular}


As aplicações foram realizadas no período da manhã com temperatura e umidade relativa médias de $22,5^{\circ} \mathrm{C}$ e $64,7 \%$, medidas também por um termo-higrômetro. Nesta ocasião, a velocidade média do vento foi de $0,5 \mathrm{~km} / \mathrm{h}$ medida por um anemômetro mecânico.

O turboatomizador Arbus 2000/Export, sempre foi posicionado a zero grau, em relação ao Norte, nas aplicações de $\mathrm{KCl}$. Posição essa, correspondente ao quadrante I no experimento 1.

\subsubsection{Amostragem}

Cada unidade amostral (planta) foi dividida em 18 setores de amostragem, sendo distribuídos em três alturas: baixo (B) até 1,20m de altura; médio (M) de 1,20 a $2,40 \mathrm{~m}$ e alto (A) superior a $2,40 \mathrm{~m}$; horizontalmente, em 3 azimutes: $0^{\circ}, 90^{\circ}$ e $180^{\circ} \mathrm{em}$ relação ao Norte e, em duas profundidades: externa (até $0,40 \mathrm{~m}$ para o interior da copa à partir da periferia) e interna (além dos $0,40 \mathrm{~m}$ ). O uso de azimutes para o estabelecimento dos setores de amostragem, em citros, já foi utilizado por JUSTE et al. (1990), porém em menor número $\left(0^{\circ}\right.$ e $\left.90^{\circ}\right)$ comparativamente ao proposto no presente estudo, nesse caso, em número de 3

De cada setor de amostragem foram retiradas 2 subamostras, constituídas por 5 folhas cada, totalizando 180 folhas amostradas por planta.

\subsubsection{Determinação da área foliar}

Para a obtenção de uma equação representativa da área foliar, em função dos valores de comprimento e largura medidos com régua milimetrada, foram retiradas 
100 folhas ao acaso, de diferentes plantas e posições da copa e a leitura da área foliar $\left(\mathrm{cm}^{2}\right)$ realizada por um medidor de área foliar digital.

A equação de regressão linear, passando pela origem dos pontos, que permitiu o conhecimento da área foliar foi $Y=0,726664$. $X$, onde $Y=$ área foliar $\left(\mathrm{cm}^{2}\right) \mathrm{e}$ $X=\left(\right.$ comprimento vezes a largura da folha) com coeficiente de determinação $\left(R^{2}\right)$ igual a 0,9846 e $F_{0,05 ; 1 ; 98}=6385,15$ (significativo).

\subsubsection{Quantificação dos depósitos}

Cada subamostra foliar foi devidamente acondicionada em saco plástico $(15,5 \times 20,0 \mathrm{~cm})$ ao qual adicionou-se 30 mililitros de água deionizada com o auxilio de um dispensador de volume. Após a agitação do conteúdo por 20 segundos, as folhas foram removidas e medidas em sua maior largura e comprimento antes de serem descartadas.

Para a quantificação dos depósitos fez-se a leitura da condutividade elétrica $(\mu \mathrm{S} / \mathrm{cm})$ na água de lavagem, proveniente de cada subamostra, com o uso de um condutivimetro digital com compensação de temperatura. As leituras foram feitas num período nunca superior a 4 horas entre a aplicão e a lavagem das folhas.

A medição da condutividade elétrica da calda, antecedendo a cada aplicação, foi necessária para uma posterior uniformização dos dados. As amostras de calda ( $\mathrm{KCI}$ em água a 3\% mais Extravon a 0,04\%) destinadas a este propósito foram retiradas do tanque após ter sido pulverizadas 2 plantas (metade do tratamento). A condutividade elétrica da calda também foi avaliada quando diferentes volumes desta solução $(1,2,4,8,16,32,64,128$ e $256 \mu l)$ foram colocados com microseringas sobre folhas que não receberam a pulverização. A leitura da condutividade elétrica na água de lavagem dessas folhas permitiu o estabelecimento da correlação entre volume de solução $(\mu \mathrm{l})$ e condutividade elétrica $(\mu \mathrm{S} / \mathrm{cm})$. 


\subsection{Efeito da distribuição e deposição das pulverizações no controle de ácaros}

Com o objetivo de avaliar o efeito da deposição e da distribuição do produto azociclotin (Peropal 250PM), aplicado sob diferentes condições operacionais com os turboatomizadores Arbus 2000/850 e Arbus 2000/Export, no controle de ácaros em citros foram instalados três ensaios em pomares comerciais desta cultura. Esse acaricida foi selecionado por ser recomendado para o controle dos principais ácaros pragas em citros (ANDREI, 1996). Os pomares de 'Valência', com 14 a 16 anos de idade e, plantados no espaçamento $7 \times 6 \mathrm{~m}$, também pertencem à Fazenda São José, Municipio de São Pedro, SP.

\subsubsection{Experimento 3 - Controle do ácaro purpúreo $P$. citri}

O presente ensaio foi instalado objetivando-se comparar o efeito da distribuição do produto azociclotin (Peropal 250PM) aplicado por dois turboatomizadores no controle do ácaro purpúreo, bem como verificar se a redução da dosagem comercialmente recomendada deste produto pode ser compensada por uma melhor distribuição da calda no controle deste artropodo, em condições de campo.

Os tratamentos estabelecidos por ocasião da realização deste experimento são apresentados na Tabela 3. A aplicação do acaricida azociclotin foi realizada em 06/11/94, utilizando-se os turboatomizadores Arbus 2000/850 e 2000/Export, respectivamente, equipados com bicos de pulverização J5 - 2 e J4 - 3 alternados num único ramal de pulverização e com bicos JA - 2 distribuídos em ramais de pulverização superior e inferior. Os dois lados das plantas foram pulverizados. 
Tabela 3. Tratamentos com diferentes equipamentos, arranjo de bicos e dosagens do produto azociclotin no controle de Panonychus citri.

\begin{tabular}{|c|c|c|c|}
\hline Trat. & Equipamentos & Arranjo & Dosagem (g p.c./1001) \\
\hline 1 & Turb. Arbus 2000/850* & $\mathrm{A}_{5}$ & 100 \\
2 & Turb. Arbus 2000/ Export ** & $\mathrm{A}_{3}$ & 100 \\
3 & Turb. Arbus 2000/ Export ** & $\mathrm{A}_{3}$ & 75 \\
4 & Turb. Arbus 2000/Export ** & $\mathrm{A}_{3}$ & 50 \\
5 & Testemunha & - & - \\
\hline
\end{tabular}

*, ${ }^{* *}$-pressão de trabalho de $300 \mathrm{lbf} / \mathrm{pol}^{2}$ e velocidade de deslocamento igual a $3,6 \mathrm{~km} / \mathrm{h}$.

\subsubsection{Avaliação da população de $P$. citri}

As avaliações da população deste ácaro foram realizadas com 1 dia, antecedendo a aplicação, e aos 2, 4, 8, 16 e 24 dias após a aplicação do acaricida Peropal 250PM. De cada planta marcada na parcela retiraram-se, ao acaso, 25 folhas ao redor da copa e sempre na parte externa. As folhas foram embaladas em sacos de papel, devidamente identificados e acondicionados em recipientes providos de isolamento térmico para o transporte até o laboratório.

Em laboratório, a população deste ácaro foi avaliada empregando-se a "máquina de varredura" (OLIVEIRA, 1983) para removê-los das folhas. A contagem de ninfas e adultos móveis procedeu-se em microscópio estereoscópico. Na ocasião da instalação deste ensaio, os frutos já haviam sido colhidos.

A porcentagem de eficiência $(\% \mathrm{E})$ do acaricida no controle do ácaro purpúreo foi calculada pela fórmula de Henderson \& Tilton (NAKANO et al., 1981), onde : 


$$
\% E=[1-\operatorname{Ad} \times \mathrm{Ta} / \mathrm{Aa} \times \mathrm{Td}] \times 100 \mathrm{e}
$$

$\mathrm{Ad}=\mathrm{n}^{\circ}$. de ácaros no tratamento após a aplicação do acaricida

$\mathrm{Aa}=\mathrm{n}^{\circ}$. de ácaros no tratamento antes da aplicação

$\mathrm{Td}=\mathrm{n}^{\circ}$. de ácaros na testemunha após a aplicação do acaricida

$\mathrm{Ta}=\mathrm{n}^{\circ}$. de ácaros na testemunha antes da aplicação

\subsubsection{Delineamento experimental}

O ensaio foi conduzido no delineamento em blocos casualizados, com 5 tratamentos e quatro repetições. As parcelas constituiram-se de 3 linhas de 6 plantas, das quais 2 foram previamente marcadas na linha central para proceder as avaliações, enquanto as demais foram mantidas como bordadura, porém recebendo também os respectivos tratamentos. Esta precaução foi tomada com o intuito de evitar o aparecimento de possiveis focos reinfestantes na área.

\subsubsection{Análise estatística}

Os dados obtidos em cada uma das avaliações foram submetidos à análise de variância e as médias comparadas pelo teste de Tukey ao nível de 5\% de probabilidade. Os valores de número médio de ácaros obtido em cada avaliação, nos respectivos tratamentos, foram transformados em $\log (x+k)$, para $k=3$. Em todas as avaliações, o coeficiente de determinação $\left(R^{2}\right)$ para a transformação escolhida foi superior a 0,95 . 


\subsubsection{Experimento 4 - Controle do ácaro da leprose $B$. phoenicis}

Este experimento teve por objetivo verificar o efeito da distribuição do acaricida azociclotin (Peropal 250PM) no controle do ácaro da leprose, quando aplicado na dosagem de $100 \mathrm{~g}$ p.c./ 100 litros d'água por diferentes turboatomizadores nas velocidades de 3,6 e $5,1 \mathrm{~km} / \mathrm{h}$.

Os tratamentos empregados, por ocasião da realização deste ensaio, estão apresentados na Tabela 4 .

Tabela 4. Tratamentos empregados no controle de Brevipalpus phoenicis com o acaricida azociclotin, aplicado por turboatomizadores equipados com diferentes arranjos de bicos de pulverização.

\begin{tabular}{|c|c|c|}
\hline Tratamento & Equipamento & Arranjo de bicos \\
\hline 1 & Turb. ARBUS 2000/850* & $\mathrm{A}_{5}$ \\
2 & Turb. ARBUS 2000/EXP.* & $\mathrm{A}_{3}$ \\
Testemunha & - & - \\
\hline
\end{tabular}

* , ${ }^{* *}$ - pulverização realizada à 3,6 e $5,1 \mathrm{~km} / \mathrm{h}$, respectivamente na pressão de $300 \mathrm{lbf} / \mathrm{pol}^{2}$.

A aplicação do acaricida foi realizada em 28/03/95, nos dois lados das plantas, e as avaliações com 1 dia, antecedendo a aplicação (prévia), e 1, 3, 7, 14, 28, e 52 dias após a aplicação.

\subsubsection{Avaliação da população de B. phoenicis}

As amostras a serem avaliadas constituíram-se de 5 frutos / planta, escolhidos ao acaso da parte interna da copa. No campo, as avaliações procederam-se através do exame ao redor de todo o fruto, com o auxílio de uma lupa de bolso (aumento 
de 10x), contando-se o número de ácaros vivos (ninfas e adultos) presentes em cada fruto que, na ocasião apresentavam um diâmetro médio de $4,0 \mathrm{~cm}$.

A utilização desta metodologia de avaliação deu-se em função do baixo nível populacional deste ácaro no pomar, porém em níveis superiores ao estabelecido para seu controle ( $3 \%$ de frutos infestados ), conforme sugerido pela Coordenadoria de Assistência Técnica Integral (CATI, 1991) para o Estado de São Paulo.

Para o cálculo da porcentagem de eficiência dos diferentes tratamentos acaricidas no controle deste ácaro utilizou-se a fórmula de Henderson \& Tilton (NAKANO et al., 1981).

\subsubsection{Delineamento experimental}

O delineamento experimental adotado foi o inteiramente casualizado com 3 tratamentos e 8 repetições. As unidades experimentais (parcelas) foram constituídas por 3 linhas, de 7 plantas cada, sendo previamente marcadas 5 plantas na linha central para proceder as avaliações. As demais plantas foram consideradas como bordadura, porém também receberam o tratamento acaricida.

\subsubsection{Análise estatística}

Os dados obtidos em cada uma das avaliações foram submetidos à análise de variância e as médias comparadas pelo teste de Tukey ao nível de $5 \%$ de probabilidade. Os dados de número médio de ácaros obtido em cada avaliação, nos respectivos tratamentos, foram transformados em $\log (x+k)$, para $k=3$. Em todas as avaliações, o coeficiente de determinação $\left(R^{2}\right)$ para a transformação escolhida foi superior a 0,99 e a probabilidade de $\mathrm{F}>0,01$. 


\subsubsection{Experimento 5 - Controle do ácaro da falsa ferrugem $P$. oleivora}

O presente ensaio teve por objetivo verificar o efeito da cobertura da pulverização no controle do ácaro da falsa ferrugem, aplicando-se o produto azociclotin (Peropal 250PM) na dosagem de $100 \mathrm{~g}$ de p.c./100 litros d'água com o turboatomizador Arbus 2000/Export sob diferentes condições operacionais. Os tratamentos selecionados para o controle do ácaro da falsa ferrugem estão apresentados na Tabela 5.

Tabela 5. Tratamentos selecionados na aplicação do acaricida azociclotin visando o controle de Phyllocoptruta oleivora especificando-se modelo de turboatomizador, arranjo de bicos, velocidade de deslocamento e volume de aplicação.

\begin{tabular}{|c|c|c|c|c|}
\hline Tratamento & Turboatomizador & Arranjo $^{*}$ & Velocidade (Km/h) & Volume (1/ha) \\
\hline 1 & Arbus 2000/Exp. & $\mathrm{A}_{3}$ & 3,6 & 2309 \\
2 & Arbus 2000/Exp. & $\mathrm{A}_{3}$ & 5,1 & 1618 \\
3 & Arbus 2000/Exp. & $\mathrm{A}_{2}$ & 3,6 & 2951 \\
4 & Arbus 2000/Exp. & $\mathrm{A}_{2}$ & 5,1 & 2094 \\
Testemunha & - & - & - & - \\
\hline
\end{tabular}

* - pulverização à $300 \mathrm{lbf} /$ pol $^{2}$

A aplicação do acaricida foi realizada em 29/08/95, nos dois lados das plantas e as avaliações com 1 dia antes (prévia) e 1, 3, 7, 14, 28 e 56 dias após a aplicação. 


\subsubsection{Avaliação da população de $P$. oleivora}

As amostras, constituídas de 6 folhas por planta, foram retiradas ao acaso da parte externa da copa e com o auxílio de uma lupa de bolso (aumento de 10x) procedeu-se a contagem de ácaros vivos em $1 \mathrm{~cm}^{2}$ no terço basal das superfícies abaxial e adaxial das folhas.

\subsubsection{Delineamento experimental}

O delineamento experimental adotado foi o de blocos casualizados com 5 tratamentos e 5 repetições. As parcelas foram constituídas por 3 linhas, de 7 plantas cada, sendo previamente marcadas 5 plantas na linha central para proceder as avaliações. As demais plantas da parcela foram consideradas bordadura, porém também receberam o tratamento acaricida.

\subsubsection{Análise estatística}

Os dados obtidos em cada avaliação foram submetidos à análise de variância e as médias comparadas pelo teste de Tukey ao nível de $5 \%$ de probabilidade. $\mathrm{O}$ número médio de ácaros em cada avaliação, nos respectivos tratamentos, para a superficie abaxial e adaxial das folhas foram transformados em raiz quadrada de $\mathrm{x}+1$, face a presença de média e variància com valores iguais a zero. 


\section{RESULTADOS E DISCUSSÃO}

\subsection{Distribuição e deposição das pulverizações}

\subsubsection{Experimento 1}

\subsubsection{Vazão e volume de aplicação}

A vazão total (litros/min.) nos diferentes ramais de pulverização estão apresentadas na Tabela 6. As menores vazões em teste foram: a convencionalmente utilizada pelo citricultor com o arranjo $A_{5}$ (7 bicos $\mathrm{J}_{5-2}$ mais 6 bicos J4-3) e, a obtida com o arranjo $A_{3}$ (35 bicos JA-2) no menor ou maior nível de pressão em teste, apesar de no arranjo $A_{3}$ estar aproximadamente o triplo do número de bicos presentes no arranjo $A_{5}$. A aplicação dos respectivos volumes, envolvendo os diferentes arranjos de bicos, em apenas um dos lados da planta possibilitou determinar o efeito dos tratamentos em toda a copa, sem a ocorrência de sobreposições.

O volume de aplicação por planta, envolvendo diferentes condições operacionais, são apresentados na Tabela 7. Os volumes de aplicação por planta variaram de 4,1 a 20,7 litros onde, para o maior volume aplicado detectou-se maiores perdas por escorrimento. 
Tabela 6. Vazão total nos ramais de pulverização para os respectivos arranjos, em um dos lados dos turboatomizadores Arbus $2000 /$ Export $\left(M_{1}\right)$ e Arbus $2000 / 850\left(\mathrm{M}_{2}\right)$, em diferentes pressões.

\begin{tabular}{|c|c|c|c|c|}
\hline \multirow[t]{2}{*}{ Turboatomizador } & \multirow[t]{2}{*}{ Arranjo } & \multirow[t]{2}{*}{ Tipo de bico } & \multicolumn{2}{|c|}{ Vazão total (litros/min.) } \\
\hline & & & $200 \mathrm{lbf} / \mathrm{pol}^{2}$ & $300 \mathrm{lbf} / \mathrm{pol}^{2}$ \\
\hline$\overline{\mathrm{M}_{1}}$ & $\mathrm{~A}_{1}{ }^{*}$ & $\mathrm{APT}$ & 40,74 & 54,39 \\
\hline $\mathrm{M}_{1}$ & $\mathrm{~A}_{2} *$ & J5 - 2 & 46,83 & 62,16 \\
\hline $\mathrm{M}_{1}$ & $\mathrm{~A}_{3} *$ & $\mathrm{JA}-2$ & 36,75 & 48,30 \\
\hline $\mathrm{M}_{1}$ & $\mathrm{~A}_{4}^{* *}$ & $\mathrm{~J} 5-2$ & 78,05 & 103,60 \\
\hline $\mathrm{M}_{2}$ & $\mathrm{~A}_{5}^{* *}$ & $\mathrm{~J} 5-2(+) \mathrm{J} 4-3$ & $16,94(+) 16,44$ & $19,88(+) 18,72$ \\
\hline $\mathrm{M}_{2}$ & $\mathrm{~A}_{6}^{* *}$ & J5 - 3 & 57,72 & 67,73 \\
\hline
\end{tabular}

* arranjos envolvidos no esquema fatorial.

** arranjos dos tratamentos adicionais (extras).

Tabela 7. Volume de aplicação, por planta, nas diferentes combinações de arranjo de bicos, pressão $\left(\mathrm{lbf} / \mathrm{pol}^{2}\right)$ e velocidade com os turboatomizadores Arbus 2000/Export $\left(M_{1}\right)$ e Arbus $2000 / 850\left(M_{2}\right)$.

\begin{tabular}{|c|c|c|c|c|c|c|c|}
\hline \multirow{2}{*}{$\begin{array}{c}\text { Modelo de } \\
\text { Turboatomizador }\end{array}$} & Arranjo & \multicolumn{5}{|c|}{ Volume (litros/planta) } \\
\cline { 3 - 8 } & Tipo de bico & \multicolumn{3}{|c|}{$\mathbf{3 , 6} \mathbf{k m} / \mathbf{h}$} & \multicolumn{2}{|c|}{$\mathbf{1} \mathbf{k m} / \mathbf{h}$} & \multicolumn{2}{|c|}{$\mathbf{2 k m} / \mathbf{h}$} \\
\cline { 3 - 8 } & & $\mathbf{2 0 0}$ & $\mathbf{3 0 0}$ & $\mathbf{2 0 0}$ & $\mathbf{3 0 0}$ & $\mathbf{2 0 0}$ & $\mathbf{3 0 0}$ \\
\hline $\mathrm{M}_{1}$ & $\mathrm{~A}_{1} / \mathrm{APT}$ & 8,1 & 10,9 & 5,7 & 7,7 & 4,1 & 5,4 \\
$\mathrm{M}_{1}$ & $\mathrm{~A}_{2} / \mathrm{J} 5-2$ & 9,4 & 12,4 & 6,6 & 8,8 & 4,7 & 6,2 \\
$\mathrm{M}_{1}$ & $\mathrm{~A}_{3} / \mathrm{JA}-2$ & 7,3 & 9,7 & 5,2 & 6,8 & 3,7 & 4,8 \\
$\mathrm{M}_{1}$ & $\mathrm{~A}_{4} / \mathrm{J} 5-2$ & $15,6^{*}$ & $20,7^{*}$ & - & - & - & - \\
\hline $\mathrm{M}_{2}$ & $\mathrm{~A}_{5} / \mathrm{J} 5-2(+) \mathrm{J} 4-3$ & 6,7 & $7,7^{*}$ & - & - & - & - \\
$\mathrm{M}_{2}$ & $\mathrm{~A}_{6} / \mathrm{J} 5-3$ & - & - & $8,1^{*}$ & - & - & - \\
\hline
\end{tabular}

* tratamentos adicionais (extras). 
No Brasil, especificamente para o Estado de São Paulo, o consumo médio de calda por planta com altura de 3,0 a 3,5m varia de 8 a 12 litros no controle de alvos externos e, de 10 a 15 litros por planta para alvos posicionados internamente à copa (CATI, 1991). Isto seria equivalente a aplicações de 1905 a 2857 e de 2381 a 3571 litros/hectare para as diferentes posições do alvo na copa, externa e internamente, considerando um espaçamento de $7 \times 6$ metros ( 238 plantas/hectare).

$\mathrm{Na}$ Flórida (EUA), volumes de aplicação ao redor de 2000 litros/hectare (equivalente a 7,2 litros / planta), e velocidade de $4,0 \mathrm{~km} / \mathrm{h}$ são considerados ótimos parâmetros de pulverização para a citricultura (SALYANI,1995).

\subsubsection{Tamanho de gotas}

Os valores do diâmetro mediano volumétrico $(\mathrm{dmv})$ e diâmetro mediano numérico $(\mathrm{dmn})$ das gotas produzidas nos bicos de pulverização à 200 e $300 \mathrm{lbf} / \mathrm{pol}^{2}$, bem como os respectivos coeficientes de dispersão (relação entre dmv e dmn, simbolizado pela letra r) estão apresentados na Tabela 8.

Da observação da Tabela 8, verifica-se que os bicos de pulverização JA - 2 e J5 - 3 apresentaram espectros de gotas bastante diferenciados. Os bicos JA - 2 mostraram um espectro de gotas mais homogêneo em relação aos obtidos com os demais bicos de pulverização ( valor de $\mathrm{r}$ mais próximo de 1). Já o bico J5 3 apresentou o espectro de gotas mais heterogêneo entre os bicos em teste. Também pode-se constatar uma pequena variação no diâmetro mediano volumétrico (dmv) e numérico (dmn) para todos os bicos nas pressões de 200 e $300 \mathrm{lbf} / \mathrm{pol}^{2}$.

A pequena variação nos valores do dmv e dmn, mostrados na Tabela 8 , pode estar relacionada à metodologia adotada na amostragem de gotas, pois, nesse caso; apenas uma fração do jato aspergido foi selecionado. As gotas menores, na maior parte das vezes, não chegaram a atingir a lâmina com $\mathrm{MgO}$ depositando-se nas paredes internas do anteparo triangular (Figura 2). A restrição à passagem da pulverização no anteparo foi necessária para evitar a coalescência das gotas, pois do contrário não seria possível 
individualizá-las para a avaliação dos parâmetros anteriormente mencionados (dmv e dmn).

Tabela 8. Diâmetro mediano volumétrico $(\mathrm{dmv})$, diâmetro mediano numérico $(\mathrm{dmn})$ e coeficiente de dispersão ( $r$ ) das gotas produzidas por diferentes bicos de pulverização em dois niveis de pressão.

\begin{tabular}{|c|c|c|c|c|}
\hline Tipo de bico & Pressão $\left(\mathbf{l b f} / \mathbf{p o l}^{\mathbf{2}}\right)$ & $\mathbf{d m v}(\boldsymbol{\mu m})$ & $\mathbf{d m n}(\boldsymbol{\mu} \mathbf{m})$ & $\mathbf{r}$ \\
\hline APT & 200 & 85 & 56 & 1,52 \\
& 300 & 80 & 56 & 1,43 \\
J5 - & 200 & 95 & 67 & 1,42 \\
& 300 & 95 & 58 & 1,64 \\
JA - 2 & 200 & 75 & 62 & 1,21 \\
& 300 & 70 & 57 & 1,23 \\
J4-3 & 200 & 120 & 75 & 1,60 \\
& 300 & 110 & 75 & 1,47 \\
J5 - 3 & 200 & 140 & 80 & 1,75 \\
& 300 & 130 & 78 & 1,67 \\
\hline
\end{tabular}

Pequenas variações nos diâmetros mediano volumétrico e numérico .de gotas provenientes de bicos J5 - 2 e J5 - 3 pulverizando a 250 e $350 \mathrm{lbf} / \mathrm{pol}^{2}$ foram constatadas por PALLADINI (1990), quando coletadas em matriz graxa. A ocorrência de pequenas variações no tamanho de gotas, quando pulverizadas na faixa de pressões entre 175 e $300 \mathrm{lbf} / \mathrm{pol}^{2}$, também foi observada por AKESSON \& YATES (1979) para bicos de jato cônico vazio.

Com o propósito de identificar o tamanho de gotas que proporciona a máxima eficiência de deposição da pulverização em folhas de citros, SALYANI (1987) desenvolveu uma metodologia de estudo em laboratório, onde a eficiência de deposição seria calculada em função da porcentagem de gotas presentes na superfície alvo (por pesagem) após a pulverização. O autor concluiu que gotas de 240 a 340 um de diâmetro 
proporcionam maiores eficiências na deposição de pulverizações em citros. Entretanto, em condições de campo a distância ao alvo a ser atingido e o transporte das gotas por uma corrente de ar, como ocorre nos turboatomizadores, pode modificar esses parâmetros (dmv, dmn e r) tornando-os bastante similares aos obtidos nesse estudo, principalmente com os bicos J4-3 e J5-3 em ambos os níveis de pressão (Tabela 8).

\subsubsection{Cobertura da pulverização}

Os resultados da cobertura foliar, provenientes da pulverização do produto fluorescente Poliglow 830 são apresentados e discutidos separadamente para as superficies adaxial e abaxial das folhas, dentro de cada quadrante, previamente estabelecidos por ocasião da aplicação. As análises estatísticas mostraram que, em geral, os fatores estudados: arranjo de bicos, pressão e velocidade atuam de forma independente na cobertura da pulverização.

A atuação independente dos fatores arranjo de bicos, pressão e velocidade na cobertura da pulverização em plantas cítricas foi constatada por PALLADINI (1990), exceto para amostras provenientes da parte interna da copa nas posições média (MI) e baixa (BI) do quadrante IV, onde as análises mostraram a existência de interações significativas entre os fatores em estudo.

Essas constatações sugerem que, cada fator seja estudado separadamente na cobertura da pulverização. Entretanto, no presente experimento também foram observadas interações estatísticamente significativas para os fatores em estudo, quando analisados pelo Teste $F$, principalmente envolvendo arranjo de bicos e pressão. Assim, a ocorrência de um percentual considerável de interações significativas, ao nível de $5 \%$ de probabilidade, mostra a existência de dependência entre os fatores em teste.

As notas atribuídas ao grau de cobertura da pulverização nas folhas em cada posição na planta e respectivo quadrante foram comparadas pelo Teste de Tukey, ao nível de 5\% de probabilidade e apresentadas nas Tabelas 9 a $\mathbf{1 6}$. O efeito de um fator dentro das interações pode ser observado pela significância nos valores de $\mathrm{F}$, ao nível de 1 e $5 \%$ de probabilidade. 
Para melhor interpretação dos resultados fez-se o desdobramento das interações entre os fatores em estudo e, também, as notas médias de cobertura foram comparadas pelo Teste de Tukey, ao nível de 0.05 de significância (Tabelas 9A a 16A).

\subsection{Quadrante I - Superfície adaxial da folha}

Os resultados referentes a cobertura da pulverização no respectivo quadrante (Tabela 9) mostraram que, em geral, independente das interações entre os fatores analisados, as folhas da parte externa apresentaram maior deposição na superficie adaxial em relação àquelas localizadas internamente à copa, neste quadrante, posicionado frontalmente à aplicação. As amostras provenientes das posições média $(1,20 \mathrm{a} 2,40 \mathrm{~m}$ de altura em relação ao solo) e baixa (inferior a $1,20 \mathrm{~m}$ de altura ), externamente à copa, apresentaram maiores notas de cobertura comparativamente àquelas retiradas da posição mais alta da planta ( superior a 2,40m de altura ). Não há dúvida que, o posicionamento das folhas em relação à direção da pulverização influenciou na ocorrência deste fato, pois a maior parte das folhas localizadas nas partes baixa e média da copa constituem-se em alvos horizontais, diferindo daquelas posicionadas na parte mais alta e consideradas alvos essencialmente verticais.

Da observação da Tabela 9 verifica-se uma tendência das folhas apresentarem maiores deposições quando pulverizadas à $300 \mathrm{lbf} / \mathrm{pol}^{2}$, porém, na maior parte das vezes, não diferindo significativamente daquelas pulverizadas à $200 \mathrm{lbf} / \mathrm{pol}^{2}$, independente do arranjo de bicos, velocidade e posicionamento das amostras na planta. Os resultados do desdobramento das interações: Arranjo x Velocidade, Arranjo x Pressão e Velocidade $x$ Pressão no respectivo quadrante são apresentados na Tabela 9A. Deposições significativamente maiores foram constatadas em aplicações à $300 \mathrm{lbf} / \mathrm{pol}^{2}$ utilizando-se o arranjo $\mathrm{A}_{\mathfrak{z}}$ (bicos JA-2) em folhas das posições alta externa (AE) e interna (AI) da copa. Este efeito também foi observado na posição mediana da copa utilizando-se o arranjo $A_{1}$ (bicos $\left.A P T\right)$. 
Ainda, em relação ao efeito do fator pressão dentro de velocidade, podese verificar que, as amostras provenientes das posições alta ( $\mathrm{AE})$ e média $(\mathrm{ME})$ externas à copa apresentaram maiores notas de cobertura na superficie adaxial das folhas à $7,2 \mathrm{~km} / \mathrm{h}$ na pressão de $300 \mathrm{lbf} / \mathrm{pol}^{2}$. Para este mesmo nível de pressão nas velocidades de 3,6 e $5,1 \mathrm{~km} / \mathrm{h}$ as notas médias de cobertura não diferiram estatísticamente entre si, independente da posição na copa amostrada (Tabela 9A).

Em geral, o efeito do fator velocidade dentro dos diferentes arranjos de bicos sobre a cobertura foliar não foi detectado, exceto para os arranjos $A_{1}$ (bicos APT) nas posições $\mathrm{AE}$ e $\mathrm{ME}$ e, $\mathrm{A}_{3}$ (bicos JA-2) nas posições internas à copa, onde menores velocidades $(3,6$ e $5,1 \mathrm{~km} / \mathrm{h})$ proporcionaram deposições significativamente maiores que as obtidas a $7,2 \mathrm{~km} / \mathrm{h}$. Já o efeito do fator velocidade dentro de pressão pode ser constatado em ambos os níveis deste último fator com deposições na superfície adaxial das folhas significativamente maiores em menores velocidades (Tabela 9A).

O efeito do arranjo de bicos dentro do fator pressão, sobre a cobertura foliar, também pode ser constatado pela observação da Tabela 9A. Os arranjos $A_{1}$ (bicos APT) e $A_{2}$ (bicos J5-2) à 200lbf/pol ${ }^{2}$, na maior parte das vezes, apresentaram notas médias significativamente maiores em relação ao arranjo $A_{3}$ (bicos JA-2). Entretanto, praticamente não foram detectadas diferenças estatísticas entre eles na pressão de $300 \mathrm{lbf} / \mathrm{pol}^{2}$, para as diferentes posições da copa em estudo. Também, em relação ao efeito deste fator dentro de velocidade, pode-se observar que o arranjo $\mathrm{A}_{3}$ (bicos JA-2) proporcionou a obtenção de uma cobertura de pulverização significativamente menor comparativamente ao arranjo $A_{2}$ (bicos J5-2), nas velocidades de 3,6 e $5,1 \mathrm{~km} / \mathrm{h}$ para as folhas da posição $\mathrm{ME}$, e à $5,1 \mathrm{~km} / \mathrm{h}$ para àquelas retiradas da posição baixa (BE), externamente à copa. Nas demais posições e velocidades não houveram diferenças significativas na cobertura da superficie adaxial das folhas para os três arranjos de bicos em teste.

Os coeficientes de variação da cobertura na superficie adaxial das folhas, para as diferentes posições em estudo, neste quadrante são mostrados na Tabela 9. Para as amostras retiradas da parte externa da copa os valores variaram de 12,63 a $18,82 \%$ da posição baixa para a mais alta, respectivamente. Isto, provavelmente se deve à maior 
interferência de alguns fatores, como a maior distância entre o equipamento e o alvo, maior intensidade do vento e ação da gravidade na trajetória das gotas, conforme mencionados por PALLADINI (1990).

Tabela 9. Efeito do arranjo de bicos, pressão e velocidade de trabalho na cobertura da superficie adaxial das folhas, nas posições alta externa $(\mathrm{AE})$ e interna (AI); média externa (ME) e interna (MI) e baixa externa (BE) e interna (BI) do quadrante I.

\begin{tabular}{|c|c|c|c|c|c|c|c|}
\hline \multirow{2}{*}{$\begin{array}{c}\text { Fatores de } \\
\text { variação }\end{array}$} & \multirow[t]{2}{*}{ G.L. } & \multicolumn{6}{|c|}{ Valores de F, CV e cobertura média nas diferentes posicōes } \\
\hline & & BE & BI & $\mathbf{M E}$ & MI & $\mathbf{A E}$ & AI \\
\hline $\operatorname{Bico}(\mathrm{A})$ & 2 & $7,89 * *$ & $1,01 \mathrm{~ns}$ & $8,32 * *$ & $1,84 \mathrm{~ns}$ & $1,47 \mathrm{~ns}$ & $3,11 \mathrm{~ns}$ \\
\hline Velocidade (V) & 2 & $4,44^{*}$ & $8,37^{* *}$ & $12,23 * *$ & $7,55^{* *}$ & $4,08 *$ & $5,81^{* *}$ \\
\hline Pressão (P) & 1 & $2,00 \mathrm{~ns}$ & $0,51 \mathrm{~ns}$ & $5,01 *$ & $0,86 \mathrm{~ns}$ & $5,49 *$ & $11,35 * *$ \\
\hline $\mathrm{A} \times \mathrm{V}$ & 4 & $0,49 \mathrm{~ns}$ & $0,88 \mathrm{~ns}$ & $2,39 \mathrm{~ns}$ & 3,44 * & $1,24 \mathrm{~ns}$ & $0,59 \mathrm{~ns}$ \\
\hline$A \times P$ & 2 & $2,62 \mathrm{~ns}$ & $0,96 \mathrm{~ns}$ & $3,63 *$ & $1,46 \mathrm{~ns}$ & $9,16 * *$ & $2,95 \mathrm{~ns}$ \\
\hline $\mathrm{V} \times \mathrm{P}$ & 2 & $0,59 \mathrm{~ns}$ & $1,12 \mathrm{~ns}$ & $1,39 \mathrm{~ns}$ & $0,00 \mathrm{~ns}$ & $1,86 \mathrm{~ns}$ & $0,14 \mathrm{~ns}$ \\
\hline$A \times V \times P$ & 4 & $1,53 \mathrm{~ns}$ & $0,68 \mathrm{~ns}$ & $0,70 \mathrm{~ns}$ & $0,90 \mathrm{~ns}$ & $0,98 \mathrm{~ns}$ & $1,54 \mathrm{~ns}$ \\
\hline Extras & 3 & $1,27 \mathrm{~ns}$ & $1,01 \mathrm{~ns}$ & $4,55 * *$ & $13,27 * *$ & $4,34 * *$ & $7,28 * *$ \\
\hline Fatorial $x$ Extras & $\begin{array}{r}1 \\
66^{1}\end{array}$ & $70,07^{* *}$ & 35,70 ** & $4,43^{*}$ & $101,71^{* *}$ & $31,89^{* *}$ & $55,40^{* *}$ \\
\hline CV (\%) & - & 12,63 & 20.36 & 14,14 & 13,57 & 18,82 & 17,56 \\
\hline
\end{tabular}

\section{Médias (notas)}

\begin{tabular}{|l|c|c|c|c|c|c|}
\hline APT (A1) & $5,583 \mathrm{~b}$ & $4,292 \mathrm{a}$ & $5,921 \mathrm{a}$ & $3,496 \mathrm{a}$ & $4,246 \mathrm{a}$ & $3,292 \mathrm{a}$ \\
J5-2 (A2) & $6,325 \mathrm{a}$ & $4,504 \mathrm{a}$ & $6,075 \mathrm{a}$ & $3,696 \mathrm{a}$ & $4,333 \mathrm{a}$ & $3,283 \mathrm{a}$ \\
JA-2 (A3) & $5,529 \mathrm{~b}$ & $4,692 \mathrm{a}$ & $5,171 \mathrm{~b}$ & $3,783 \mathrm{a}$ & $3,942 \mathrm{a}$ & $2,917 \mathrm{a}$ \\
\hline DMS 5\% & 0,537 & 0,676 & 0,570 & 0,369 & 0,575 & 0,412 \\
\hline
\end{tabular}

\begin{tabular}{|l|c|c|c|c|c|c|}
\hline $3,6 \mathrm{~km} / \mathrm{h}(\mathrm{V} 1)$ & $6,121 \mathrm{a}$ & $4,942 \mathrm{a}$ & $6,396 \mathrm{a}$ & $3,788 \mathrm{a}$ & $4,525 \mathrm{a}$ & $3,500 \mathrm{a}$ \\
$5,1 \mathrm{~km} / \mathrm{h}(\mathrm{V} 2)$ & $5,858 \mathrm{ab}$ & $4,700 \mathrm{a}$ & $5,446 \mathrm{~b}$ & $3,871 \mathrm{a}$ & $3,842 \mathrm{~b}$ & $3,025 \mathrm{~b}$ \\
$7,2 \mathrm{~km} / \mathrm{h}(\mathrm{V} 3)$ & $5,458 \mathrm{~b}$ & $3,846 \mathrm{~b}$ & $5,325 \mathrm{~b}$ & $3,317 \mathrm{~b}$ & $4,154 \mathrm{ab}$ & $2,967 \mathrm{~b}$ \\
\hline DMS $5 \%$ & 0,537 & 0,676 & 0,570 & 0,369 & 0,575 & 0,412 \\
\hline
\end{tabular}

\begin{tabular}{|c|c|c|c|c|c|c|}
\hline $200 \mathrm{lbf} / \mathrm{pol}^{2}{ }^{2}(\mathrm{Pl})$ & $5,683 a$ & $4,414 \mathrm{a}$ & $5,506 \mathrm{~b}$ & $3,600 \mathrm{a}$ & $3,944 \mathrm{~b}$ & $2,928 \mathrm{~b}$ \\
\hline $300 \mathrm{lbf} / \mathrm{pol}^{2}$ (P2) & $5,942 \mathrm{a}$ & $4,578 \mathrm{a}$ & $5,939 \mathrm{a}$ & $3,717 \mathrm{a}$ & $4,403 \mathrm{a}$ & $3,400 \mathrm{a}$ \\
\hline DMS 5\% & 0,365 & 0,459 & 0,387 & 0,251 & 0,391 & 0,280 \\
\hline
\end{tabular}

${ }^{*},{ }^{* *}=$ significativo ao nível de 5 e $1 \%$ de probabilidade, respectivamente.

ns $=$ não significativo

Médias na mesma coluna e dentro do mesmo fator não diferem estatisticamente entre si, ao nível de $5 \%$ de probabilidade pelo teste de Tukey.

${ }^{1}=$ Graus de liberdade do resíduo. 


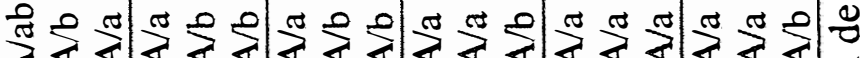

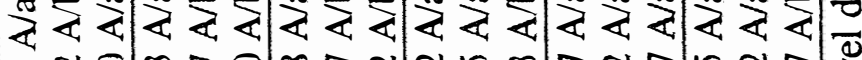

ב

艺

$\cdot \frac{\pi}{x}$

﨎

$\frac{1}{4}$

垈

के

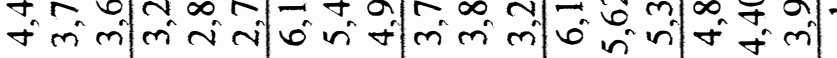

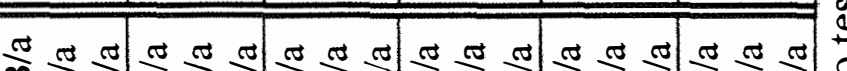

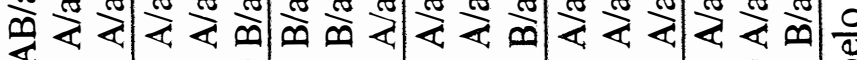

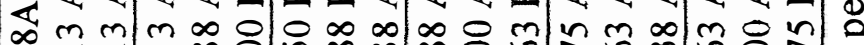

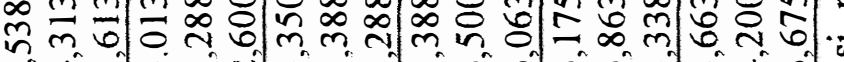
\begin{tabular}{|l|l|l|l|l|l|l}
\hline & & & & & \\
\hline
\end{tabular}

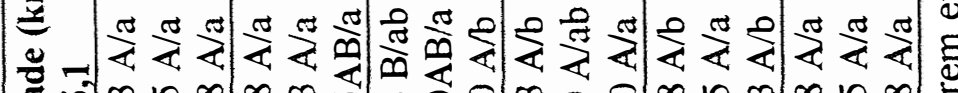
불

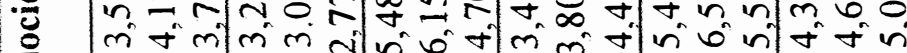
$\frac{2}{2}$

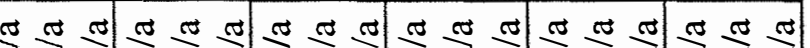

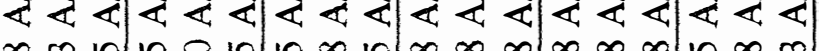
m $\tilde{\sigma} \bar{n}$ f

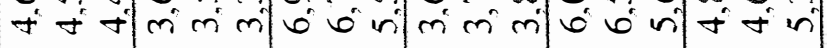

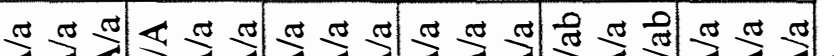

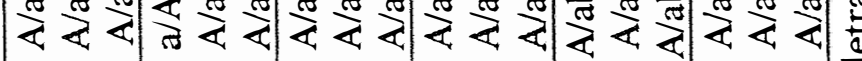

五

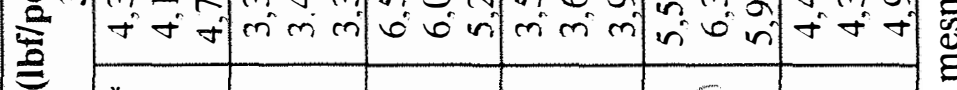
尊

min n

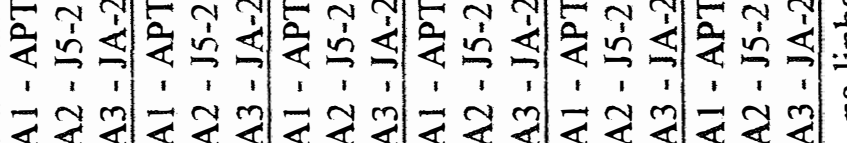

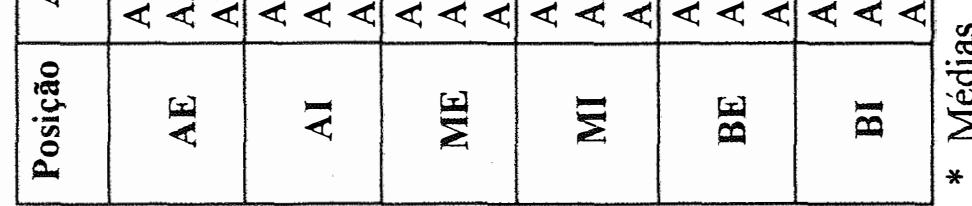

0

엄

i̊

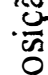

2

ఫ్త్ర

丹

点

$\stackrel{0}{7}$

亶

홍

焉 


\subsection{Quadrante I - Superficie abaxial da folha}

As notas médias de deposição da pulverização foram superiores nas amostras provenientes da parte externa em relação àquelas localizadas internamente à copa neste quadrante, independente dos niveis de pressão e velocidade testados (Tabela 10), quando avaliada a superficie abaxial das folhas. As amostras provenientes da parte interna da copa mostraram claramente uma relação inversamente proporcional entre cobertura foliar e altura da copa.

Em geral, não houve diferenças significativas na cobertura da página inferior das folhas das plantas citricas pulverizadas à 200 e $300 \mathrm{lbf} / \mathrm{pol}^{2}$ com os diferentes arranjos de bicos dentro de cada posição e entre as posições em estudo. A ausência destas diferenças entre notas médias de cobertura envolvendo ambos os niveis de pressão dentro do fator velocidade, também pode ser constatado na Tabela 10A para praticamente todas as posições neste quadrante.

Independente do arranjo de bicos e da posição das folhas na copa as velocidades de 3,6 e $5,1 \mathrm{~km} / \mathrm{h}$, na maior parte das vezes, proporcionaram a obtenção de maiores notas médias de cobertura na superficie abaxial destas folhas posicionadas frontalmente à pulverização. Este fato, também foi constatado quando avaliou-se o efeito de velocidade dentro dos niveis do fator pressão, independente da localização das folhas na planta. A velocidade de $3,6 \mathrm{~km} / \mathrm{h}$ propiciou a obtenção de deposições significativamente maiores para as folhas retiradas das posições médias da copa, diferindo das obtidas nas demais velocidades para estas posições, exceto à 200lbf/pol ${ }^{2}$ onde não houve diferença estatística entre notas médias de cobertura nas diferentes velocidades de deslocamento para as folhas posicionadas externamente à copa (Tabela 10A).

$\mathrm{O}$ arranjo $\mathrm{A}_{1}$ (bicos APT) sob a pressão de $200 \mathrm{lbf} / \mathrm{pol}^{2}$ proporcionou a obtenção de maior cobertura na superficie abaxial das folhas, presentes na parte externa da copa, em relação aos demais arranjos. Os arranjos $A_{1}$ (bicos APT) e $A_{2}$ (bicos J5-2) proporcionaram maiores deposições nas folhas localizadas na parte externa da copa quando o conjunto trator-pulverizador deslocou nas velocidades de 5,1 e $7,2 \mathrm{~km} / \mathrm{h}$. A avaliação da cobertura na superficie abaxial das folhas revelou a ocorrência de maiores 
variações na deposição quando comparada a realizada na parte superior, apresentando coeficientes de variação da ordem de 11,07 a 30,16\% (Tabela 10). Este efeito foi visivelmente maior para as folhas posicionadas na parte mais alta e internamente à copa.

Tabela 10. Efeito do arranjo de bicos, pressão e velocidade de trabalho na cobertura da superficie abaxial das folhas nas posições alta externa (AE) e interna (AI); média externa (ME) e interna (MI) e baixa externa (BE) e interna $(\mathrm{BI})$ do quadrante I.

\begin{tabular}{|c|c|c|c|c|c|c|c|}
\hline \multirow{2}{*}{$\begin{array}{l}\text { Fatores de } \\
\text { variação }\end{array}$} & \multirow[t]{2}{*}{ G.L. } & \multicolumn{6}{|c|}{ Valores de $F, C V$ e cobertura média nas diferentes posicões } \\
\hline & & BE & BI & ME & MI & $\mathbf{A E}$ & AI \\
\hline Bico (A) & 2 & $7,72 * *$ & $2,41 \mathrm{~ns}$ & $9,89 * *$ & $0,16 \mathrm{~ns}$ & $4,57^{*}$ & $2,06 \mathrm{~ns}$ \\
\hline Velocidade (V) & 2 & $0,83 \mathrm{~ns}$ & $19,96^{* *}$ & $22,63 * *$ & $24,15 * *$ & $7,47^{* *}$ & $15,25 * *$ \\
\hline Pressão (P) & 1 & $2,46 \mathrm{~ns}$ & $3,16 \mathrm{~ns}$ & $1,05^{*}$ & $0,11 \mathrm{~ns}$ & $0,31 \mathrm{~ns}$ & $0,29 \mathrm{~ns}$ \\
\hline$A \times V$ & 4 & $2,72 *$ & $0,50 \mathrm{~ns}$ & $2,11 \mathrm{~ns}$ & $0,17^{*}$ & $0,85 \mathrm{~ns}$ & $0,72 \mathrm{~ns}$ \\
\hline$A \times P$ & 2 & $6,12 * *$ & $1,17 \mathrm{~ns}$ & $5,50^{* *}$ & $3,27^{*}$ & $2,66 \mathrm{~ns}$ & $0,71 \mathrm{~ns}$ \\
\hline $\mathrm{V} \times \mathrm{P}$ & 2 & $0,26 \mathrm{~ns}$ & $2,08 \mathrm{~ns}$ & $8,47^{* *}$ & $0,13 \mathrm{~ns}$ & $0,32 \mathrm{~ns}$ & $0,14 \mathrm{~ns}$ \\
\hline$A \times V \times P$ & 4 & $1,13 \mathrm{~ns}$ & $1,16 \mathrm{~ns}$ & $0,36 \mathrm{~ns}$ & $0,99 \mathrm{~ns}$ & $0,28 \mathrm{~ns}$ & $0,21 \mathrm{~ns}$ \\
\hline Extras & 3 & $3,26 *$ & $3,25 *$ & $8,10^{* *}$ & $8,79^{* *}$ & $3,15^{*}$ & $4,01^{*}$ \\
\hline Fatorial $x$ Extras & $\begin{array}{r}1 \\
66^{1} \\
\end{array}$ & $1,95 \mathrm{~ns}$ & $5,70 *$ & $1,22 \mathrm{~ns}$ & $0,33 \mathrm{~ns}$ & $1,53 \mathrm{~ns}$ & $1,98 \mathrm{~ns}$ \\
\hline $\mathrm{CV}(\%)$ & - & 16,85 & 21,60 & 11,07 & 23,23 & 14,97 & 30,16 \\
\hline \multicolumn{8}{|l|}{ Médias (notas) } \\
\hline APT (Al) & & $5,350 \mathrm{ab}$ & $3,196 \mathrm{a}$ & $6,767 \mathrm{a}$ & $3,788 \mathrm{a}$ & $6,142 b$ & $4,683 \mathrm{a}$ \\
\hline J5-2 (A2) & & $5,525 \mathrm{a}$ & $3,446 \mathrm{a}$ & $6,942 \mathrm{a}$ & $3,642 \mathrm{a}$ & $6,713 \mathrm{a}$ & $5,050 \mathrm{a}$ \\
\hline JA-2 (A3) & & $4,588 \mathrm{~b}$ & $3,679 \mathrm{a}$ & $6,063 \mathrm{~b}$ & $3,708 \mathrm{a}$ & $5,929 \mathrm{~b}$ & $4.246 \mathrm{a}$ \\
\hline DMS 5\% & & 0.609 & 0.529 & 0.503 & 0.628 & 0,644 & 0.954 \\
\hline $36 \mathrm{~km} / \mathrm{h}(\mathrm{V})$ & & $5138 \mathrm{a}$ & $4138 \mathrm{a}$ & $7163 \mathrm{a}$ & $4613 a$ & $6713 \mathrm{a}$ & $5.654 \mathrm{a}$ \\
\hline $5,1 \mathrm{~km} / \mathrm{h}(\mathrm{V} 2)$ & & $5,325 \mathrm{a}$ & $3,438 \mathrm{~b}$ & $6,608 \mathrm{a}$ & $3,729 \mathrm{~b}$ & $6,375 \mathrm{a}$ & $4,842 \mathrm{a}$ \\
\hline $7,2 \mathrm{~km} / \mathrm{h}(\mathrm{V} 3)$ & & $5,000 \mathrm{a}$ & $2,746 \mathrm{c}$ & $5,804 \mathrm{~b}$ & $2,796 \mathrm{c}$ & $5,696 \mathrm{~b}$ & $3,483 \mathrm{~b}$ \\
\hline DMS 5\% & & 0,609 & 0.529 & 0,503 & 0,628 & 0,644 & 0,954 \\
\hline
\end{tabular}

\begin{tabular}{|c|c|c|c|c|c|c|}
\hline $\begin{array}{l}200 \mathrm{lbf} / \mathrm{pol}^{2}{ }^{2} \text { (P1) } \\
300 \mathrm{lbf} / \mathrm{pol}^{2}{ }^{2} \text { (P2) }\end{array}$ & $\begin{array}{l}4,992 \mathrm{a} \\
5.317 \mathrm{a}\end{array}$ & $\begin{array}{l}3,281 \mathrm{a} \\
3.600 \mathrm{a}\end{array}$ & $\begin{array}{l}6,678 \mathrm{a} \\
6,503 \mathrm{a}\end{array}$ & $\begin{array}{l}3,678 \mathrm{a} \\
3.747 \mathrm{a}\end{array}$ & $\begin{array}{l}6,322 \mathrm{a} \\
6,200 \mathrm{a}\end{array}$ & $\begin{array}{l}4,572 \mathrm{a} \\
4,747 \mathrm{a}\end{array}$ \\
\hline DMS $5 \%$ & 0,414 & 0,359 & 0,342 & 0,427 & 0,437 & 0,648 \\
\hline
\end{tabular}

$*, * *=$ significativo ao nivel de 5 e $1 \%$ de probabilidade, respectivamente.

ns = não significativo

Médias na mesma coluna e dentro do mesmo fator não diferem estatisticamente entre si, ao nivel de $5 \%$ de probabilidade pelo teste de Tukey.

${ }^{1}=$ Graus de liberdade do residuo. 


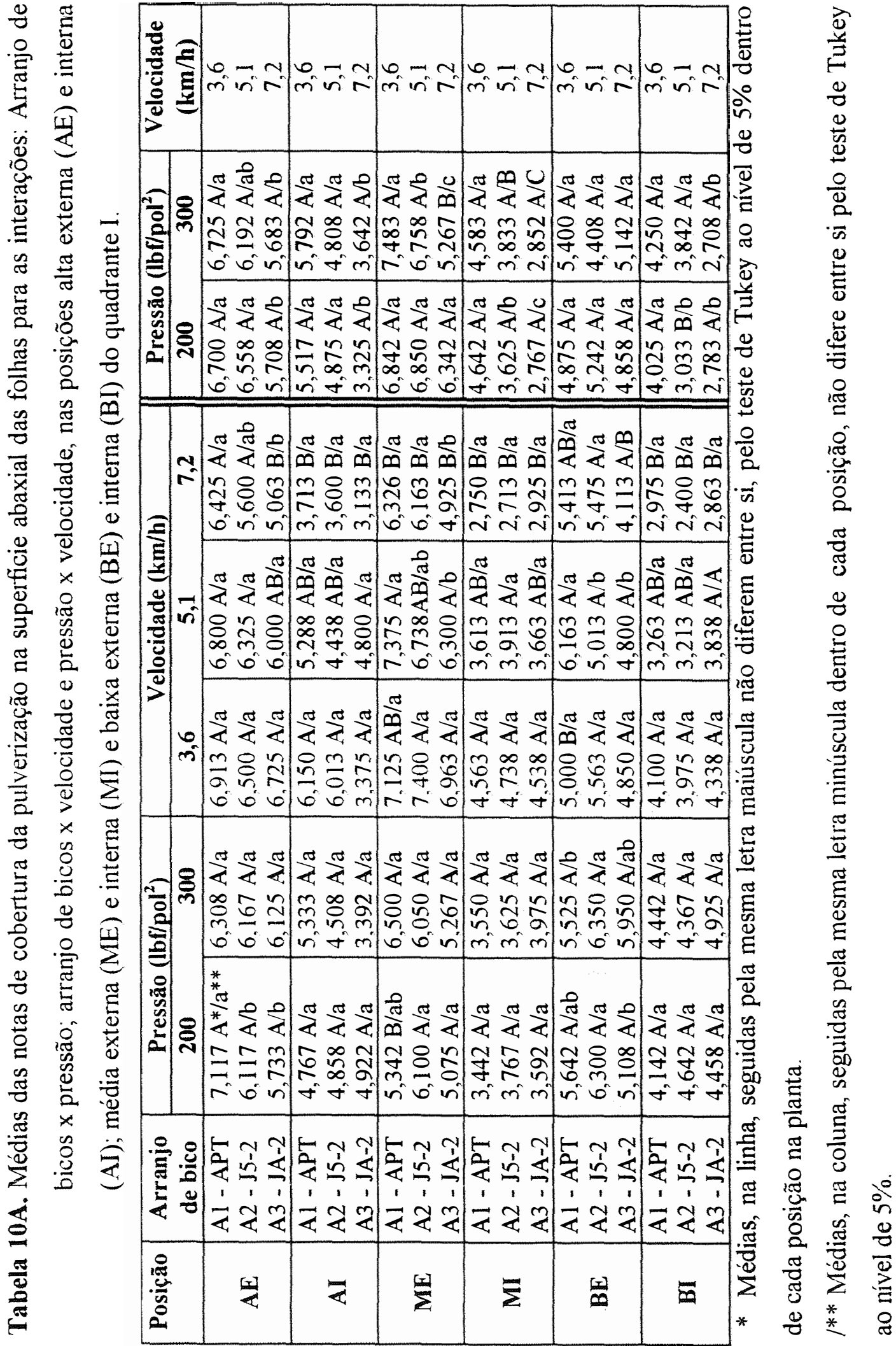




\subsection{Quadrante II - Superficie adaxial da folha}

Em geral, a cobertura na superficie adaxial das folhas provenientes das posições externas foi maior que a obtida por aquelas localizadas internamente à copa, independente do fator analisado, no quadrante II posicionado lateralmente à pulverização (Tabela 11).

Em todas as posições amostradas na copa praticamente não foram observadas diferenças significativas na cobertura das pulverizações realizadas à $200 \mathrm{e}$ $300 \mathrm{lbf} / \mathrm{pol}^{2}$, independente do arranjo de bicos em teste (Tabela 11A). O efeito da pressão de trabalho dentro do fator velocidade, também pode ser constatado pela observação dos resultados na Tabela 11A, onde a pulverização realizada à $300 \mathrm{lbf} / \mathrm{pol}^{2}$ proporcionou a obtenção de notas médias de cobertura significativamente maiores em mais de $50 \%$ das posições avaliadas na velocidade de $7,2 \mathrm{~km} / \mathrm{h}$. Mas, em geral, a cobertura obtida em pulverizações realizadas à 200 e $300 \mathrm{lbf} / \mathrm{pol}^{2}$ não diferiram entre si dentro das velocidades de 3,6 e $5,1 \mathrm{~km} / \mathrm{h}, V_{1}$ e $V_{2}$, respectivamente.

$\mathrm{Na}$ maior parte das vezes não foram observadas diferenças significativas na cobertura foliar entre as velocidades testadas dentro de um mesmo arranjo de bicos. Todavia, houve uma tendência na obtenção de maiores deposições em menor velocidade, independente do posicionamento da folha na copa e do arranjo de bicos em teste. Esta tendência também foi observada dentro de cada nível do fator pressão (Tabela 11A). Em $50 \%$ dos resultados 0 arranjo $\mathrm{A}_{3}$ (bicos JA-2) proporcionou deposições significativamente maiores à $300 \mathrm{lbf} / \mathrm{pol}^{2}$. Ainda, da observação da Tabela 11 A verifica-se que os arranjos $\mathrm{A}_{2}$ (bicos J5-2) e $\mathrm{A}_{3}$ (bicos JA-2), em mais de $60 \%$ das vezes, com o equipamento deslocando-se à $5,1 \mathrm{~km} / \mathrm{h}$ proporcionaram coberturas estatísticamente superiores às obtidas com o arranjo $A_{1}$ (bicos APT), sendo este efeito mais claramente observado para as folhas posicionadas na parte interna da copa. Praticamente, não foram observadas diferenças estatísticas na cobertura foliar para os diferentes arranjos na menor e maior velocidade em teste, independente do posicionamento das folhas na planta. 
Os valores dos coeficientes de variação foram de 17,06 a 26,41\%(Tabela 11), sendo superiores aos obtidos no quadrante I quando avaliou-se a superficie adaxial das folhas.

Tabela 11. Efeito do arranjo de bicos, pressão e velocidade de trabalho na cobertura da superficie adaxial das folhas nas posições alta externa (AE) e interna (AI); média externa (ME) e interna $(\mathrm{MI})$ e baixa externa (BE) e interna (BI) do quadrante II.

\begin{tabular}{|l|c|c|c|c|c|c|c|}
\hline \multirow{2}{*}{$\begin{array}{l}\text { Fatores de } \\
\text { variação }\end{array}$} & G.L. & \multicolumn{3}{|c|}{ Valores de F, CV e cobertura média nas diferentes posiçóes } \\
\cline { 3 - 8 } & & BE & BI & ME & MI & AE & AI \\
\hline Bico (A) & 2 & $6,77^{* *}$ & $3,11 \mathrm{~ns}$ & $4,60^{*}$ & $4,41^{*}$ & $0,17 \mathrm{~ns}$ & $5,01^{* *}$ \\
Velocidade (V) & 2 & $4,08^{*}$ & $4,96 * *$ & $3,08 \mathrm{~ns}$ & $4,87^{*}$ & $0,01 \mathrm{~ns}$ & $6,80^{* *}$ \\
Pressão (P) & 1 & $10,67^{* *}$ & $2,73 \mathrm{~ns}$ & $11,47^{* *}$ & $3,89 \mathrm{~ns}$ & $14,14^{* *}$ & $23,02^{* *}$ \\
A x V & 4 & $1,69 \mathrm{~ns}$ & $1,47 \mathrm{~ns}$ & $0,35 \mathrm{~ns}$ & $4,11 * *$ & $0,76 \mathrm{~ns}$ & $0,71 \mathrm{~ns}$ \\
A x P & 2 & $1,26 \mathrm{~ns}$ & $0,13 \mathrm{~ns}$ & $0,03 \mathrm{~ns}$ & $2,11 \mathrm{~ns}$ & $3,76 *$ & $4,41^{*}$ \\
V x P & 2 & $0,94 \mathrm{~ns}$ & $0,02 \mathrm{~ns}$ & $0,98 \mathrm{~ns}$ & $0,15 \mathrm{~ns}$ & $1,70 \mathrm{~ns}$ & $4,24^{*}$ \\
A x V x P & 4 & $2,33 \mathrm{~ns}$ & $0,70 \mathrm{~ns}$ & $0,45 \mathrm{~ns}$ & $1,45 \mathrm{~ns}$ & $0,74 \mathrm{~ns}$ & $1,74 \mathrm{~ns}$ \\
Extras & 3 & $1,29 \mathrm{~ns}$ & $8,15^{* *}$ & $0,55 \mathrm{~ns}$ & $7,81 * *$ & $0,28 \mathrm{~ns}$ & $2,44 \mathrm{~ns}$ \\
Fatorial x Extras & 1 & $65,43^{* *}$ & $30,99 * *$ & $11,88 * *$ & $5,93 *$ & $9,98 * *$ & $65,35 * *$ \\
& 66 & & & & & & \\
\hline CV (\%) & - & 17,06 & 19,68 & 20,78 & 19,33 & 26,41 & 22,81 \\
\hline
\end{tabular}

\section{Médias (notas)}

\begin{tabular}{|l|c|c|c|c|c|c|}
\hline APT (A1) & $3,242 \mathrm{~b}$ & $3,375 \mathrm{~b}$ & $3,096 \mathrm{~b}$ & $2,725 \mathrm{~b}$ & $2,667 \mathrm{a}$ & $2,021 \mathrm{~b}$ \\
J5-2 (A2) & $3,688 \mathrm{ab}$ & $3,917 \mathrm{a}$ & $3,742 \mathrm{a}$ & $3,121 \mathrm{ab}$ & $2,783 \mathrm{a}$ & $2,433 \mathrm{a}$ \\
JA-2 (A3) & $3,938 \mathrm{a}$ & $3,600 \mathrm{ab}$ & $3.429 \mathrm{ab}$ & $3,204 \mathrm{a}$ & $2,771 \mathrm{a}$ & $2,521 \mathrm{a}$ \\
\hline DMS 5\% & 0,460 & 0,524 & 0,511 & 0,414 & 0,524 & 0,405 \\
\hline
\end{tabular}

\begin{tabular}{|l|c|c|c|c|c|c|}
\hline $3,6 \mathrm{~km} / \mathrm{h}(\mathrm{Vl})$ & $3,483 \mathrm{ab}$ & $3,975 \mathrm{a}$ & $3,238 \mathrm{a}$ & $3,325 \mathrm{a}$ & $2,742 \mathrm{a}$ & $2,675 \mathrm{a}$ \\
$5,1 \mathrm{~km} / \mathrm{h}(\mathrm{V} 2)$ & $3,446 \mathrm{~b}$ & $3,629 \mathrm{ab}$ & $3,304 \mathrm{a}$ & $2,896 \mathrm{ab}$ & $2,721 \mathrm{a}$ & $2,221 \mathrm{~b}$ \\
$7,2 \mathrm{~km} / \mathrm{h}(\mathrm{V} 3)$ & $3,938 \mathrm{a}$ & $3,288 \mathrm{~b}$ & $3,725 \mathrm{a}$ & $2,829 \mathrm{~b}$ & $2,758 \mathrm{a}$ & $2,079 \mathrm{~b}$ \\
\hline DMS $5 \%$ & 0,537 & 0,676 & 0,570 & 0,369 & 0,575 & 0,412 \\
\hline
\end{tabular}

\begin{tabular}{|l|c|c|c|c|c|c|}
\hline $200 \mathrm{lbf} /$ pol. $^{2}$ (P1) & $3,367 \mathrm{~b}$ & $3,483 \mathrm{a}$ & $3,128 \mathrm{~b}$ & $2,878 \mathrm{a}$ & $2,406 \mathrm{~b}$ & $1,994 \mathrm{~b}$ \\
$300 \mathrm{lbf} / \mathrm{pol}^{2}{ }^{2}$ (P2) & $3,878 \mathrm{a}$ & $3,778 \mathrm{a}$ & $3,717 \mathrm{a}$ & $3,156 \mathrm{a}$ & $3,075 \mathrm{a}$ & $2,656 \mathrm{a}$ \\
\hline DMS 5\% & 0,313 & 0,356 & 0,348 & 0,281 & 0,356 & 0,275 \\
\hline
\end{tabular}

$*,{ }^{*}=$ significativo ao nível de 5 e $1 \%$ de probabilidade, respectivamente.

ns $=$ não significativo

Médias na mesma coluna e dentro do mesmo fator não diferem estatisticamente entre si, ao nível de $5 \%$ de probabilidade pelo teste de Tukey.

${ }^{1}=$ Graus de liberdade do resíduo. 


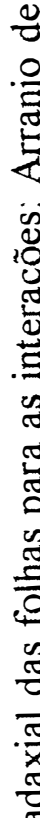

喜

$\stackrel{\mathscr{E}}{\stackrel{\mathscr{E}}{G}}$

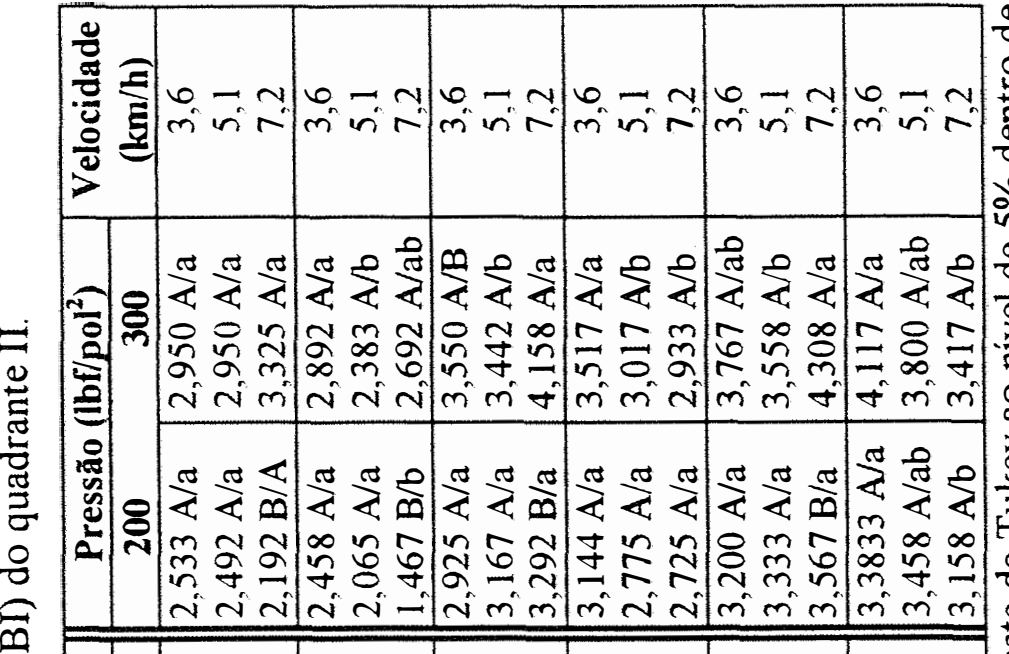

?

峞

$\exists$

$\stackrel{0}{0}$

$\stackrel{0}{2}$

证

$\stackrel{2}{\rightleftarrows}$

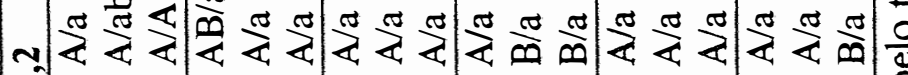

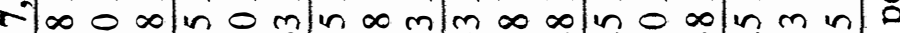

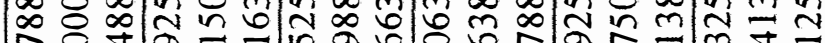

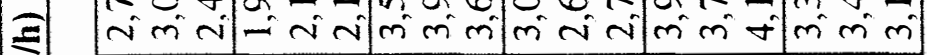

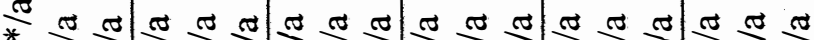

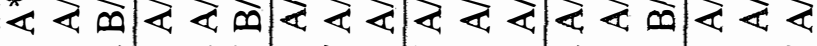
m ㄱำ 舟 


\subsection{Quadrante II - Superficie abaxial da folha}

À semelhança do ocorrido no quadrante frontal à pulverização (I), a deposição na superficie abaxial das folhas, posicionadas lateralmente à aplicação, neste quadrante foi maior para aquelas provenientes da parte externa da copa, independente da pressão, velocidade e arranjo de bicos utilizados por ocasião da realização deste ensaio (Tabela 12). Também pode-se constatar, na maior parte das vezes, maior deposição nesta superficie em relação à adaxial, independente dos fatores envolvidos neste estudo.

Da observação da Tabela 12A pode-se verificar que não houve diferenças significativas entre notas médias de cobertura na superficie abaxial das folhas quando pulverizadas à 200 e $300 \mathrm{lbf} / \mathrm{pol}^{2}$, independente do arranjo de bicos e do posicionamento delas na planta. Porém, na pressão de $300 \mathrm{lbf} / \mathrm{pol}^{2}$ houve uma tendência para a obtenção de maior cobertura da pulverização nas folhas. Este efeito, também pode ser observado dentro de qualquer um dos níveis do fator velocidade, conforme mostrados na Tabela $12 \mathrm{~A}$.

As velocidades de 3,6 e $5,1 \mathrm{~km} / \mathrm{h}$, geralmente proporcionaram maiores deposições, independente dos demais fatores envolvidos neste estudo. Este efeito foi mais acentuado para as folhas localizadas internamente à copa. Ainda que, na maior parte das vezes, as notas médias de cobertura não diferissem estatísticamente entre si nas velocidades de 3,6 e $5,1 \mathrm{~km} / \mathrm{h}$, em mais de $80 \%$ dos resultados obtidos, a menor velocidade propiciou a obtenção de maiores notas de cobertura da pulverização nas folhas.

Em relação aos arranjos de bicos testados pode-se verificar pela Tabela 12A que, os arranjos $\mathrm{A}_{2}$ (bicos J5-2) e $\mathrm{A}_{3}$ (bicos JA-2), em geral, proporcionaram maiores deposições quando comparados ao arranjo $A_{1}$ (bicos APT), dentro de ambos os niveis do fator pressão.

Amostras provenientes da parte baixa da planta, quando pulverizadas à $300 \mathrm{lbf} / \mathrm{pol}^{2}$ e na velocidadede $3,6 \mathrm{~km} / \mathrm{h}$, exibiram maiores níveis de cobertura no arranjo $\mathrm{A}_{3}$ (bicos JA-2), especialmente para aquelas retiradas da parte interna da copa. Nas velocidades de 5,1 e $7,2 \mathrm{~km} / \mathrm{h}$ não foram verificadas diferenças estatísticas na cobertura 
foliar dentro dos níveis do fator em discussão, exceto na maior velocidade e para as folhas localizadas na parte alta, externamente à copa, onde o arranjo $\mathrm{A}_{2}$ proporcionou uma cobertura significativamente maior em relação ao $A_{3}$ (Tabela 12A).

Tabela 12. Efeito do arranjo de bicos, pressão e velocidade de trabalho na cobertura da superfície abaxial das folhas nas posições alta externa (AE) e interna (AI); média externa (ME) e interna (MI) e baixa externa (BE) e interna (BI) do quadrante II.

\begin{tabular}{|c|c|c|c|c|c|c|c|}
\hline \multirow{2}{*}{$\begin{array}{c}\text { Fatores de } \\
\text { variação }\end{array}$} & \multirow[t]{2}{*}{ G.L. } & \multicolumn{6}{|c|}{ Valores de F, CV e da cobertura média nas diferentes posicões } \\
\hline & & BE & BI & ME & MI & $\mathbf{A E}$ & AI \\
\hline $\operatorname{Bico}(\mathrm{A})$ & 2 & $3,31^{*}$ & $7,22 * *$ & $1,20 \mathrm{~ns}$ & $1,57 \mathrm{~ns}$ & $1,75 \mathrm{~ns}$ & $2,00 \mathrm{~ns}$ \\
\hline Velocidade (V) & 2 & $5,87 * *$ & $23,89 * *$ & $10,28 * *$ & $24,09 * *$ & $3,68 *$ & $17,80 * *$ \\
\hline Pressão (P) & 1 & $6,15 *$ & $1,55 \mathrm{~ns}$ & $0,98 \mathrm{~ns}$ & $1,46 \mathrm{~ns}$ & $1,60 \mathrm{~ns}$ & $2,38 \mathrm{~ns}$ \\
\hline$A \times V$ & 4 & $0,73 \mathrm{~ns}$ & $2,98 *$ & $1,31 \mathrm{~ns}$ & $1,24 \mathrm{~ns}$ & $1,24 \mathrm{~ns}$ & $0,53 \mathrm{~ns}$ \\
\hline$A \times P$ & 2 & $1,11 \mathrm{~ns}$ & $1,61 \mathrm{~ns}$ & $3,96 *$ & $0,14 \mathrm{~ns}$ & $4,12 *$ & $0,66 \mathrm{~ns}$ \\
\hline $\mathrm{V} \times \mathrm{P}$ & 2 & $1,12 \mathrm{~ns}$ & $2,53 \mathrm{~ns}$ & $0,22 \mathrm{~ns}$ & $0,02 \mathrm{~ns}$ & $2,36 \mathrm{~ns}$ & $1,17 \mathrm{~ns}$ \\
\hline$A \times V \times P$ & 4 & $0,97 \mathrm{~ns}$ & 1,72 ns & $0,17 \mathrm{~ns}$ & $0,08 \mathrm{~ns}$ & $0,57 \mathrm{~ns}$ & $0,18 \mathrm{~ns}$ \\
\hline Extras & 3 & $9,52 * *$ & $6,52 * *$ & $12,79 * *$ & $14,47 * *$ & $7,58 * *$ & $6,06 * *$ \\
\hline Fatorial $\times$ Extras & $\begin{array}{r}1 \\
66^{1} \\
\end{array}$ & $0,09 \mathrm{~ns}$ & $0,73 \mathrm{~ns}$ & $0.21 \mathrm{~ns}$ & $0,35 \mathrm{~ns}$ & $0,27 \mathrm{~ns}$ & $1,97 \mathrm{~ns}$ \\
\hline CV $(\%)$ & - & 22,75 & 24,87 & 22,46 & 34,68 & 28.36 & 42.75 \\
\hline \multicolumn{8}{|l|}{ Médias (notas) } \\
\hline $\mathrm{APT}(\mathrm{Al})$ & & $3,750 \mathrm{ab}$ & $2,596 \mathrm{~b}$ & $3,646 \mathrm{a}$ & $2,429 \mathrm{a}$ & $3,346 \mathrm{a}$ & $2,263 \mathrm{a}$ \\
\hline $\mathrm{J} 5-2(\mathrm{~A} 2)$ & & $3,521 \mathrm{~b}$ & $2,404 \mathrm{~b}$ & $3,633 \mathrm{a}$ & $2,375 \mathrm{a}$ & $3,446 \mathrm{a}$ & $1,796 \mathrm{a}$ \\
\hline$J \mathrm{~A}-2(\mathrm{~A} 3)$ & & $4.158 \mathrm{a}$ & $3,125 \mathrm{a}$ & $3,967 \mathrm{a}$ & $2.783 \mathrm{a}$ & $2,992 \mathrm{a}$ & $1,867 \mathrm{a}$ \\
\hline DMS 5\% & & 0.603 & 0.472 & 0.587 & 0.602 & 0.646 & 0.603 \\
\hline $3,6 \mathrm{~km} / \mathrm{h}(\mathrm{Vl})$ & & $4,179 \mathrm{a}$ & $3,133 \mathrm{a}$ & $4,275 \mathrm{a}$ & $3,354 \mathrm{a}$ & $3,633 a$ & $2,571 \mathrm{a}$ \\
\hline $5,1 \mathrm{~km} / \mathrm{h}(\mathrm{V} 2)$ & & $3,913 \mathrm{ab}$ & $3,067 \mathrm{a}$ & $3,800 \mathrm{a}$ & $2,613 \mathrm{~b}$ & $3,246 \mathrm{ab}$ & $2,221 \mathrm{a}$ \\
\hline $7,2 \mathrm{~km} / \mathrm{h}(\mathrm{V} 3)$ & & $3,338 \mathrm{~b}$ & $1,925 \mathrm{~b}$ & $3,171 \mathrm{~b}$ & $1,621 \mathrm{c}$ & $2,904 \mathrm{~b}$ & $1,133 \mathrm{~b}$ \\
\hline DMS 5\% & & 0,603 & 0.472 & 0.587 & 0,602 & 0,646 & 0,603 \\
\hline
\end{tabular}

\begin{tabular}{|l|c|c|c|c|c|c|}
\hline $200 \mathrm{lbf} /$ pol. $^{2}(\mathrm{P} 1)$ & $3,556 \mathrm{~b}$ & $2,608 \mathrm{a}$ & $3,650 \mathrm{a}$ & $2,406 \mathrm{a}$ & $3,122 \mathrm{a}$ & $1,817 \mathrm{a}$ \\
$300 \mathrm{lbf} / \mathrm{pol}^{2}{ }^{2}$ (P2) & $4,064 \mathrm{a}$ & $2,808 \mathrm{a}$ & $3,847 \mathrm{a}$ & $2,653 \mathrm{a}$ & $3,400 \mathrm{a}$ & $2.133 \mathrm{a}$ \\
\hline DMS $5 \%$ & 0,410 & 0,321 & 0,399 & 0,409 & 0,439 & 0,410 \\
\hline
\end{tabular}

${ }^{*},{ }^{* *}=$ significativo ao nível de 5 e $1 \%$ de probabilidade, respectivamente.

ns $=$ não significativo

Médias na mesma coluna e dentro do mesmo fator não diferem estatisticamente entre si, ao nível de $5 \%$ de probabilidade pelo teste de Tukey.

${ }^{1}=$ Graus de liberdade do resíduo. 


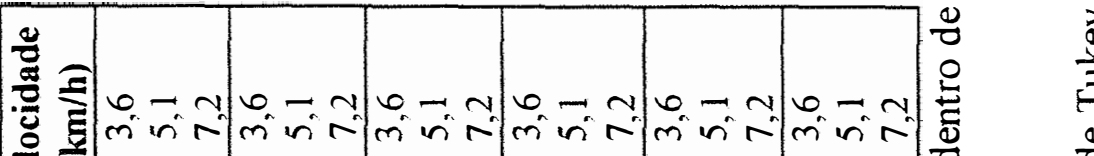

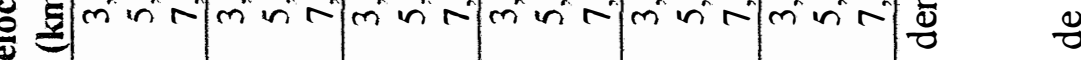

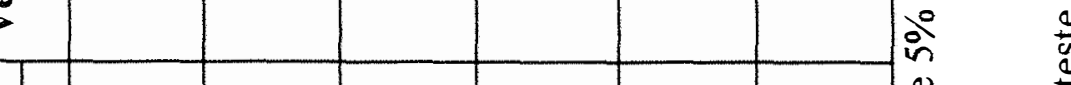

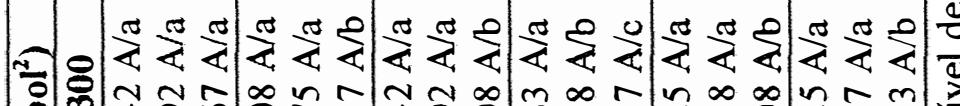
융 f

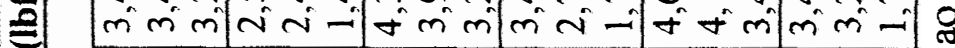

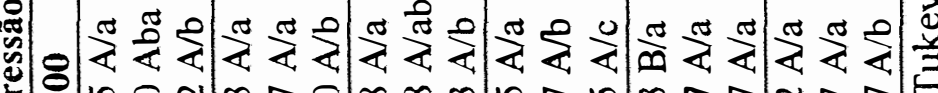
亡 ஸे

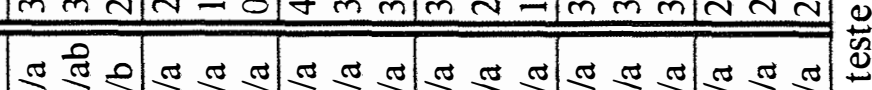
तै द द

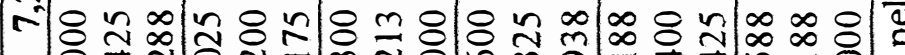

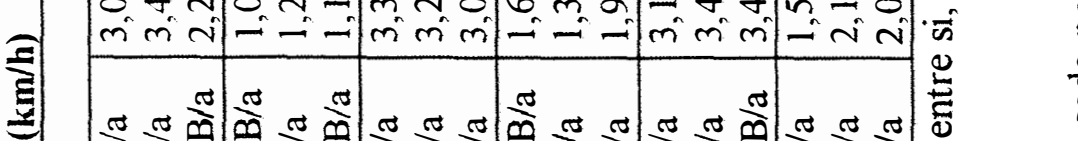
की

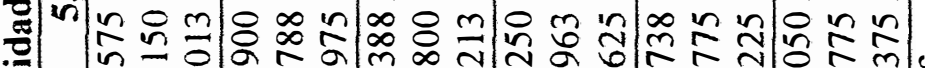
- mi m.

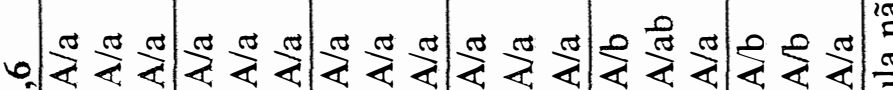
$m$ m min $m o$ ol m in $\infty$ in 0 告 守 mं mंर्तरी

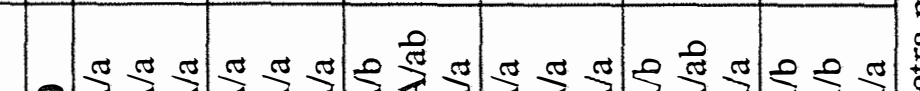
न्री

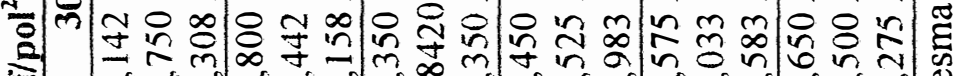

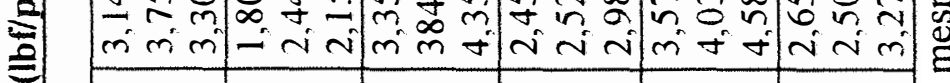

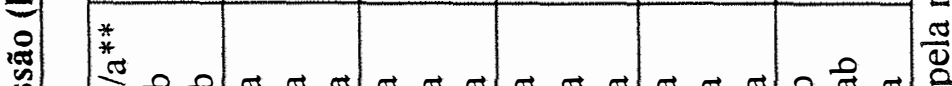
20

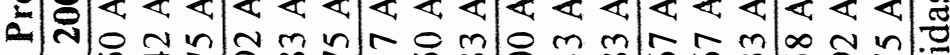

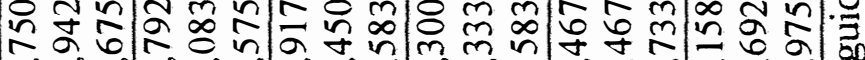

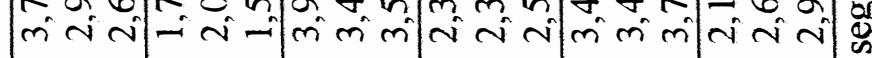

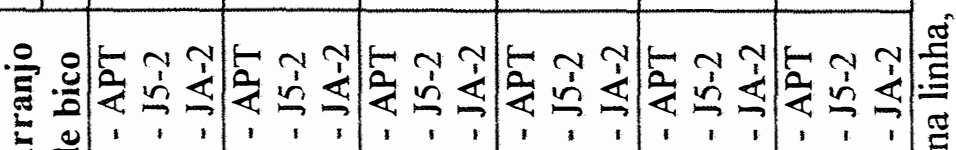

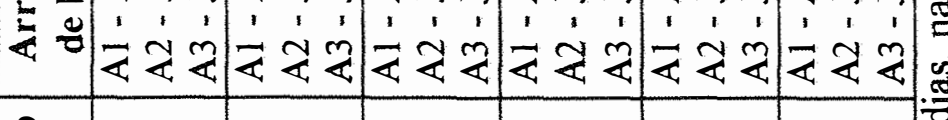

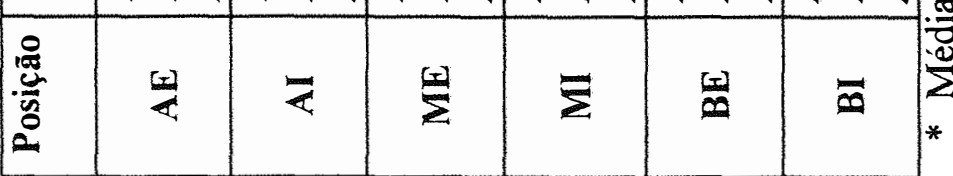

足

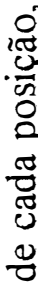

莺

花

包

正

$\underline{\underline{E}}$

苞

$\stackrel{\mathscr{E}}{\Xi}$

$\frac{\pi}{0}$

:

क्व

$\mathscr{\infty}$

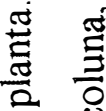

$\stackrel{\Xi}{\Xi}$

ஐี

.

.ే

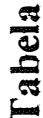

矛

$\sum^{0} \overrightarrow{0}$

导 * 
Da mesma forma ao ocorrido no quadrante frontal à aplicação (I), a variação na cobertura da pulverização no quadrante II foi maior quando avaliou-se a superficie abaxial das folhas, apresentando coeficientes de variação de 22,46 a 42,75\%, porém em maiores niveis aos obtidos no quadrante I (Tabela 12).

\subsection{Quadrante III - Superfície adaxial da folha}

A inclusão deste quadrante no presente estudo, teve por objetivo verificar a cobertura das folhas posicionadas mais distantes em relação ao lançamento das gotas pulverizadas.

Observando-se a Tabela 13, pode-se verificar uma relação inversamente proporcional entre deposição e altura das folhas na copa, ou seja, quanto mais alta estiver posicionada a amostra menor a cobertura na superficie adaxial e vice-versa, no quadrante III, oposto à pulverização. A ocorrência deste fato foi constatado na parte externa e interna da copa, porém, nesta última, o nível de cobertura tendeu a ser superior em relação às posições correspondentes externamente à copa, o que em parte pode ser explicado pela menor distância em relação ao lançamento das gotas.

Apesar de mais de 50\% das notas médias de cobertura não apresentarem diferenças significativas para os niveis de pressão dentro dos fatores arranjo de bicos e velocidade, sempre foram obtidas maiores deposições na pressão de $300 \mathrm{lbf} / \mathrm{pol}^{2}$ (Tabela 13A). Este fato também foi observado para todas as posições amostradas na copa das plantas em presença do arranjo $\mathrm{A}_{3}$ (bicos JA-2). Ainda, pode-se constatar na Tabela 13A o efeito da pressão de trabalho dentro do fator velocidade, sobre a cobertura de pulverização. A pressão de $300 \mathrm{lbf} / \mathrm{pol}^{2}$ na maior velocidade de deslocamento sempre proporcionou maiores niveis de cobertura independente da posição da folha na copa.

Nas posições alta externa (AE) e interna (AI) e média externa (ME) à copa praticamente não houve diferenças estatísticas na cobertura da pulverização para as velocidades em estudo. No entanto, nas demais posições amostradas a menor velocidade $(3,6 \mathrm{~km} / \mathrm{h})$ sempre proporcionou maiores cobertura de pulverização quando utilizado o 
arranjo $A_{1}$ (bicos APT). Fato semelhante também ocorreu com o arranjo $A_{3}$ (bicos JA-2), exceto para a posição baixa interna (BI) à copa.

Tabela 13. Efeito do arranjo de bicos, pressão e velocidade de trabalho na cobertura da superficie adaxial das folhas nas posições alta externa (AE) e interna (AI); média externa (ME) e interna (MI) e baixa externa (BE) e interna (BI) do quadrante III.

\begin{tabular}{|c|c|c|c|c|c|c|c|}
\hline \multirow{2}{*}{$\begin{array}{c}\text { Fatores de } \\
\text { variação }\end{array}$} & \multirow[t]{2}{*}{ G.L. } & \multicolumn{6}{|c|}{ Valores de F, CV e cobertura média nas diferentes posiçóes } \\
\hline & & BE & BI & ME & MI & $\mathbf{A E}$ & AI \\
\hline $\operatorname{Bico}(\mathrm{A})$ & 2 & $16,72 * *$ & $10,88^{* *}$ & $7,22 * *$ & $7,04 * *$ & $4,93 *$ & $11,89 * *$ \\
\hline Velocidade (V) & 2 & $10,13 * *$ & $18,02 * *$ & $2,21 \mathrm{~ns}$ & $19,39 * *$ & $0,59 \mathrm{~ns}$ & $4,41 *$ \\
\hline Pressão (P) & 1 & $28,41 * *$ & $12,51^{* *}$ & $13,49 * *$ & $18,96 * *$ & $27,68 * *$ & $18,71^{* *}$ \\
\hline$A \times V$ & 4 & $6,08 * *$ & $1,42 \mathrm{~ns}$ & $1,02 \mathrm{~ns}$ & $1,48 \mathrm{~ns}$ & $0,34 \mathrm{~ns}$ & $1,27 \mathrm{~ns}$ \\
\hline $\mathrm{A} \times \mathrm{P}$ & 2 & $1,76 \mathrm{~ns}$ & $2,92 \mathrm{~ns}$ & $1,73 \mathrm{~ns}$ & $3,07 \mathrm{~ns}$ & $2,32 \mathrm{~ns}$ & $4,69 *$ \\
\hline $\mathrm{V} \times \mathrm{P}$ & 2 & $0,72 \mathrm{~ns}$ & $1,59 \mathrm{~ns}$ & $2,07 \mathrm{~ns}$ & $0,59 \mathrm{~ns}$ & $2,76 \mathrm{~ns}$ & $1,36 \mathrm{~ns}$ \\
\hline$A \times V \times P$ & 4 & $4,37 * *$ & $2,17 \mathrm{~ns}$ & $1,83 \mathrm{~ns}$ & $1,26 \mathrm{~ns}$ & $1,19 \mathrm{~ns}$ & $0,93 \mathrm{~ns}$ \\
\hline Extras & 3 & $10,70^{* *}$ & $24,59 * *$ & $2,65 \mathrm{~ns}$ & $13,42 * *$ & $0,83 \mathrm{~ns}$ & $2,71 \mathrm{~ns}$ \\
\hline Fatorial $x$ Extras & $\begin{array}{r}1 \\
66^{1}\end{array}$ & $20,36 * *$ & $26,85^{* *}$ & $6,84^{*}$ & $37,92 * *$ & $9,98^{* *}$ & $43,31 * *$ \\
\hline CV (\%) & - & 20,27 & 17,78 & 36,81 & 23,62 & 38,91 & 32,26 \\
\hline \multicolumn{8}{|l|}{ Médias (notas) } \\
\hline APT (Al) & & $1,758 \mathrm{~b}$ & $2,817 \mathrm{a}$ & $1575 \mathrm{~b}$ & $2,333 \mathrm{ab}$ & $1,613 \mathrm{~b}$ & $1,575 \mathrm{~b}$ \\
\hline J5-2 (A2) & & $2,183 a b$ & $2,817 \mathrm{a}$ & $1,575 \mathrm{~b}$ & $2,333 a b$ & $1,613 \mathrm{~b}$ & $1,575 \mathrm{~b}$ \\
\hline JA-2 (A3) & & $2,521 \mathrm{a}$ & $3,154 \mathrm{a}$ & $2,188 \mathrm{a}$ & $2,533 \mathrm{a}$ & $2,258 \mathrm{a}$ & $2,200 \mathrm{a}$ \\
\hline DMS $5 \%$ & & 0,317 & 0.363 & 0,472 & 0,400 & 0.534 & 0.429 \\
\hline $3.6 \mathrm{k}$ & & $2479 a$ & $3225 \mathrm{a}$ & 15 & 2829 a & $1858 \mathrm{a}$ & \\
\hline $5,1 \mathrm{~km} / \mathrm{h}(\mathrm{V} 2)$ & & $2,088 \mathrm{ab}$ & $2,871 \mathrm{a}$ & $1,746 \mathrm{a}$ & $2,146 \mathrm{~b}$ & $1,738 \mathrm{a}$ & $1.692 \mathrm{ab}$ \\
\hline $7,2 \mathrm{~km} / \mathrm{h}$ (V3) & & $1,896 \mathrm{~b}$ & $2,325 \mathrm{~b}$ & $1.558 \mathrm{a}$ & $1,813 \mathrm{~b}$ & $1.979 \mathrm{a}$ & $1.458 \mathrm{~b}$ \\
\hline DMS $5 \%$ & & 0,317 & 0,363 & 0,472 & 0,400 & 0,534 & 0,429 \\
\hline
\end{tabular}

\begin{tabular}{|l|c|c|c|c|c|c|}
\hline $200 \mathrm{lbf} /$ pol. $^{2}$ (P1) & $1,867 \mathrm{~b}$ & $2,589 \mathrm{~b}$ & $1,464 \mathrm{~b}$ & $1,967 \mathrm{~b}$ & $1,381 \mathrm{~b}$ & $1,397 \mathrm{~b}$ \\
$300 \mathrm{lb} /$ pol. $^{2}$ (P2) & $2,442 \mathrm{a}$ & $3,025 \mathrm{a}$ & $2,053 \mathrm{a}$ & $2,558 \mathrm{a}$ & $2,336 \mathrm{a}$ & $2,028 \mathrm{a}$ \\
\hline DMS $5 \%$ & $\mathbf{0} 216$ & 0,247 & 0,320 & 0,272 & 0,363 & 0,291 \\
\hline
\end{tabular}

${ }^{*},{ }^{* *}=$ significativo ao nível de 5 e $1 \%$ de probabilidade, respectivamente.

$\mathrm{ns}=$ não significativo

Médias na mesma coluna e dentro do mesmo fator não diferem estatisticamente entre si, ao nivel de $5 \%$ de probabilidade pelo teste de Tukey.

${ }^{1}=$ Graus de liberdade do resíduo. 


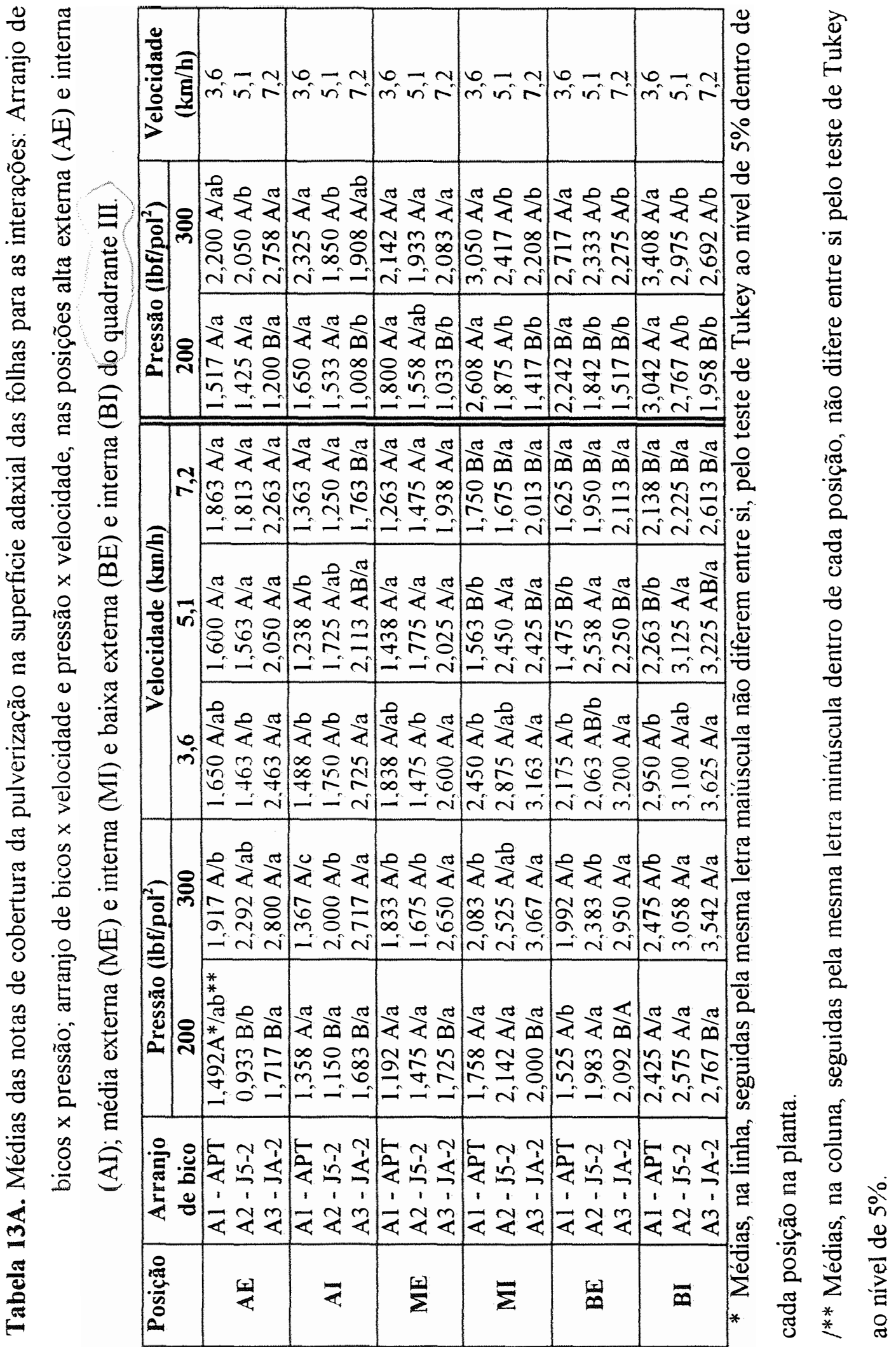


O efeito do fator velocidade dentro dos niveis de pressão, também pode ser observado na Tabela 13A, onde geralmente, a menor velocidade proporcionou uma cobertura de pulverização significativamente maior em relação às demais velocidades, tanto à 200 quanto à $300 \mathrm{lbf} / \mathrm{pol}^{2}$, sendo neste maior nível o efeito mais pronunciado.

As notas médias de cobertura na superficie adaxial das folhas com o arranjo $A_{3}$ (bicos JA-2), mesmo não diferindo estatísticamente das obtidas com o arranjo $\mathrm{A}_{2}$ (bicos J5-2) para algumas posições, na maior parte das vezes, mostraram-se superiores em ambos os níveis do fator pressão. Não foram observadas diferenças significativas nas deposições obtidas com os arranjos $\mathrm{A}_{2}$ (bicos J5-2) e $\mathrm{A}_{3}$ (bicos JA-2) dentro das maiores velocidades testadas, mas à $3,6 \mathrm{~km} / \mathrm{h}$ o arranjo $A_{2}$ apresentou maior cobertura em mais de $60 \%$ dos resultados (Tabela 13A).

A variação entre notas médias de cobertura foi maior para as folhas posicionadas externamente à copa $(20,27$ a $38,9 \%)$ em relação àquelas da parte interna $(17,78$ a $32,26 \%)$.

\subsection{Quadrante III - Superfície abaxial da folha}

Os resultados apresentados na Tabela 14, mostram maiores deposições na superficie abaxial das folhas situadas abaixo de $1,20 \mathrm{~m}$ de altura, principalmente para amostras provenientes da parte interna da copa, as quais apresentaram notas médias de cobertura superiores comparativamente àquelas da parte externa. $O$ fato das folhas localizadas na posição superior interna (AI) à copa apresentarem menor cobertura em relação às demais posições deve-se, em parte, ao posicionamento delas na copa em relação a pulverização.

Quanto ao efeito da pressão de trabalho, em geral, não foram observadas diferenças significativas entre as médias das notas de cobertura na superficie abaxial das folhas quando pulverizadas à 200 e $300 \mathrm{lbf} / \mathrm{pol}^{2}$, independente do arranjo de bicos e velocidade envolvidos neste estudo. Entretanto, as folhas das posições ME e MI à copa apresentaram deposições estatísticamente maiores à $300 \mathrm{lbf} / \mathrm{pol}^{2}$ em presença do arranjo 
$\mathrm{A}_{3}$ (bicos JA-2). O efeito deste fator dentro de velocidade, também pode ser observado na Tabela 14A, onde maiores médias das notas de cobertura foram obtidas para folhas provenientes das posições $\mathrm{AE}$ e $\mathrm{ME}$, com o equipamento pulverizando à $300 \mathrm{lbf} / \mathrm{pol}^{2}$, na maior velocidade em teste.

Independente do posicionamento das folhas na copa, quanto menor a velocidade de deslocamento maior a cobertura foliar e vice - versa. Porém, em aproximadamente $100 \%$ dos resultados as médias das notas de cobertura obtidas à 3,6 e $5,1 \mathrm{~km} / \mathrm{h}$ não diferiram estatísticamente tanto em presença do arranjo $A_{1}$ (bicos APT) quanto do $\mathrm{A}_{2}$ (bicos $\mathrm{J} 5-2$ ), mas foram significativamente superiores às obtidas na maior velocidade para as amostras provenientes da parte interna da copa quando pulverizadas com o arranjo $\mathrm{A}_{2}$ (Tabela 14A). A velocidade de $3,6 \mathrm{~km} / \mathrm{h}$ proporcionou a obtenção de maiores deposições para ambos os níveis do fator pressão, para amostras retiradas da parte interna, exceto para aquelas da posição mais baixa da copa.

Analisando o efeito de arranjo de bicos dentro de velocidade pode-se verificar que o arranjo $A_{3}$ (bicos JA-2) pulverizando à $3,6 \mathrm{~km} / \mathrm{h}$, sempre proporcionou deposições significativamente superiores às obtidas com os demais arranjos, exceto para as folhas situadas nas posições AE e BI à copa. Na maior parte das vezes, as médias das notas de cobertura obtidas com os diferentes arranjos não diferiram entre si, nas velocidades de 5,1 e $7,2 \mathrm{~km} / \mathrm{h}$. Quando os arranjos de bicos pulverizaram à $200 \mathrm{lbf} / \mathrm{pol}^{2}$, não foram constatadas diferenças significativas entre as médias das notas de cobertura, mas à $300 \mathrm{lbf} / \mathrm{pol}^{2}$ o arranjo $\mathrm{A}_{3}$, na maior parte das vezes, proporcionou a obtenção de deposições superiores aos demais arranjos (Tabela 14A).

Os coeficientes de variação para a cobertura na superfície abaxial das folhas atingiram níveis elevados, com valores de 29,14 a 65,85\%. A maior distância do ponto de lançamento das gotas e a barreira formada pela própria planta, dificultando o transporte das gotas contribuíram para a maior variação entre as médias das notas de cobertura neste quadrante (Tabela 14). 
Tabela 14. Efeito do arranjo de bicos, pressão e velocidade de trabalho na cobertura da superficie abaxial das folhas nas posições alta externa (AE) e interna (AI); média externa (ME) e interna (MI) e baixa externa (BE) e interna (BI) do quadrante III.

\begin{tabular}{|c|c|c|c|c|c|c|c|}
\hline \multirow{2}{*}{$\begin{array}{c}\text { Fatores de } \\
\text { variacão }\end{array}$} & \multirow[t]{2}{*}{ G.L. } & \multicolumn{6}{|c|}{ Valores de $\mathrm{F}, \mathrm{CV}$ e cobertura média nas diferentes posicões } \\
\hline & & BE & BI & ME & MI & $\mathbf{A E}$ & AI \\
\hline Bico (A) & 2 & $14,27 * *$ & $3,69^{*}$ & $21,47^{* *}$ & $4,26^{*}$ & $1,64 \mathrm{~ns}$ & $3,60^{*}$ \\
\hline $\operatorname{ade}(\mathrm{V})$ & 2 & $10,56 * *$ & $15,23 * *$ & $2,46 \mathrm{~ns}$ & $24,58 * *$ & $1,21 \mathrm{~ns}$ & $15,44 * *$ \\
\hline Press & 1 & $3,62 \mathrm{~ns}$ & $6,60^{*}$ & ** & $4,57^{*}$ & $10,74^{* *}$ & $1,27 \mathrm{~ns}$ \\
\hline Ax & 4 & 2,63 & $0,41 \mathrm{~ns}$ & & $5,52 * *$ & $0,71 \mathrm{~ns}$ & $2,69 *$ \\
\hline A & 2 & 3,74 & 2,21 & 9,3 & $4,30 *$ & 2,5 & $2,59 \mathrm{~ns}$ \\
\hline $\mathrm{Vx}$ & 2 & $0,30 \mathrm{~ns}$ & $0,03 \mathrm{~ns}$ & 2,45 & $0,207 \mathrm{~ns}$ & $1,37 \mathrm{~ns}$ & $0,02 \mathrm{~ns}$ \\
\hline$x P$ & 4 & $0,83 \mathrm{~ns}$ & $1,98 \mathrm{~ns}$ & $2,08 \mathrm{~ns}$ & $0,34 \mathrm{~ns}$ & $3,35 *$ & $0,56 \mathrm{~ns}$ \\
\hline Extr & 3 & $9,00 * *$ & $11,10^{* *}$ & 16,3 & $12,56^{* *}$ & $2,61 \mathrm{~ns}$ & $8,90 * *$ \\
\hline Fator & $\begin{array}{r}1 \\
66^{1} \\
\end{array}$ & $21,90^{* *}$ & $5,50 *$ & ns & $0,81 \mathrm{~ns}$ & $0,63 \mathrm{~ns}$ & $0,30 \mathrm{~ns}$ \\
\hline $\mathrm{CV}(\%)$ & - & 2 & 28,62 & & 8,26 & 47,18 & 55,85 \\
\hline \multicolumn{8}{|l|}{ Médias } \\
\hline APT & & 800 & $2,075 \mathrm{~b}$ & & 1,400 & $1,158 \mathrm{a}$ & $1,163 \mathrm{ab}$ \\
\hline J5- & & 80 & $2,246 \mathrm{ab}$ & & 1,317 & 1,3 & $0,796 \mathrm{~b}$ \\
\hline $\mathrm{JA}-\mathrm{Z}^{-}$ & & $2,400 \mathrm{a}$ & $2,600 \mathrm{a}$ & & $1,908 \mathrm{a}$ & $1,475 \mathrm{a}$ & $1,363 \mathrm{a}$ \\
\hline DMS $5 \%$ & & 0,412 & 0,474 & 0,304 & 0,527 & 0,429 & 0,515 \\
\hline 3,6 & & 34 & $2,763 \mathrm{a}$ & & 2,392 & & $1,763 \mathrm{a}$ \\
\hline & & & & & & & $0,958 \mathrm{~b}$ \\
\hline $7,2 \mathrm{k}$ & & $1.583 \mathrm{~b}$ & $1.704 \mathrm{~b}$ & & $0,892 \mathrm{~b}$ & $1.242 \mathrm{a}$ & $0,600 \mathrm{~b}$ \\
\hline DMS 5\% & & 0.412 & 0,474 & 0.304 & 0.527 & 0.429 & 0.515 \\
\hline
\end{tabular}

\begin{tabular}{|l|c|c|c|c|c|c|}
\hline $200 \mathrm{lb} /$ pol.2 (P1) & $1,767 \mathrm{a}$ & $2,100 \mathrm{~b}$ & $0,928 \mathrm{~b}$ & $1,450 \mathrm{~b}$ & $1,097 \mathrm{~b}$ & $1,008 \mathrm{a}$ \\
$300 \mathrm{lb} /$ pol.2(P2) & $2,033 \mathrm{a}$ & $2,514 \mathrm{a}$ & $1,350 \mathrm{a}$ & $1,733 \mathrm{a}$ & $1,575 \mathrm{a}$ & $1,206 \mathrm{a}$ \\
\hline DMS 5\% & 0,280 & 0,322 & 0,207 & 0,358 & $\mathbf{0} 291$ & 0,350 \\
\hline
\end{tabular}

$*,{ }^{*}=$ significativo ao nivel de 5 e $1 \%$ de probabilidade, respectivamente.

ns $=$ não significativo

Médias na mesma coluna e dentro do mesmo fator não diferem estatisticamente entre si, ao nível de $5 \%$ de probabilidade pelo teste de Tukey.

${ }^{1}=$ Graus de liberdade do resíduo. 
导

$\ddot{E}$

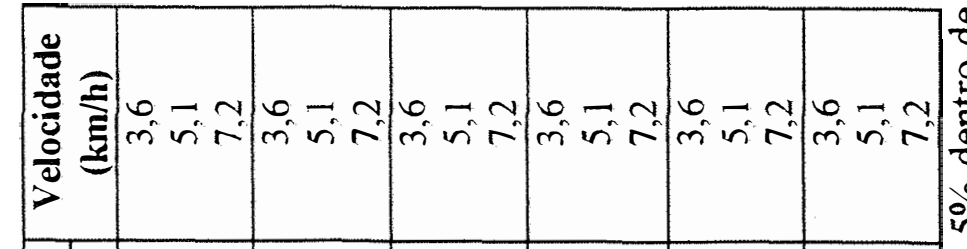

\&

త్ర

送

c

党

胥

त. .

은

胥

.

造

$\frac{0}{2} \stackrel{0}{>}$

ب

亭

๘

0 (1)

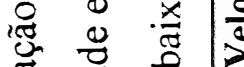

-10

ఏ

0

\begin{tabular}{l|l|l|l|l|l|}
\hline & & & & & \\
\hline
\end{tabular}

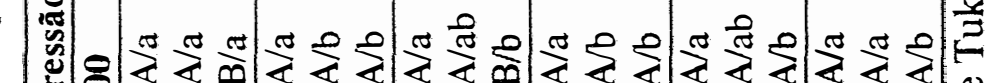

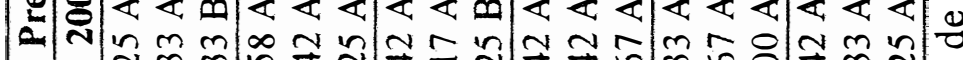

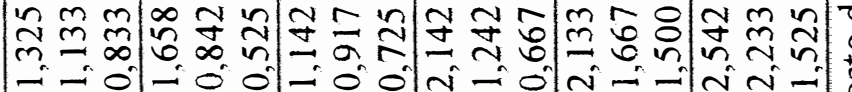

党

|r

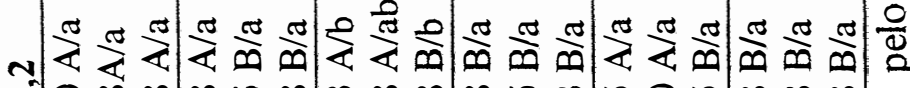

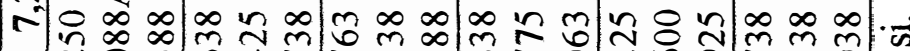

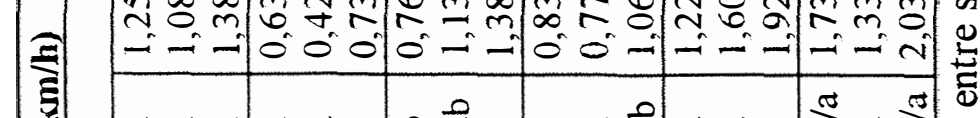

(2)

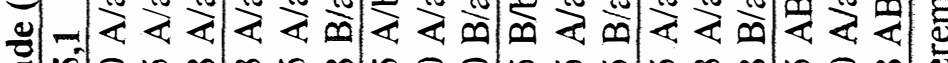

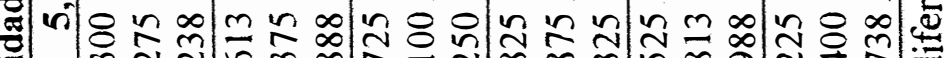

m

$\frac{0}{2}$

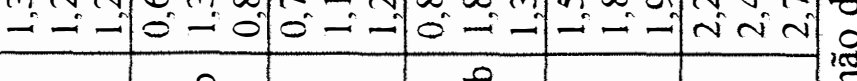

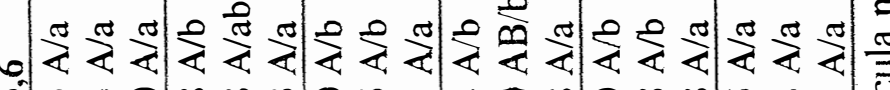

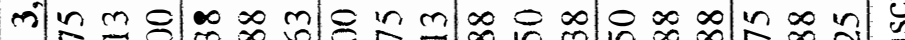

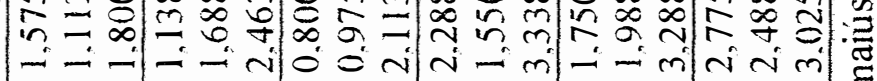

๘ 0

当

๑)

党

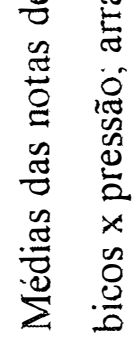

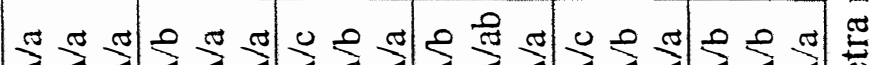

-

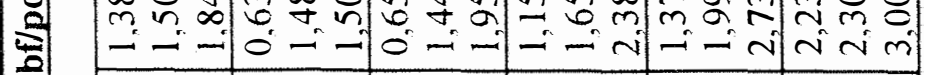

窟

:

*

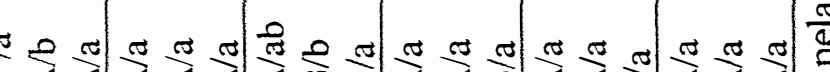

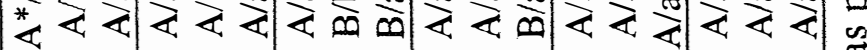

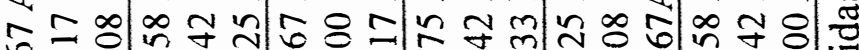

乍

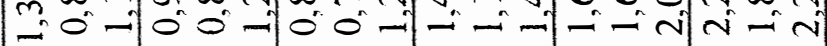

\begin{tabular}{|c|c|c|c|c|c|c|}
\hline 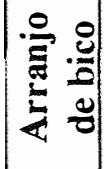 & 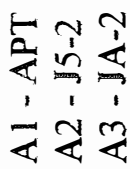 & 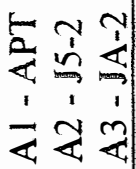 & 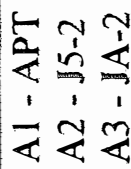 & 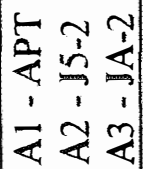 & 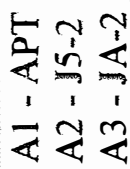 & 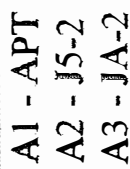 \\
\hline . & $\frac{1}{4}$ & $<$ & $\sum$ & $\sum$ & 디 & $\overline{0}$ \\
\hline
\end{tabular}

总

屯.

$\overline{7}$

胥

20্ণ

$\frac{2}{2}$

苂

$\stackrel{0}{\frac{0}{0}}$

党

즉

包

E

छ્ี

$\frac{\pi}{2}$

苂

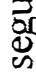




\subsection{Quadrante IV - Superfície adaxial da folha}

Da observação da Tabela 15, verifica-se que as deposições na superficie adaxial das folhas localizadas externamente à copa foram maiores em relação àquelas provenientes da parte interna desse quadrante posicionado, também, lateralmente à direção de lançamento das gotas de pulverização. Da comparação entre os valores médios de cobertura neste quadrante aos obtidos nos demais, nota-se que foram superiores aos obtidos no quadrante oposto à aplicação (III) e inferiores aqueles obtidos frontalmente a pulverização (quadrante I).

Avaliando-se o efeito da pressão de trabalho dentro dos demais fatores, verifica-se que não foram observadas diferenças entre deposições obtidas à 200 e $300 \mathrm{lbf} / \mathrm{pol}^{2}$, independente do arranjo de bicos e da posição das folhas na copa, exceto para as posições AI e MI à copa, onde na pressãode $300 \mathrm{lbf} / \mathrm{pol}^{2}$ obtiveram-se deposições significativamente maiores com o arranjo $A_{3}$ (Tabela 15A). Da mesma forma, não observaram-se diferenças na cobertura para folhas provenientes das posições $\mathrm{BE}, \mathrm{ME} \mathrm{e}$ AE à copa quando pulverizadas à 200 ou $300 \mathrm{lbf} / \mathrm{pol}^{2}$, dentro de cada nível do fator velocidade. A superficie adaxial das folhas quando avaliada nestas mesmas posições porém, internamente à copa exibiram cobertura significativamente maiores à $300 \mathrm{lbf} / \mathrm{pol}^{2}$ na menor velocidade em teste.

Em geral, as médias das notas de cobertura não diferiram para as velocidades em teste. Entretanto, para as folhas localizadas internamente à copa, as velocidades de 3,6 e $5,1 \mathrm{~km} / \mathrm{h}$ proporcionaram coberturas significativamente maiores em relação à $7,2 \mathrm{~km} / \mathrm{h}$ com o arranjo $\mathrm{A}_{3}$ (bicos $\mathrm{JA}-2$ ). Também, não foram constatadas diferenças na cobertura para os arranjos de bicos em teste, independente da pressão empregada, exceto para as posições AI e MI à copa, já citadas anteriormente, com o arranjo $\mathrm{A}_{3}$ sob $300 \mathrm{lbf} / \mathrm{pol}^{2}$ (Tabela 15A).

A variação na cobertura foliar, independente da posição em estudo, foi semelhante à obtida no Quadrante II para a parte superior das folhas com valores de 17,46 a $26,01 \%$ ( Tabela 15 ). 
Tabela 15. Efeito do arranjo de bicos, pressão e velocidade de trabalho na cobertura da superficie adaxial das folhas nas posições alta externa (AE) e interna (AI); média externa $(\mathrm{ME})$ e interna $(\mathrm{MI})$ e baixa externa $(\mathrm{BE})$ e interna $(\mathrm{BI})$ do quadrante IV.

\begin{tabular}{|c|c|c|c|c|c|c|c|}
\hline \multirow{2}{*}{$\begin{array}{c}\text { Fatores de } \\
\text { variação }\end{array}$} & \multirow[t]{2}{*}{ G.L. } & \multicolumn{6}{|c|}{ Valores de F, CV e cobertura média nas diferentes posicões } \\
\hline & & $\mathbf{B E}$ & BI & ME & MI & $\mathbf{A E}$ & AI \\
\hline $\operatorname{Bico}(\mathrm{A})$ & 2 & $0,16 \mathrm{~ns}$ & $2,91 \mathrm{~ns}$ & $0,64 \mathrm{~ns}$ & $6,62 * *$ & $4,86^{*}$ & $15,31 * *$ \\
\hline Velocidade (V) & 2 & $0,11 \mathrm{~ns}$ & $6,20 * *$ & $2,23 \mathrm{~ns}$ & $8,58 * *$ & $2,32 \mathrm{~ns}$ & $1,63 \mathrm{~ns}$ \\
\hline Pressão (P) & 1 & $1,81 \mathrm{~ns}$ & $3,26 \mathrm{~ns}$ & $0,08 \mathrm{~ns}$ & $8,80 * *$ & $4,83 *$ & $16,86 * *$ \\
\hline $\mathrm{A} \times \mathrm{V}$ & 4 & $0,09 \mathrm{~ns}$ & $1,13 \mathrm{~ns}$ & $0,68 \mathrm{~ns}$ & $1,47 \mathrm{~ns}$ & $2,18 \mathrm{~ns}$ & $1,36 \mathrm{~ns}$ \\
\hline $\mathrm{A} \times \mathrm{P}$ & 2 & $0,47 \mathrm{~ns}$ & $0,04 \mathrm{~ns}$ & $1,33 \mathrm{~ns}$ & $2,71 \mathrm{~ns}$ & $0,95 \mathrm{~ns}$ & $3,55^{*}$ \\
\hline $\mathrm{V} \times \mathrm{P}$ & 2 & $0,07 \mathrm{~ns}$ & $2,44 \mathrm{~ns}$ & $0,81 \mathrm{~ns}$ & $0,68 \mathrm{~ns}$ & $1,27 \mathrm{~ns}$ & $1,77 \mathrm{~ns}$ \\
\hline$A \times V \times P$ & 4 & $0,92 \mathrm{~ns}$ & $0,80 \mathrm{~ns}$ & $0,27 \mathrm{~ns}$ & $0,39 \mathrm{~ns}$ & $0,24 \mathrm{~ns}$ & $0,25 \mathrm{~ns}$ \\
\hline Extras & 3 & $0,91 \mathrm{~ns}$ & $6,52 * *$ & $0,95 \mathrm{~ns}$ & $6,54^{* *}$ & $7,74^{* *}$ & $3,00 *$ \\
\hline Fatorial $x$ Extras & $\begin{array}{r}1 \\
66\end{array}$ & $28,83^{* *}$ & $50,23 * *$ & $10,77^{* *}$ & $38,15^{* *}$ & $23,65 * *$ & $34,17^{* *}$ \\
\hline CV (\%) & - & 20.08 & 17,46 & 26,01 & 18,20 & 22,21 & 21,35 \\
\hline \multicolumn{8}{|l|}{ Médias (notas) } \\
\hline APT (Al) & & $4,250 \mathrm{a}$ & $3,688 \mathrm{a}$ & $3,758 \mathrm{a}$ & $3,192 \mathrm{a}$ & $3,567 \mathrm{a}$ & $2,850 \mathrm{a}$ \\
\hline $\mathrm{J} 5-2(\mathrm{~A} 2)$ & & $4,133 \mathrm{a}$ & $3.488 \mathrm{a}$ & $3,446 \mathrm{a}$ & $2,738 \mathrm{~b}$ & $2,904 \mathrm{~b}$ & $1,983 \mathrm{~b}$ \\
\hline JA-2 (A3) & & $4,121 \mathrm{a}$ & $3,967 \mathrm{a}$ & $3,671 \mathrm{a}$ & $3,338 \mathrm{a}$ & $3,121 \mathrm{ab}$ & $2,650 \mathrm{a}$ \\
\hline DMS 5\% & & 0.613 & 0,479 & 0,683 & 0,413 & 0,520 & 0,394 \\
\hline
\end{tabular}

\begin{tabular}{|l|c|c|c|c|c|c|}
\hline $3,6 \mathrm{~km} / \mathrm{h}(\mathrm{V} 1)$ & $4,229 \mathrm{a}$ & $3,967 \mathrm{a}$ & $3,967 \mathrm{a}$ & $3,421 \mathrm{a}$ & $3,429 \mathrm{a}$ & $2,663 \mathrm{a}$ \\
$5,1 \mathrm{~km} / \mathrm{h}(\mathrm{V} 2)$ & $4,167 \mathrm{a}$ & $3,863 \mathrm{a}$ & $3,504 \mathrm{a}$ & $3,133 \mathrm{a}$ & $2,963 \mathrm{a}$ & $2,383 \mathrm{a}$ \\
$7.2 \mathrm{~km} / \mathrm{h}(\mathrm{V} 3)$ & $4.108 \mathrm{a}$ & $3.313 \mathrm{~b}$ & $3.404 \mathrm{a}$ & $2,713 \mathrm{~b}$ & $3,200 \mathrm{a}$ & $2.438 \mathrm{a}$ \\
\hline DMS $5 \%$ & 0.613 & 0.479 & 0.683 & 0.413 & 0,520 & 0.394 \\
\hline
\end{tabular}

\begin{tabular}{|c|c|c|c|c|c|c|}
\hline $\begin{array}{l}200 \mathrm{lbf} / \mathrm{pol}^{2}{ }^{2} \text { (P1) } \\
300 \mathrm{lbf} / \mathrm{pol}^{2}{ }^{2} \text { (P2) }\end{array}$ & $\begin{array}{l}4,028 \mathrm{a} \\
4,308 \mathrm{a}\end{array}$ & $\begin{array}{l}3,567 \mathrm{a} \\
3.861 \mathrm{a}\end{array}$ & $\begin{array}{l}3.592 \mathrm{a} \\
3.658 \mathrm{a}\end{array}$ & $\begin{array}{l}2.881 \mathrm{~b} \\
3.297 \mathrm{a}\end{array}$ & $\begin{array}{l}3,003 \mathrm{~b} \\
3.392 \mathrm{a}\end{array}$ & $\begin{array}{l}2,219 \mathrm{~b} \\
2.769 \mathrm{a}\end{array}$ \\
\hline DMS 5\% & 0.417 & 0.326 & 0.464 & 0.281 & 0,354 & 0.268 \\
\hline
\end{tabular}

${ }^{*},{ }^{* *}=$ significativo ao nível de 5 e $1 \%$ de probabilidade, respectivamente.

ns $=$ não significativo

Médias na mesma coluna e dentro do mesmo fator não diferem estatisticamente entre si, ao nivel de $5 \%$ de probabilidade pelo teste de Tukey.

${ }^{1}=$ Graus de liberdade do residuo. 


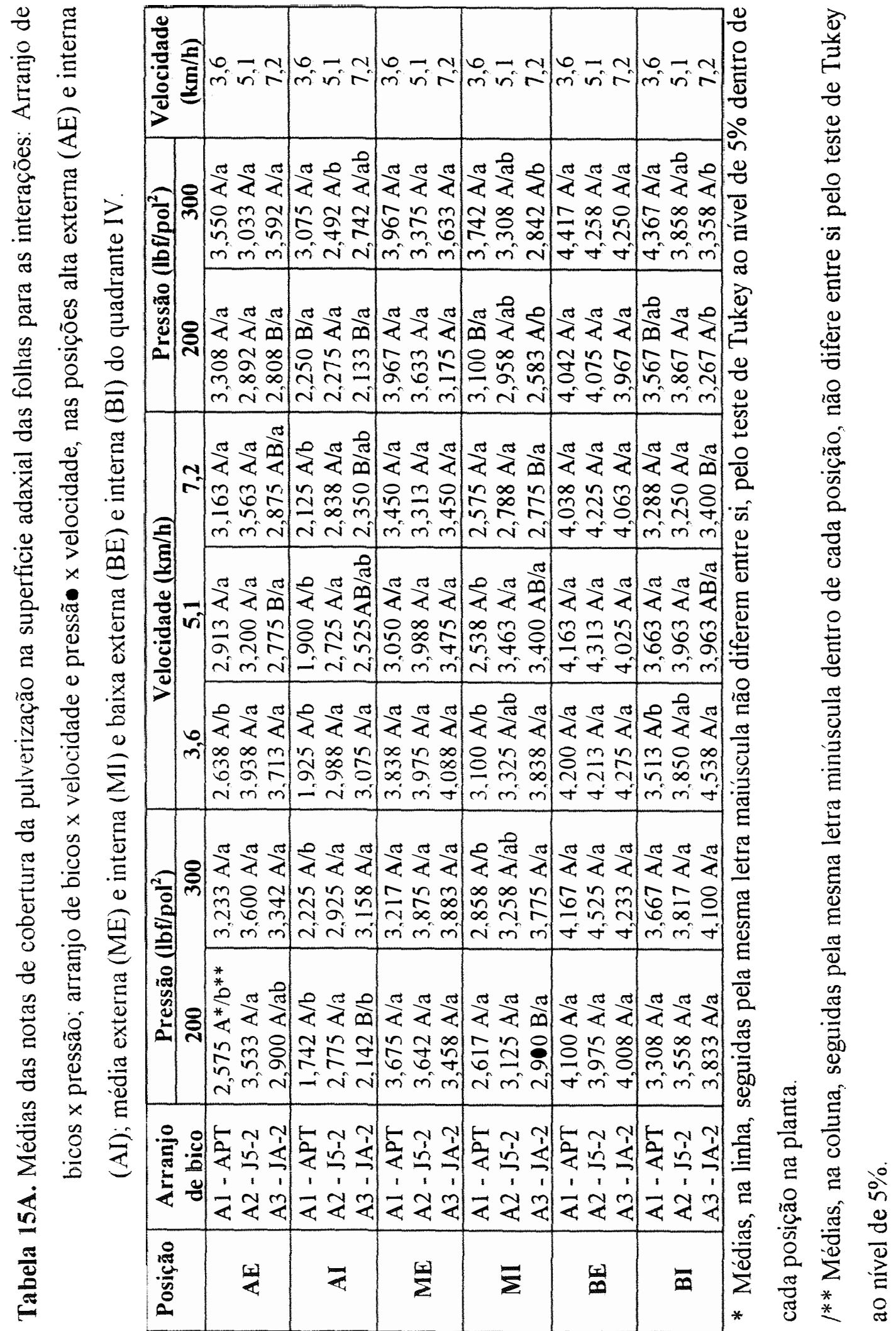




\subsection{Quadrante IV - Superfície abaxial da folha}

Os resultados apresentados na Tabela 16, mostram que a cobertura na superficie abaxial das folhas neste quadrante foi maior nas posições externas à copa, a semelhança do ocorrido para a superficie adaxial, conforme relatado anteriormente.

Analisando-se o efeito do fator pressão verifica-se que, em geral, não houveram diferenças estatísticas entre as médias das notas de cobertura obtidas com pulverizações realizadas à 200 e $300 \mathrm{lbf} / \mathrm{pol}^{2}$, independente do arranjo de bicos utilizado, exceto para as folhas situadas nas posições BI e MI à copa, que sob a pressão de $300 \mathrm{lbf} / \mathrm{pol}^{2}$ mostraram maiores deposições com o arranjo $\mathrm{A}_{2}$ (bicos J5-2). Também, pode-se constatar na Tabela 16A que, as médias das notas de cobertura não diferiram entre si quando as pulverizações foram realizadas sob pressões de 200 e $300 \mathrm{lbf} / \mathrm{pol}^{2}$, em praticamente todos os niveis do fator velocidade.

Quanto às velocidades em teste, 3,6 e $5,1 \mathrm{~km} / \mathrm{h}$ proporcionaram coberturas superiores às obtidas na maior velocidade $(7,2 \mathrm{~km} / \mathrm{h})$. Este efeito pode ser facilmente constatado nas folhas provenientes das posições internas da copa, onde a cobertura de pulverização na maior velocidade foi significativamente menor quando a aplicação foi realizada com o arranjo $A_{2}$ (bicos J5-2). A tendência das menores velocidades proporcionarem maiores cobertura foliar ocorreu para ambos os niveis do fator pressão, mas a $300 \mathrm{lbf} / \mathrm{pol}^{2}$ as folhas das posições BI e MI à copa quando pulverizadas à $3,6 \mathrm{~km} / \mathrm{h}$ apresentaram deposições superiores às demais velocidades, independente do arranjo de bicos em teste (Tabela 16A).

Praticamente, não foram observadas diferenças significativas na cobertura da superficie abaxial das folhas para os arranjos testados, independente da pressão e velocidade de trabalho. A pulverização realizada com o arranjo $A_{1}$ (bicos APT) na pressão de $200 \mathrm{lbf} / \mathrm{pol}^{2}$ proporcionou a obtenção de médias de notas de cobertura superiores àquelas com os demais arranjos, quando avaliadas as folhas localizadas externamente à copa. Já para as folhas retiradas da parte interna, houve uma tendência do arranjo $\mathrm{A}_{3}$ (bicos JA-2) proporcionar maior cobertura, mesmo não diferindo da obtida 
com os demais arranjos em ambos os níveis de pressão. Este arranjo de bicos pulverizando à $3,6 \mathrm{~km} / \mathrm{h}$, geralmente proporcionou maiores médias de notas de cobertura em relação aos demais arranjos para as folhas situadas na parte interna da copa. As deposições com os arranjos $A_{2}$ (bicos J5-2) e $A_{3}$ (bicos JA-2), pulverizando à $5,1 \mathrm{~km} / \mathrm{h}$, não diferiram entre si para as folhas da parte interna da copa, mas mostraram-se superiores às obtidas com o arranjo $A_{1}$ (Tabela 16A).

A variação entre as médias das notas de cobertura nas diferentes posições em estudo foi de 21,04 a $37,64 \%$, quando avaliada a superficie abaxial das folhas neste quadrante lateral à pulverização (Tabela 16).

Apesar dos quadrantes II e IV serem equivalentes quanto ao posicionamento em relação ao deslocamento do equipamento de aplicação, o quadrante II recebe a pulverização antes do IV. Quanto à aerodinâmica, pode-se considerar duas situações distintas, pois no início da pulverização o ar saturado de gotículas deverá expulsar o ar existente no interior da copa e, ao final da aplicação, a massa de ar sêco ainda presente na parte interna da copa torna-se bastante reduzida.

Em geral, o quadrante IV apresentou maiores médias das notas de cobertura em relação ao posicionado no início da aplicação (quadrante II), independente da superfície foliar analisada. Efeitos aerodinâmicos e do vento (horizontal) podem ter influenciado na ocorrência desse fato, alterando a trajetória de grande parte das gotas e, conseqüentemente, apresentando diferentes niveis de cobertura nos respectivos quadrantes.

A diferença nos níveis de cobertura detectada nos quadrantes II e IV poderia tornar-se ainda maior, caso a aplicação fosse novamente realizada na mesma direção e sentido, em plantas já anteriormente pulverizadas em um único lado. Em condição normal, essa diferença seria anulada pela passagem do turboatomizador em sentidos opostos pulverizando em ambos os lados da planta (quadrantes I e III). 
Tabela 16. Efeito do arranjo de bicos, pressão e velocidade de trabalho na cobertura da superficie abaxial das folhas nas posições alta externa ( $\mathrm{AE})$ e interna (AI); média externa (ME) e interna (MI) e baixa externa (BE) e interna (BI) do quadrante IV.

\begin{tabular}{|c|c|c|c|c|c|c|c|}
\hline \multirow{2}{*}{$\begin{array}{c}\text { Fatores de } \\
\text { variação }\end{array}$} & \multirow[t]{2}{*}{ G.L. } & \multicolumn{6}{|c|}{ Valores de F, CV e cobertura média nas diferentes posicões } \\
\hline & & $\mathbf{B E}$ & BI & ME & MI & $\overline{\mathrm{AE}}$ & $\overline{A I}$ \\
\hline $\operatorname{Bico}(\mathrm{A})$ & 2 & $0,82 \mathrm{~ns}$ & $9,85 * *$ & $4,23 *$ & $1,78 \mathrm{~ns}$ & $1,15 \mathrm{~ns}$ & $3,39^{*}$ \\
\hline Velocidade (V) & 2 & $5,61 * *$ & $14,23 * *$ & $8,43 * *$ & $16,28 * *$ & $4,03 *$ & $10,20 * *$ \\
\hline Pressão (P) & 1 & $0,08 \mathrm{~ns}$ & $7,59 * *$ & $2,31 \mathrm{~ns}$ & $9,13 * *$ & $1,20 \mathrm{~ns}$ & $0,91 \mathrm{~ns}$ \\
\hline$A \times V$ & 4 & $0,45 \mathrm{~ns}$ & $1,69 \mathrm{~ns}$ & $2,94 \mathrm{~ns}$ & $4,08 * *$ & $1,02 \mathrm{~ns}$ & $2,81 *$ \\
\hline$A \times P$ & 2 & $3,68 *$ & $1,76 \mathrm{~ns}$ & $2,23 \mathrm{~ns}$ & $4,13 *$ & $1,33 \mathrm{~ns}$ & $1,44 \mathrm{~ns}$ \\
\hline $\mathrm{V} \times \mathrm{P}$ & 2 & $0,12 \mathrm{~ns}$ & $0,45 \mathrm{~ns}$ & $1,06 \mathrm{~ns}$ & $4,40^{*}$ & $0,17 \mathrm{~ns}$ & $0,18 \mathrm{~ns}$ \\
\hline$A \times V \times P$ & 4 & $2,30 \mathrm{~ns}$ & $0,24 \mathrm{~ns}$ & $3,00 *$ & $0,74 \mathrm{~ns}$ & $2,61 *$ & $0,45 \mathrm{~ns}$ \\
\hline Extras & 3 & $6,80^{* *}$ & $22,97 * *$ & $16,59 * *$ & $22,82 * *$ & $10,01 * *$ & $14,73 * *$ \\
\hline Fatorial $x$ Extras & $\begin{array}{r}1 \\
66\end{array}$ & $2,24 \mathrm{~ns}$ & $29,39 * *$ & $0,92 \mathrm{~ns}$ & $0,06 \mathrm{~ns}$ & $0,17 \mathrm{~ns}$ & $3,01 \mathrm{~ns}$ \\
\hline $\mathrm{CV}(\%)$ & - & 23,32 & 21,11 & 21,04 & 25,08 & 26,57 & 37,64 \\
\hline
\end{tabular}

Médias (notas)

\begin{tabular}{|l|c|c|c|c|c|c|}
\hline APT (A1) & $3,758 \mathrm{a}$ & $2,304 \mathrm{~b}$ & $4,350 \mathrm{a}$ & $2,646 \mathrm{a}$ & $3,375 \mathrm{a}$ & $2,058 \mathrm{~b}$ \\
J5-2 (A2) & $3,608 \mathrm{a}$ & $2,471 \mathrm{~b}$ & $3,938 \mathrm{ab}$ & $2,596 \mathrm{a}$ & $34293 \mathrm{a}$ & $2,575 \mathrm{ab}$ \\
JA-2 (A3) & $3,442 \mathrm{a}$ & $3,017 \mathrm{a}$ & $3,658 \mathrm{~b}$ & $2,942 \mathrm{a}$ & $3,075 \mathrm{a}$ & $2,683 \mathrm{a}$ \\
\hline DMS 5\% & 0,593 & 0,403 & 0,575 & 0,476 & 0,603 & 0,616 \\
\hline
\end{tabular}

\begin{tabular}{|l|c|c|c|c|c|c|}
\hline $3,6 \mathrm{~km} / \mathrm{h}(\mathrm{V} 1)$ & $4,000 \mathrm{a}$ & $3,046 \mathrm{a}$ & $4,521 \mathrm{a}$ & $3,246 \mathrm{a}$ & $3,596 \mathrm{a}$ & $2,963 \mathrm{a}$ \\
$5,1 \mathrm{~km} / \mathrm{h}(\mathrm{V} 2)$ & $3,633 \mathrm{ab}$ & $2,596 \mathrm{a}$ & $3,867 \mathrm{~b}$ & $2,813 \mathrm{a}$ & $3,383 \mathrm{ab}$ & $2,538 \mathrm{a}$ \\
$7,2 \mathrm{~km} / \mathrm{h}(\mathrm{V} 3)$ & $3,175 \mathrm{~b}$ & $2.150 \mathrm{~b}$ & $3,558 \mathrm{~b}$ & $2,125 \mathrm{~b}$ & $2,900 \mathrm{~b}$ & $1.817 \mathrm{~b}$ \\
\hline DMS $5 \%$ & 0,593 & 0,403 & 0,575 & 0,476 & 0.603 & 0,616 \\
\hline
\end{tabular}

\begin{tabular}{|l|c|c|c|c|c|c|}
\hline $200 \mathrm{lbf} / \mathrm{pol}^{-}$(P1) & $3,575 \mathrm{a}$ & $2,408 \mathrm{~b}$ & $3,833 \mathrm{a}$ & $2,483 \mathrm{~b}$ & $3,181 \mathrm{a}$ & $2,339 \mathrm{a}$ \\
$300 \mathrm{lbf} / \mathrm{pol}^{2}$ (P2) & $3.631 \mathrm{a}$ & $2.786 \mathrm{a}$ & $4,131 \mathrm{a}$ & $2.972 \mathrm{a}$ & $3,406 \mathrm{a}$ & $2.539 \mathrm{a}$ \\
\hline DMS $5 \%$ & 0,403 & 0,274 & 0,391 & 0,323 & 0,410 & 0,419 \\
\hline
\end{tabular}

$*,{ }^{* *}=$ significativo ao nível de 5 e $1 \%$ de probabilidade, respectivamente.

ns = não significativo

Médias na mesma coluna e dentro do mesmo fator não diferem estatisticamente entre si, ao nível de $5 \%$ de probabilidade pelo teste de Tukey.

${ }^{1}=$ Graus de liberdade do resíduo. 


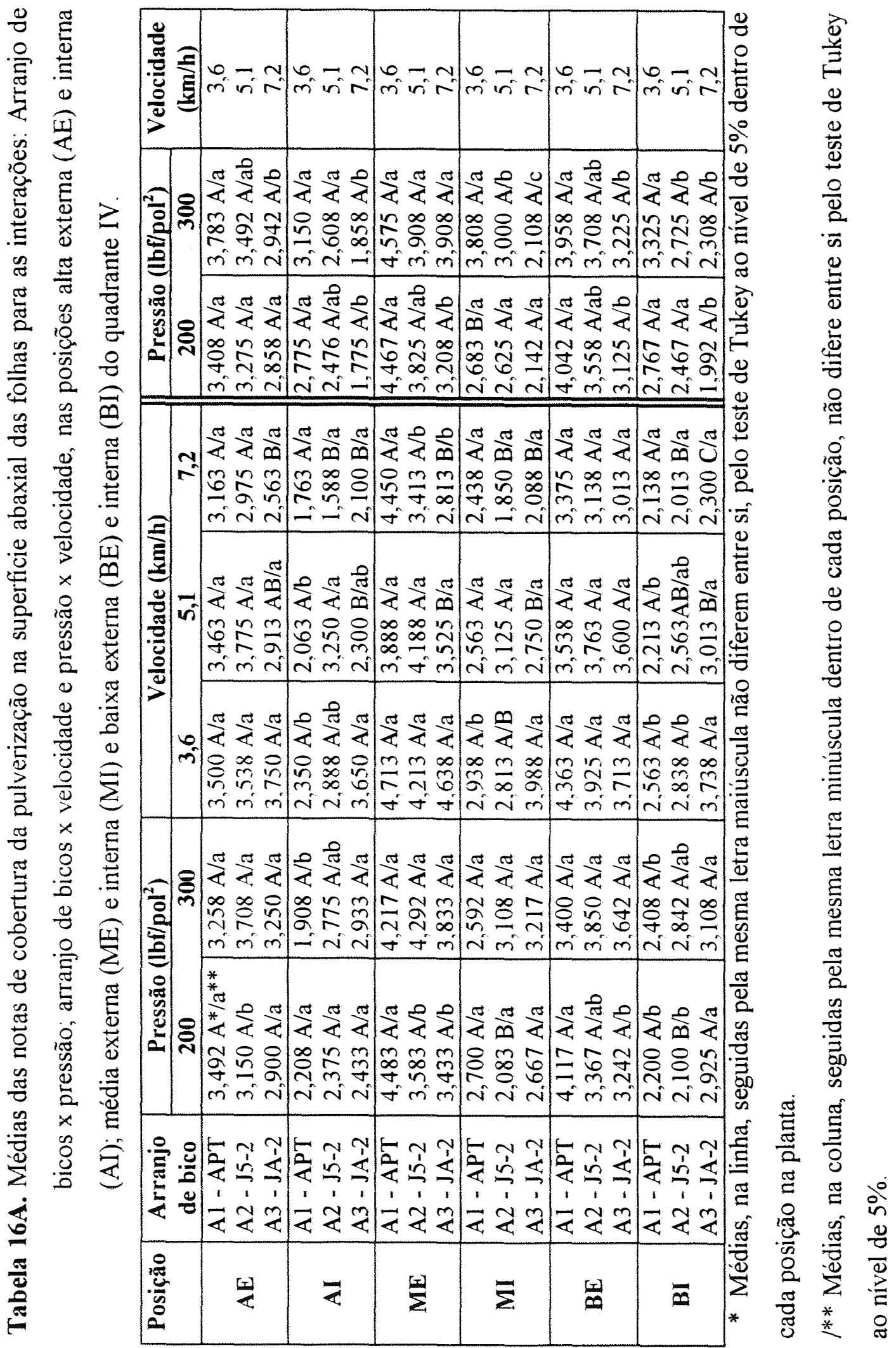




\subsection{Comparação entre os fatores arranjo de bicos, pressão e velocidade nos quatro quadrantes}

As análises estatísticas revelaram que, em geral, os fatores testados atuam de forma independente na deposição foliar. Entretanto, 18\% das interações, excluindo as interações envolvendo os tratamentos adicionais, foram estatísticamente significativas quando analisadas pelo Teste $\mathrm{F}$, ao nível de $5 \%$ de probabilidade.

Estes resultados, em parte, concordam com os obtidos por WHITNEY et al., (1989) e PALLADINI (1990);(1991), onde constataram a não ocorrência de interações entre estes fatores. Porém, no presente estudo, quando se duplicou o número de bicos no ramal de pulverização e trabalhou-se com pressões mais elevadas, mantendo praticamente o mesmo volume de aplicação, pode-se constatar a ocorrência de interações significativas entre os fatores testados. Assim sendo, esta particularidade coloca em questionamento a forma de atuação dos fatores neste e nos futuros estudos envolvendo as condições de trabalho mencionadas.

\subsection{Arranjo de bicos}

Pelos resultados apresentados nas Tabelas 9 a 16, pode-se constatar no quadrante I (frontal à pulverização) uma menor cobertura com o arranjo $\mathrm{A}_{3}$ (bicos JA-2) nas superficies adaxial e abaxial das folhas provenientes da parte externa da copa. Nos quadrantes laterais à pulverização (II e IV), praticamente não foram observadas diferenças significativas entre os arranjos $A_{2}$ (bicos $J 5-2$ ) e $A_{3}$, quando avaliada a cobertura em ambas as superficies das folhas nas diferentes posições amostradas na copa.

No quadrante oposto à aplicação (III), o arranjo $A_{3}$ (bicos JA-2) sempre proporcionou maiores médias das notas de cobertura em ambas as superficies foliar, embora algumas vezes não diferindo das obtidas com o arranjo $A_{2}$ (bicos J5-2). Em condições operacionais semelhantes, ou seja, velocidade e pressão de trabalho o arranjo 
$\mathrm{A}_{3}$ (bicos JA-2) apresenta como vantagem o menor volume de aplicação comparativamente ao $\mathrm{A}_{2}$ (Tabela 7).

\subsection{Pressão}

A avaliação da deposição na superficie adaxial das folhas situadas nas posições externas à copa (BE, ME e $\mathrm{AE})$ mostrou diferenças de efeito das pressões de 200 e $300 \mathrm{lbf} / \mathrm{pol}^{2}$, exceto para as posições BE (quadrante I), BE e ME (quadrante IV) onde estas diferenças não foram exibidas. No quadrante III, a diferença de efeito entre os níveis de pressão foi marcante em todas as posições amostradas, apresentando maior cobertura à 300lbf $/ \mathrm{pol}^{2}$, quando avaliada a superficie adaxial das folhas (Tabelas 9 a 16).

A deposição na superficie abaxial das folhas quando pulverizadas à $200 \mathrm{e}$ $300 \mathrm{lbf} / \mathrm{pol}^{2}$ não diferiu estatísticamente em $75 \%$ das comparações entre as médias das notas de cobertura foliar. CARPENTER et al., (1983) e HALL et al., (1981) não constataram diferenças significativas na cobertura foliar trabalhando com pressões entre 100 e $400 \mathrm{lbf} / \mathrm{pol}^{2}$. Este fato, também foi constatado por PALLADINI (1990) e (1991) trabalhando com pressões entre 250 a $350 \mathrm{lbf} / \mathrm{pol}^{2}$ em citros e, 200 a $300 \mathrm{lbf} / \mathrm{pol}^{2}$ em macieiras.

No presente experimento, embora não hajam diferenças significativas em $50 \%$ das comparações entre as médias das notas de cobertura para os níveis de pressão em estudo (200 e 300 lbf/ $/ \mathrm{pol}^{2}$ ), independente da posição da amostra e quadrante analisado, houve uma tendência em se obter maior deposição tanto na superficie abaxial quanto adaxial das folhas quando pulverizadas à $300 \mathrm{lbf} / \mathrm{pol}^{2}$, o que pode ser comprovado nas Tabelas 9 a 16. Isto pode ser atribuído ao menor tamanho e maior número e velocidade das gotas no maior nível de pressão em teste.

Atualmente, o nível máximo de pressão recomendado (300lbf $\left./ \mathrm{pol}^{2}\right)$ para pulverizações realizadas com turboatomizadores não vêm sendo respeitado e, muitos citricultores freqüentemente têm trabalhado com pressões próximas à $400 \mathrm{lbf} / \mathrm{pol}^{2}$. Se por um lado o aumento da pressão de trabalho pode refletir em uma melhor cobertura de 
pulverização, também pode reduzir a vida útil dos bicos de pulverização, e conseqüêntemente alterar a vazão.

\subsection{Velocidade}

Da observação das Tabelas 9 a 16 pode-se verificar que, em geral, quanto menor a velocidade de deslocamento maior a cobertura de pulverização nas folhas. As velocidades de 3,6 e $5,1 \mathrm{~km} / \mathrm{h}$ proporcionaram deposições significativamente maiores em relação à maior velocidade em teste $(7,2 \mathrm{~km} / \mathrm{h})$. A avaliação das superficies abaxial e adaxial das folhas, em todos os quadrantes, mostrou maiores deposições à $3,6 \mathrm{~km} / \mathrm{h}$ para amostras provenientes das posições internas à copa, diferindo significativamente das obtidas na velocidade de $5,1 \mathrm{~km} / \mathrm{h}$.

TRAVIS et al., (1987b) e PALLADINI (1991) obtiveram maiores deposições em macieiras nas velocidades de 3,2 e 2,5km/h, respectivamente. Em citros, PALLADINI (1990) também já havia constatado maior cobertura da pulverização na velocidade de $3,0 \mathrm{~km} / \mathrm{h}$, embora na maior parte das vezes não diferindo da obtida à $5,3 \mathrm{~km} / \mathrm{h}$.

\subsubsection{Penetração da pulverização}

Da observação das Tabelas 9 a $\mathbf{1 6}$ pode-se constatar niveis de cobertura diferenciados para amostras provenientes de posições interna e externa à copa. Para se avaliar a ocorrência de diferenças na deposição interna e externamente à copa, utilizou-se o "indice de penetração" sugerido por PALLADINI (1990). Este índice mostra de forma direta a percentagem da cobertura interna em relação à externa. Dessa forma, maiores valores indicam maior penetração ou cobertura na parte interna da planta.

A relação entre a cobertura interna e externa ( índice de penetração ) para as superficies abaxial e adaxial das folhas nos quadrantes I, II e IV são apresentadas na Tabela 17. A exclusão do quadrante III no estabelecimento do índice de penetração 
deveu-se ao posicionamento dele em relação a aplicação, pois na pulverização da próxima linha passará a se posicionar frontalmente à pulverização, à semelhança do quadrante I.

Pelos resultados apresentados na Tabela 17, pode-se verificar que, em média, a cobertura nas superficies abaxial e adaxial das folhas na parte interna da copa foi 68 e $84 \%$, respectivamente, da obtida externamente para as diferentes alturas consideradas neste estudo.

Tabela 17. Índice de penetração para a relação entre cobertura foliar interna (I) e externa (E) na parte baixa (B), média (M) e alta (A) da planta, em diferentes arranjos de bicos, pressões e velocidades nas superfícies adaxial e abaxial da folha nos respectivos quadrantes.

\begin{tabular}{|c|c|c|c|c|c|}
\hline Quadrantes & Superficie & \multicolumn{3}{|c|}{ Índices de penetração } & \multirow{2}{*}{ Média geral } \\
\cline { 3 - 5 } & Foliar & BI / BE & MI / ME & AI / AE & \\
\hline I & Adaxial & 0,78 & 0,68 & 0,77 & 0,74 \\
& Abaxial & 0,68 & 0,57 & 0,73 & 0,66 \\
\hline II & Adaxial & 0,99 & 0,87 & 0,89 & 0,92 \\
& Abaxial & 0,72 & 0,66 & 0,62 & 0,67 \\
\hline IV & Adaxial & 0,90 & 0,86 & 0,79 & 0,85 \\
& Abaxial & 0,75 & 0,69 & 0,72 & 0,72 \\
\hline \multicolumn{2}{|c|}{ Média p/ sup. adaxial } & 0,89 & 0,80 & 0,82 & 0,84 \\
Média p/ sup. abaxial & 0,72 & 0,64 & 0,69 & 0,68 \\
\hline \multicolumn{2}{|r}{ Média geral } & & & 0,76 \\
\hline
\end{tabular}

Nos quadrantes I, II e IV o índice de penetração sempre foi maior para a superficie adaxial da folha, com valores variando de 0,68 a 0,99 ; independente da posição das folhas na copa. Em média, no quadrante I foram obtidos menores indices de penetração em relação aos quadrantes posicionados lateralmente à pulverização. Em 
campo, este fato pode ser facilmente constatado, pois as folhas externas formam uma barreira à penetração da pulverização, principalmente na região mediana da copa.

Neste trabalho, pode-se verificar a ocorrência de maiores índices de penetração da pulverização na posição mais baixa da copa e, assim, mostrando maiores deposições em relação às posições média e alta. Este fato, também foi constatado por CARMAN \& JEPPSON (1974), MATUO (1988) e PALLADINI (1990), em citros.

\subsubsection{1. Índice médio de penetração da pulverização e freqüência (\%) de notas de cobertura foliar}

Os índices médios de penetração da pulverização, bem como o volume de aplicação, nos tratamentos envolvendo diferentes combinações de arranjo de bicos $\left(\mathrm{A}_{2} \mathrm{e}\right.$ $A_{3}$ pertencentes ao esquema fatorial e $A_{4}, A_{5}$ e $A_{6}$ aos tratamentos adicionais), pressão e velocidade são mostrados na Tabela 18.

Tabela 18. Índices médios de penetração da pulverização para as superfícies adaxial e abaxial das folhas e volume de aplicação nos respectivos tratamentos envolvendo diferentes arranjos de bicos $\left(A_{2}, A_{3}, A_{4}, A_{5}\right.$ e $\left.A_{6}\right)$, pressões $\left(P_{1}=\right.$ $200 \mathrm{lbf} / \mathrm{pol}^{2}$ e $\left.\mathrm{P}_{2}=300 \mathrm{lbf} / \mathrm{pol}^{2}\right)$ e velocidades $\left(\mathrm{V}_{1}=3,6 \mathrm{~km} / \mathrm{h} \mathrm{e} \mathrm{V}_{2}=\right.$ $5,1 \mathrm{~km} / \mathrm{h})$.

\begin{tabular}{|c|c|c|c|c|}
\hline \multicolumn{2}{|c|}{ Tratamentos } & \multicolumn{2}{c|}{ Índice médio de penetração } & $\begin{array}{c}\text { Volume de } \\
\text { aplicação (l/ha) }\end{array}$ \\
\cline { 1 - 3 } $\mathbf{N}^{\mathbf{0}}$ & Identificação & Sup. adaxial & Sup. abaxial & 2951 \\
2 & $\mathrm{~A}_{2} / \mathrm{V}_{1} / \mathrm{P}_{2}$ & 0,88 & 0,76 & 2309 \\
3 & $\mathrm{~A}_{3} / \mathrm{V}_{1} / \mathrm{P}_{2}$ & 0,95 & 0,82 & 1618 \\
4 & $\mathrm{~A}_{3} / \mathrm{V}_{2} / \mathrm{P}_{2}$ & 0,93 & 0,76 & 3713 \\
5 & $\mathrm{~A}_{4} / \mathrm{V}_{1} / \mathrm{P}_{1}$ & 0,95 & 0,72 & 4927 \\
6 & $\mathrm{~A}_{4} / \mathrm{V}_{1} / \mathrm{P}_{2}$ & 0,97 & 0,83 & 1833 \\
7 & $\mathrm{~A}_{5} / \mathrm{V}_{1} / \mathrm{P}_{2}$ & 0,80 & 0,66 & 1928 \\
\hline
\end{tabular}


Pelos resultados apresentados na Tabela 18, pode-se constatar maiores índices médios de penetração quando a cobertura de pulverização foi avaliada na superficie superior das folhas, mostrando, assim a ocorrência de maiores níveis de deposição nesta superficie em relação à inferior. Maiores volumes de aplicação (4927 e 3713 litros/hectare) proporcionaram maiores níveis de deposição na superficie adaxial de folhas posicionadas na parte interna da copa, com valores de até $97 \%$ da cobertura obtida externamente, neste caso para o tratamento 5 . Os tratamentos com arranjos de bicos $\mathrm{A}_{3}$ (35 bicos JA-2) e $\mathrm{A}_{4}$ (35 bicos J5-2) apresentaram maiores índices médios de penetração da pulverização em relação aos demais, para ambas as superficies foliar, com volumes de aplicação variando de 1618 a 2309 e de 3713 a 4927 litros/hectare, para os respectivos arranjos.

Embora, os tratamentos 4 e 5 apresentem índices de penetração da pulverização próximos de 1 (cobertura interna igual a externa numa determinada superficie foliar) o volume de aplicação nestes tratamentos são considerados extremamente altos, inviabilizando assim, a realização de uma aplicação econômica.

A aplicação de volume superior a 20 litros, por planta, tem-se constituído uma prática freqüênte na citricultura paulista. A adoção dessa prática pelos citricultores pode ser explicada pelos altos indices de penetração obtidos nos tratamentos 4 e 5 . A conseqüência de aplicações em que se obtêm menores índices de penetração da pulverização está na possibilidade da ocorrência de reinfestações e a necessidade de um maior número de aplicações.

A perda por escorrimento nos tratamentos 4 e 5 foi visível, porém não quantificada. Neste particular, os tratamentos 2 e 3 apresentaram-se mais vantajosos, pois com a metade e um terço do volume de aplicação gasto no tratamento 5 , respectivamente foram obtidos índices similares de penetração da pulverização.

A freqüência $(\%)$ de notas de cobertura, também foi utilizada para comparar o efeito de diferentes condições operacionais sobre a cobertura foliar para alguns tratamentos de maior interesse envolvidos neste experimento (apresentados na Tabela 18) e, estão ilustradas graficamente nas Figuras 6 e 7 , respectivamente para 
notas pares e ímpares, conforme apresentadas seqüêncialmente em escala anteriormente descrita.

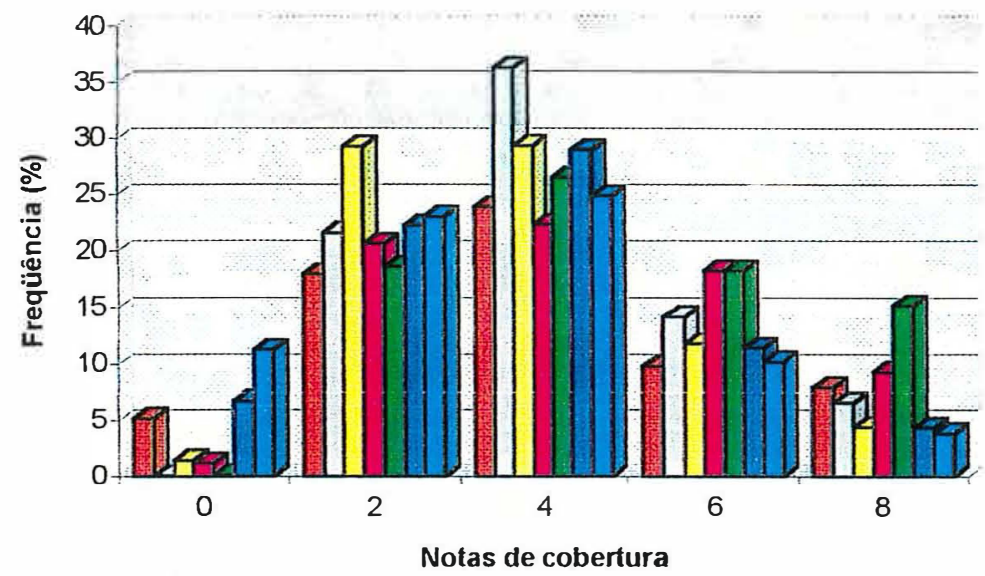

TT1=A2 / V1 / P2 $\square T 2=A 3 / V 1 / P 2$ $\square T 3=A 3 / V 2 / P 2$ DT4=A4/V1 / P1

ET5=A4/V1 / P2 - $T 6=\mathrm{A} 5 / \mathrm{V} 1 / \mathrm{P} 2$ $\square T 7=A 6 / V 2 / P 1$

Figura 6. Freqüência (\%) de notas pares (cobertura em toda a superficie foliar) nos diferentes tratamentos envolvendo os arranjos de bicos $A_{2}, A_{3}, A_{4}, A_{5}$ e $A_{6}$, sob pressões de $200\left(\mathrm{P}_{1}\right)$ ou $300 \mathrm{lbf} / \mathrm{pol}^{2}\left(\mathrm{P}_{2}\right)$ nas velocidades de 3,6 $\left(\mathrm{V}_{1}\right)$ ou $5,1 \mathrm{~km} / \mathrm{h}\left(\mathrm{V}_{2}\right)$

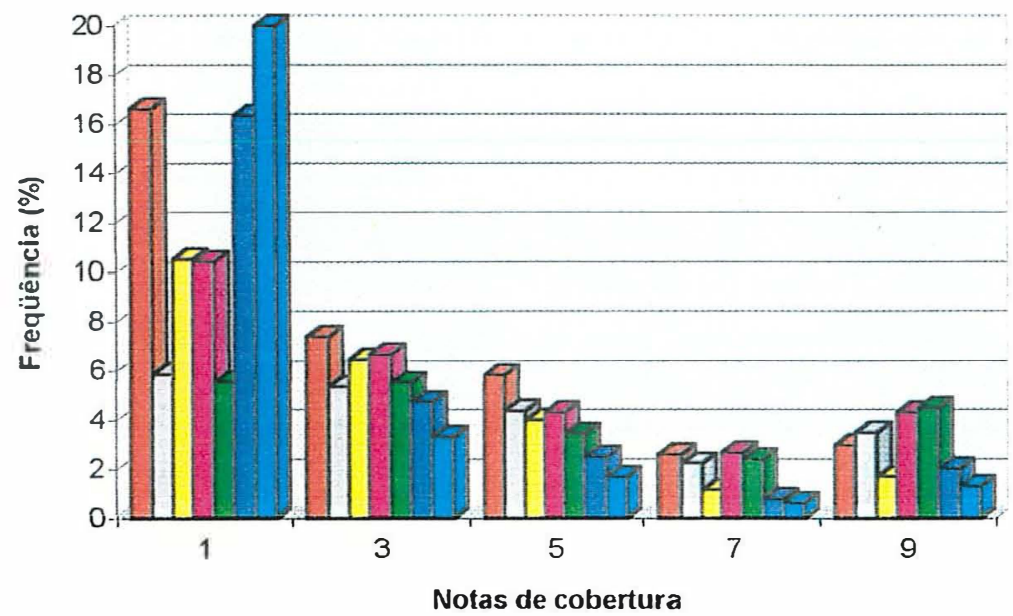

$\square T 1=A 2 / V 1 / P 2$ $\mathrm{DT} 2=\mathrm{A} 3 / \mathrm{V} 1 / \mathrm{P} 2$ $\mathrm{DT} 3=\mathrm{A} 3 / \mathrm{V} 2 / \mathrm{P} 2$ 는 $4=\mathrm{A} 4 / \mathrm{V} 1 / \mathrm{P} 1$

T5=A4/V1 / P2 圄 $\mathrm{T}=\mathrm{A} 5 / \mathrm{V} 1 / \mathrm{P} 2$ $\mathrm{T} 7=\mathrm{A} 6 / \mathrm{V} 2 / \mathrm{P} 1$

Figura 7. Freqüência (\%) de notas ímpares (cobertura em segmentos da superficie foliar) nos diferentes tratamentos envolvendo os arranjos de bicos $A_{2}, A_{3}, A_{4}, A_{5}$ e $A_{6}$, sob pressões de $200\left(\mathrm{P}_{1}\right)$ ou $300 \mathrm{lbf} / \mathrm{pol}^{2}\left(\mathrm{P}_{2}\right)$ nas velocidades de 3,6 $\left(\mathrm{V}_{1}\right)$ ou $5,1 \mathrm{~km} / \mathrm{h}\left(\mathrm{V}_{2}\right)$. 
Teoricamente, era de se esperar que os tratamentos que apresentassem menor freqüência de nota zero (ausência de deposição) e maior freqüência para maiores notas de cobertura foliar fossem considerados mais eficientes. Entretanto, a análise gráfica para notas pares (diferentes niveis de cobertura em toda superficie foliar) e ímpares (diferentes niveis de cobertura em frações da superficie foliar) separadamente revelaram a existência de curvas distintas para as respectivas notas de cobertura da pulverização (Figuras 6 e 7).

Da observação das Figuras 6 e 7 pode-se constatar que o tratamento que apresentar menor e maior freqüência, respectivamente, para menores notas e para a nota 4 proporcionará maiores niveis de cobertura em toda planta e, neste aspecto, o tratamento $2\left(\mathrm{~A}_{3}=35\right.$ bicos JA-2 $\left./ \mathrm{V}_{1}=3,6 \mathrm{~km} / \mathrm{h} / \mathrm{P}_{2}=300 \mathrm{lbf} / \mathrm{pol}^{2}\right)$ destacou-se dos demais. A constatação deste fato, não implica dizer que este tratamento seja o mais eficaz biologicamente, pois outros fatores como: comportamento da praga e redistribuição dos defensivos na planta podem influenciar na obtenção dos resultados e constituirão motivos de discussão nos ensaios de campo visando o controle de ácaros-praga em citros.

\subsubsection{Experimento 2}

\subsubsection{Quantificação dos depósitos da solução de $\mathrm{KCl}$ nas folhas}

Para a determinação dos depósitos da solução de $\mathrm{KCl}$, em folhas citricas, houve a necessidade do ajuste dos dados entre a condutividade elétrica $(\mu \mathrm{S} / \mathrm{cm})$ e $o$ volume das soluções $(\mu \mathrm{l})$ segundo o modelo: Volume da solução $(\mu l)=0,132022 \mathrm{x}$ condutividade da solução $(\mu \mathrm{S} / \mathrm{cm})-2,69035\left(\mathrm{R}^{2}=0,9975\right)$.

Os coeficientes a e b, com os respectivos valores de 0,132022 e 2,69035, presentes no referido modelo matemático foram obtidos da razão entre a condutividade da solução menos a condutividade do "branco" (condutividade da água deionizada mais 
saco plástico com 5 folhas) e o coeficiente angular da reta $(\operatorname{tg} \alpha=7,574478)$. O espalhante adesivo Extravon na concentração utilizada não influenciou na condutividade.

A determinação do intervalo de tempo máximo aceitável entre a aplicação de $\mathrm{KCl}$ e a lavagem das folhas, bem como a taxa de recuperação do $\mathrm{KCl}$ não foram realizadas face às constatações feitas por VELINI et al. (1995) para o mesmo produto aplicado em diferentes superficies alvo e período de tempo entre a aplicação e a lavagem do substrato. Entretanto, ao se utilizar de substratos naturais, a absorção dos elementos, nesse caso cloro e potássio, podem subestimar a leitura da condutividade com o tempo entre a aplicação e a lavagem desse substrato.

Os depósitos médios da solução de $\mathrm{KCl}$, quando avaliados na parte externa da copa, mostraram a existência de uma relação diretamente proporcional entre o volume de calda aplicado e o nível de depósito nas folhas. Os tratamentos 1 e 3, com volume de aplicação de 2017 e 1839 litros/hectare (Tabela 2), respectivamente exibiram maiores níveis médios de depósitos da calda nas folhas posicionadas externamente à copa (Figura 8). Em geral, maiores variações nos níveis de depósitos da calda foram obtidos nas folhas externas com os tratamentos 4 e 5 , independente da posição da amostra foliar. Os coeficientes médios de variação (\%) para os níveis de depósitos da calda obtidos nesses tratamentos variaram entre 38,60 a $64,07 \%$ (tratamento 4), e de 46,17 a $51,49 \%$ (tratamento 5), respectivamente para amostras provenientes das partes baixa e alta da copa.

$\mathrm{O}$ efeito da velocidade sobre o nivel de depósito da solução de $\mathrm{KCl}$ nas folhas, mostrou uma relação inversamente proporcional quando comparados os tratamentos com o mesmo arranjo de bicos e mesma pressão de trabalho. Os tratamentos 1 e 3 sempre proporcionaram maiores niveis de depósito da calda em relação aos tratamentos 2 e 4, independente da localização das folhas na copa (Figuras 8 e 9). Os depósitos da calda nas partes alta, média e baixa da planta, quando avaliados na parte externa da copa mostraram-se superiores aos obtidos internamente, nas respectivas posições. Ainda, a avaliação na parte interna da copa mostrou a existência de uma relação inversamente proporcional entre os níveis de depósito e a altura das amostras foliares. 


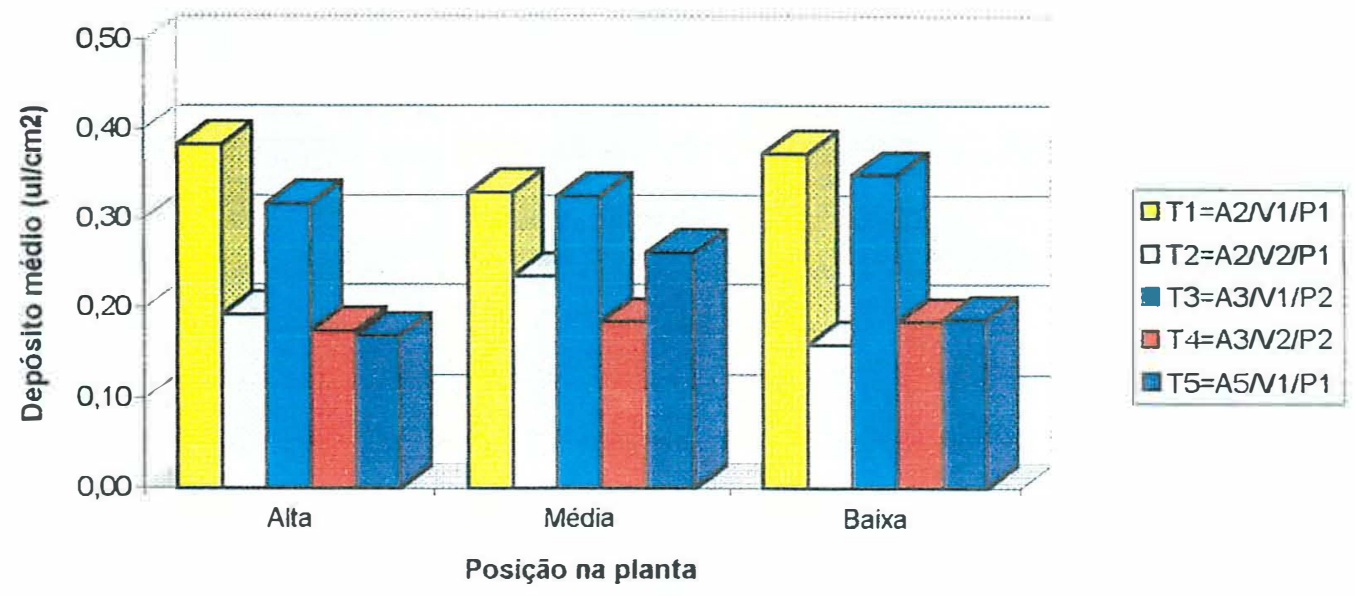

Figura 8. Depósito médio de calda $\left(\mu \mathrm{l} / \mathrm{cm}^{2}\right)$ nas folhas externas da parte alta, média e baixa da copa aplicado em diferentes condições operacionais, avaliado através da condutividade elétrica do $\mathrm{KCl}$ em água.

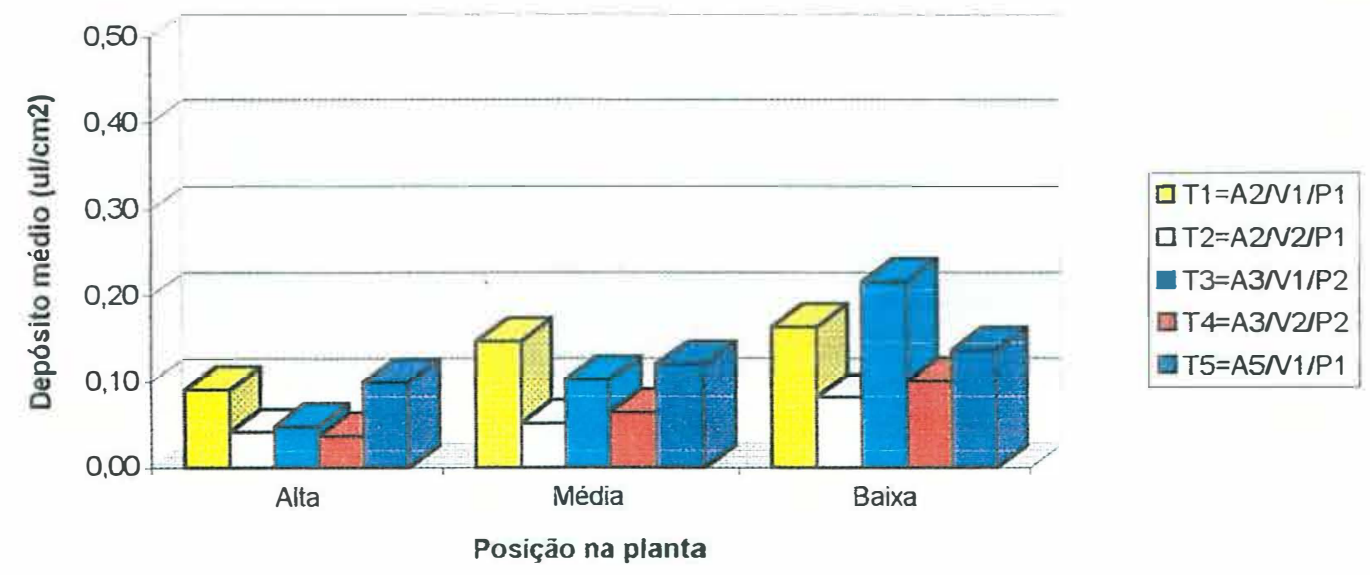

Figura 9. Depósito médio de calda $\left(\mu \mathrm{l} / \mathrm{cm}^{2}\right)$ nas folhas internas da parte alta, média e baixa da copa aplicado em diferentes condições operacionais, avaliado através da condutividade elétrica do $\mathrm{KCl}$ em água. 
Quando os depósitos da solução de $\mathrm{KCl}$ foram avaliados em diferentes azimutes, independente da altura da amostra na copa, níveis decrescentes da calda foram obtidos respectivamente para amostras provenientes de $0^{\circ}, 90^{\circ}$ e $180^{\circ}$, em relação ao Norte. Da mesma forma, os depósitos nos tratamentos 1 e 3 sempre foram superiores aos obtidos nos tratamentos 3 e 4, externa e internamente (Figuras 10 e 11). Entretanto, em geral, os depósitos da calda na parte interna da copa foram inferiores à metade dos obtidos nas folhas posicionadas externamente à copa (Figura 11).

Independente da altura ou azimute, os tratamentos 1 e 3 proporcionaram maiores níveis de depósitos de $\mathrm{KCl}$ em plantas cítricas.

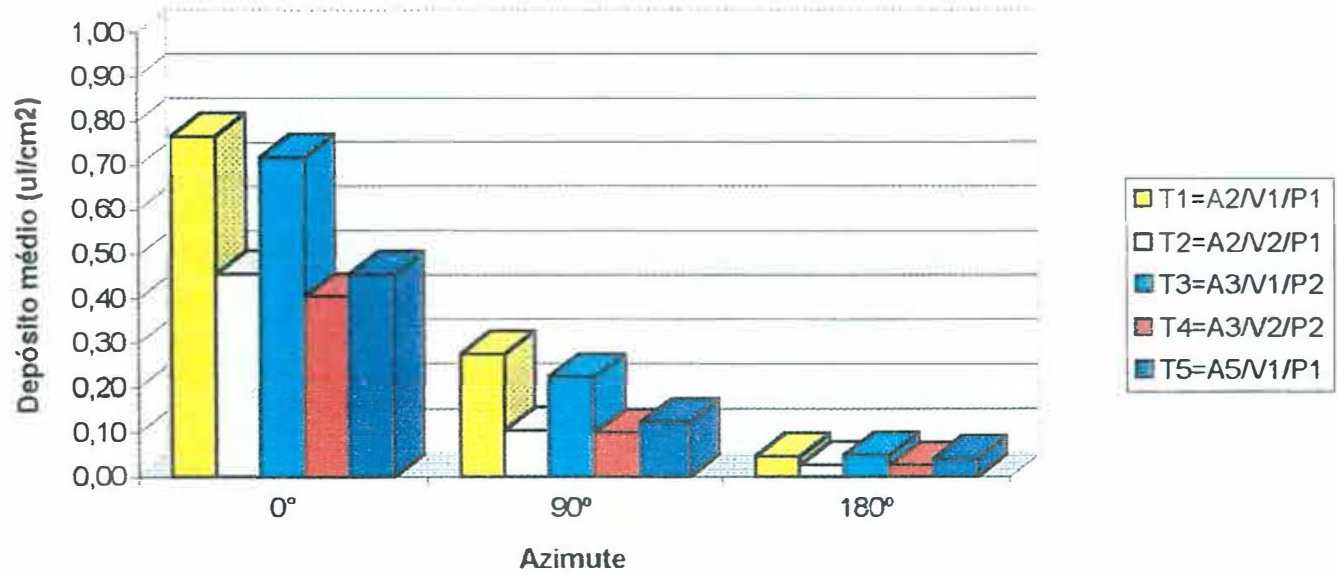

Figura 10. Depósito médio de calda $\left(\mu 1 / \mathrm{cm}^{2}\right)$ nas folhas externas da copa posicionadas a $0^{\circ}, 90^{\circ}$ e $180^{\circ}$ em relação à pulverização realizada sob diferentes condições operacionais, avaliado através da condutividade elétrica do $\mathrm{KCl}$ em água. 


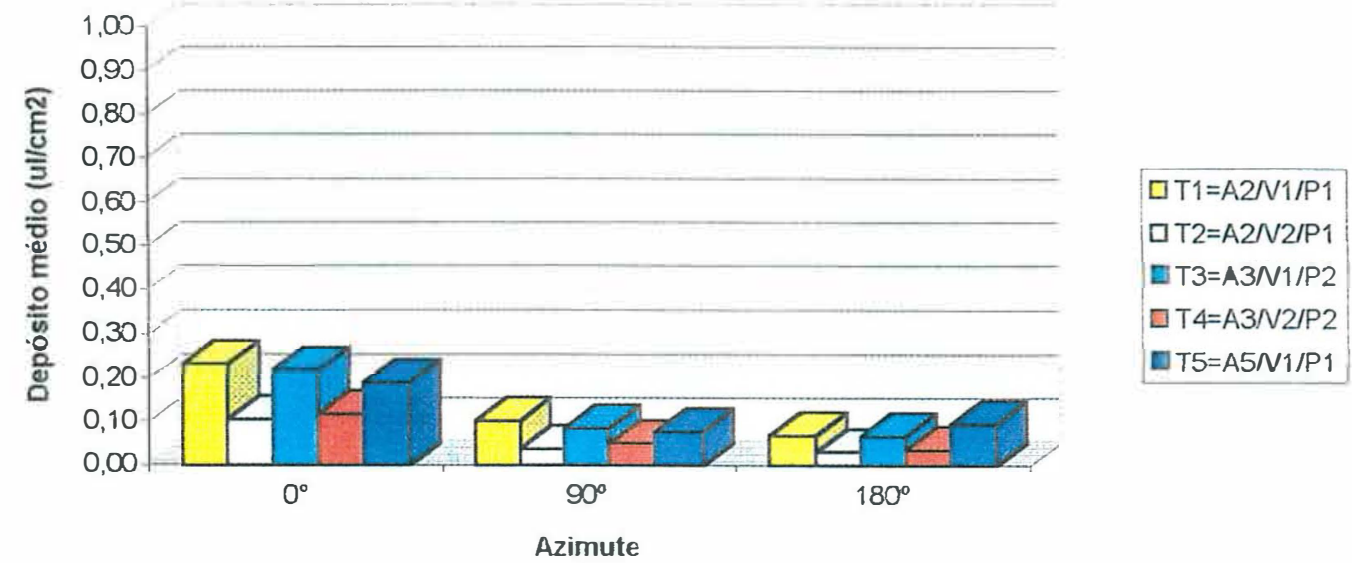

Figura 11. Depósito médio de calda $\left(\mu \mathrm{l} / \mathrm{cm}^{2}\right)$ nas folhas internas da copa posicionadas a $0^{\circ}, 90^{\circ}$ e $180^{\circ}$ em relação à pulverização realizada sob diferentes condições operacionais, avaliado através da condutividade elétrica do $\mathrm{KCl}$ em água.

\subsection{Efeito da distribuição e depósito de pulverizações no controle de ácaros}

\subsubsection{Experimento 3 - Controle do ácaro purpúreo ( $P$. citri)}

Da observação da Tabela 19 pode-se verificar que não houve diferenças significativas no número médio de ácaros entre os tratamentos 1 e 2 , após a pulverização do produto azociclotin com $100 \%$ da dosagem comercialmente recomendada, utilizandose os arranjos de bicos $A_{5}$ (7 bicos J5-2 e 6 bicos J4-3) e $A_{3}$ (35 bicos JA-2), respectivamente à $300 \mathrm{lbf} / \mathrm{pol}^{2}$ e na velocidade de $3,6 \mathrm{~km} / \mathrm{h}$. Embora, o volume de aplicação no tratamento 2 seja superior em 2 litros, por planta, em relação ao 1 e, provavelmente, a utilização do turboatomizador Arbus 2000 / Export nas condições operacionais anteriormente descritas tenha proporcionado melhor distribuição da pulverização não foram suficientes para apresentar diferenças significativas entre os tratamentos ao nivel de $5 \%$ de probabilidade. 
Os tratamentos 2 e 3 , utilizando o mesmo equipamento de aplicação e idênticas condições operacionais, também não mostraram diferenças estatísticas quando avaliou-se o número médio de $P$. citri (ninfas móveis e adultos), tanto a 100 quanto a $75 \%$ da dosagem comercialmente recomendada do azociclotin para o controle desse ácaro.

Tabela 19. Número médio de Panonychus citri, em 25 folhas, antes $(-)$ e após $(+)$ a pulverização do acaricida azociclotin em diferentes dosagens. São Pedro, SP. Novembro /1994.

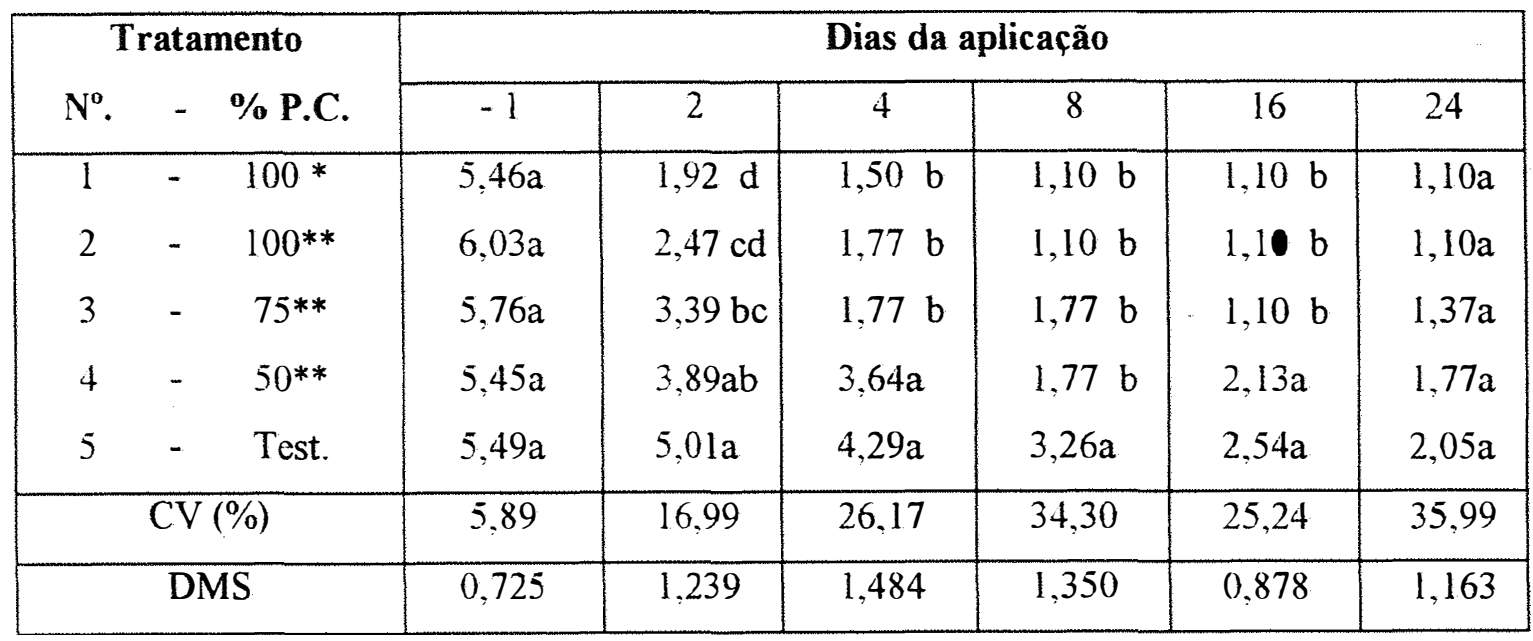

* $\mathrm{M}_{2} / \mathrm{A}_{5}$ - turboatomizador Arbus 2000/850 equipado com arranjo de bicos $\mathrm{A}_{5}$.

** $\mathrm{M}_{1} / \mathrm{A}_{3}$ - turboatomizador Arbus 2000/Export equipado com arranjo de bicos $\mathrm{A}_{3}$.

$*$, ** - Na velocidade de $3,6 \mathrm{~km} / \mathrm{h}$ e à $300 \mathrm{lbf} / \mathrm{pol}^{2}$.

Obs. : Médias seguidas pela mesma letra, dentro da mesma coluna, não diferem entre si pelo teste de Tukey ao nível de 5\%. Dados transformados em $\log (x+k)$, para $k=3$.

A ocorrência deste fato, sugere que a aplicação de $75 \%$ da dosagem recomendada para este produto comercial pode proporcionar resultados equivalentes à aplicação de $100 \%$ da dosagem deste acaricida em citros ( $100 \mathrm{~g} / 100$ litros d'água), quando aplicado com o turboatomizador Arbus 2000/Export equipado com o arranjo de bicos $\mathrm{A}_{3}$ (bicos JA-2). Porém, observando-se a Tabela 20, pode-se verificar menores eficiências no controle deste artrópodo à medida em que foi reduzida a dosagem. 
Provavelmente, aos 8 dias da aplicação, a menor eficiência de controle com os tratamentos 3 e 4 deve-se aos menores níveis de resíduos presentes na superficie foliar e não mais à distribuição da pulverização.

Tabela 20. Eficiência média (\%) dos diferentes tratamentos no controle de Panonychus citri após a aplicação do acaricida azociclotin em diferentes dosagens. São Pedro, SP. Novembro/1994.

\begin{tabular}{|c|c|c|c|c|c|}
\hline Tratamento & \multicolumn{5}{|c|}{ Dias após a aplicação } \\
\cline { 2 - 6 } $\mathbf{N}^{\mathbf{0}}$ - - \%P.C. & $\mathbf{2}$ & $\mathbf{4}$ & $\mathbf{8}$ & $\mathbf{1 6}$ & $\mathbf{2 4}$ \\
\hline $1-100^{*}$ & 94,63 & 97,08 & 100,00 & 100,00 & 100,00 \\
$2-100^{* *}$ & 95,36 & 96,42 & 100,00 & 100,00 & 100,00 \\
$3-75 * *$ & 83,95 & 94,04 & 74,38 & 100,00 & 65,91 \\
$4-50^{* *}$ & 67,15 & 45,08 & 70,63 & 27,57 & 15,93 \\
$5-$ Test. & - & - & - & - & - \\
\hline
\end{tabular}

* $\mathrm{M}_{2} / \mathrm{A}_{5}$ - turboatomizador Arbus 2000/850 equipado com arranjo de bicos $\mathrm{A}_{5}$.

** $\mathrm{M}_{1} / \mathrm{A}_{3}$ - turboatomizador Arbus 2000/Export equipado com arranjo de bicos $\mathrm{A}_{3}$.

$*, * *$ - Na velocidade de $3,6 \mathrm{~km} / \mathrm{h}$ e à $300 \mathrm{lbf} / \mathrm{pol}^{2}$.

Os menores níveis de eficiência foram obtidos com o tratamento 4, na maior parte das vezes, não diferindo do número médio de ácaros avaliados na testemunha, com valores variando de 15,93 a 70,63\%, conforme apresentados na Tabela 20. O número médio de $P$. citri (dados não transformados) antes $(-)$ e após $(+)$ a aplicação estão apresentados graficamente na Figura 12. 


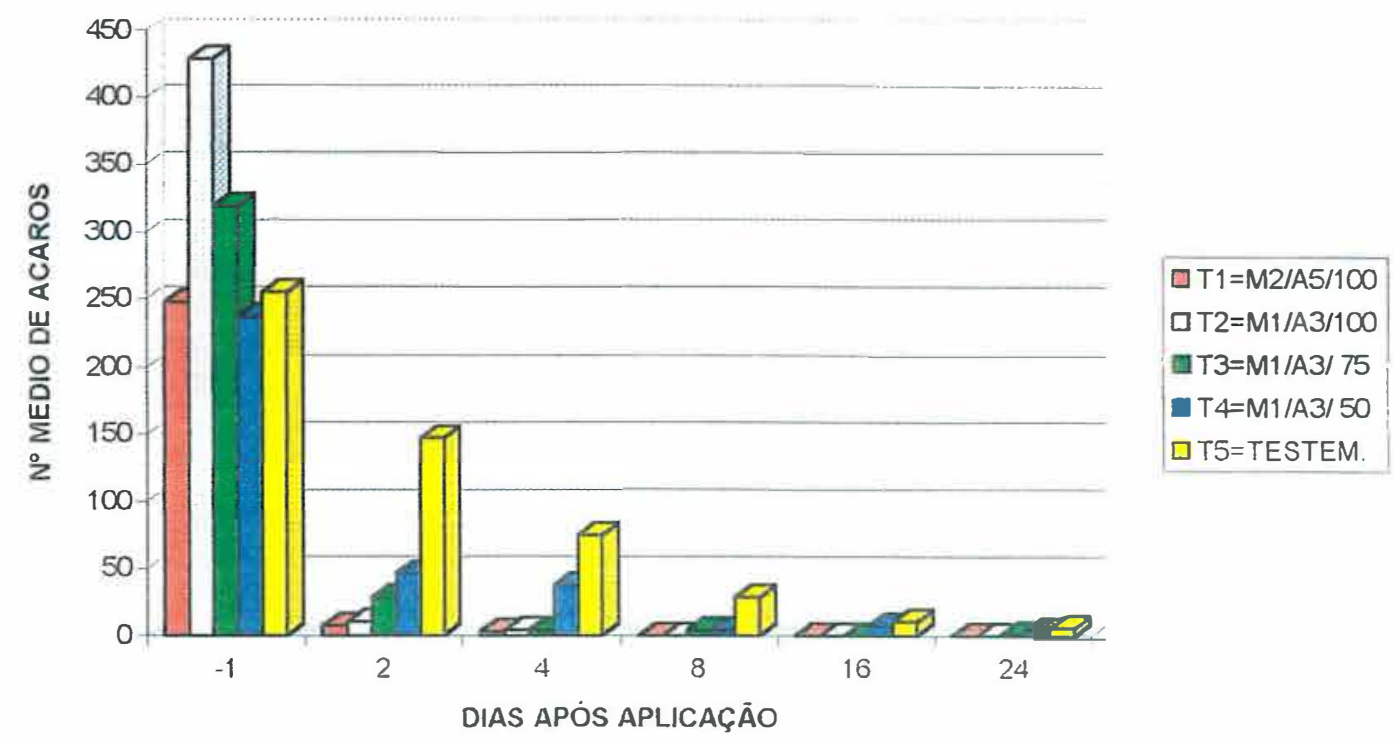

Figura 12. Número médio de Panonychus citri antes (-) e após $\left(^{+}\right)$a aplicação nos diferentes tratamentos: $\mathrm{M}_{2} / \mathrm{A}_{5} / 100$ - turboatomizador Arbus 2000/850 com arranjo $A_{5}$ pulverizando $100 \mathrm{~g}$ p.c.//00litros d'água; $\mathrm{M}_{1} / \mathrm{A}_{3} / 50,75$ e 100 turboatomizador Arbus 2000/Export com arranjo $A_{3}$ pulverizando 50, 75 e $100 \mathrm{~g}$ p.c./100 litros d'água, respectivamente e testemunha.

\subsubsection{Experimento 4 - Controle do ácaro da leprose (B. phoenicis)}

O número médio de ácaros la leprose presente nos frutos até 52 dias, após a aplicação do acaricida azociclotin na dosagem comercialmente recomendada ( $100 \mathrm{~g}$ do produto Peropal 250PM / 100 litros d'água), nos diferentes tratamentos são apresentados na Tabela 21 . 
Tabela 21. Número médio de Brevipalpus phoenicis, por fruto, antes (-) e após (+) a aplicação do acaricida azociclotin nos diferentes tratamentos. São Pedro, SP. Março a maio/1995.

\begin{tabular}{|c|c|c|c|c|c|c|c|}
\hline \multirow{2}{*}{ Tratamento } & \multicolumn{7}{|c|}{ Dias da aplicacão } \\
\cline { 2 - 8 } & $\mathbf{- 1}$ & $\mathbf{1}$ & $\mathbf{3}$ & $\mathbf{7}$ & $\mathbf{1 4}$ & $\mathbf{2 8}$ & $\mathbf{5 2}$ \\
\hline $\mathrm{M}_{2} / \mathrm{A}_{5} / \mathrm{V}_{1}{ }^{*}$ & $2,71 \mathrm{a}$ & $1,40 \mathrm{~b}$ & $1,17 \mathrm{~b}$ & $1,10 \mathrm{~b}$ & $1,13 \mathrm{~b}$ & $1,13 \mathrm{~b}$ & $1,21 \mathrm{~b}$ \\
$\mathrm{M}_{1} / \mathrm{A}_{3} / \mathrm{V}_{2}{ }^{* *}$ & $2,65 \mathrm{a}$ & $1,31 \mathrm{~b}$ & $1,13 \mathrm{~b}$ & $1,10 \mathrm{~b}$ & $1,10 \mathrm{~b}$ & $1,10 \mathrm{~b}$ & $1,13 \mathrm{~b}$ \\
Testemunha & $2,68 \mathrm{a}$ & $2,41 \mathrm{a}$ & $2,37 \mathrm{a}$ & $2,57 \mathrm{a}$ & $2,35 \mathrm{a}$ & $2,70 \mathrm{a}$ & $2,65 \mathrm{a}$ \\
\hline $\mathrm{CV}(\%)$ & 16,66 & 31,03 & 19,68 & 18,30 & 29,44 & 26,36 & 22,01 \\
\hline DMS & 0,563 & 0,667 & 0,387 & 0,366 & 0,567 & 0,546 & 0,462 \\
\hline
\end{tabular}

* $\mathrm{M}_{2} / \mathrm{A}_{5} / \mathrm{V}_{1}$ - turb. Arbus 2000/850 com arranjo $\mathrm{A}_{5}$ e velocidade de $3,6 \mathrm{~km} / \mathrm{h}$.

** $\mathrm{M}_{1} / \mathrm{A}_{3} / \mathrm{V}_{2}$ - turb. Arbus 2000/Export com arranjo $\mathrm{A}_{3}$ e velocidade de $5,1 \mathrm{~km} / \mathrm{h}$.

*, ${ }^{* *}$ - Ambos trabalhando à $300 \mathrm{lbf} / \mathrm{pol}^{2}$.

Obs. : Médias seguidas pela mesma letra, dentro da mesma coluna, não diferem entre si pelo teste de Tukey ao nível de $5 \%$. Dados transformados em $\log (x+k)$, para $k=3$.

Os tratamentos $1 \quad\left(\mathrm{M}_{2} / \mathrm{A}_{5} / \mathrm{V}_{1}\right)$ e $2 \quad\left(\mathrm{M}_{1} / \mathrm{A}_{3} / \mathrm{V}_{2}\right)$ não diferiram estatísticamente entre si, em todo o periodo de avaliação, apresentando números médios de ácaros significativamente menores em relação aos obtidos na testemunha, ao nível de $5 \%$ de probabilidade. Entretanto, o tratamento 2, com o turboatomizador Arbus $2000 /$ Export trabalhando em maior velocidade $(5,1 \mathrm{~km} / \mathrm{h})$ e menor volume de aplicação (1618 litros, por hectare) apresentou uma tendência em se obter maior eficiência de controle deste ácaro (Tabela 22). 
Tabela 22. Eficiência média (\%) de controle de Brevipalpus phoenicis após a aplicação do acaricida azociclotin por turboatomizadores trabalhando sob diferentes condições operacionais. São Pedro, SP. Março a maio/1995.

\begin{tabular}{|c|c|c|c|c|c|c|}
\hline \multirow{2}{*}{ Tratamento } & \multicolumn{7}{|c|}{ Dias após a aplicacão } \\
\cline { 2 - 7 } & $\mathbf{1}$ & $\mathbf{3}$ & $\mathbf{7}$ & $\mathbf{1 4}$ & $\mathbf{2 8}$ & $\mathbf{5 2}$ \\
\hline $\mathrm{M}_{2} / \mathrm{A}_{5} / \mathrm{V}_{\mathbf{1}}{ }^{*}$ & 90,29 & 97,27 & 100,00 & 98,86 & 99,21 & 97,27 \\
$\mathrm{M}_{1} / \mathrm{A}_{3} / \mathrm{V}_{2}{ }^{* *}$ & 93,07 & 98,61 & 100,00 & 100,00 & 100,00 & 99,07 \\
Testemunha & - & - & - & - & - & - \\
\hline
\end{tabular}

* $\mathrm{M}_{2} / \mathrm{A}_{5} / \mathrm{V}_{1}$ - turb. Arbus 2000/850 com arranjo $\mathrm{A}_{5}$ e velocidade de $3,6 \mathrm{~km} / \mathrm{h}$.

** $\mathrm{M}_{1} / \mathrm{A}_{3} / \mathrm{V}_{2}$ - turb. Arbus 2000/Export com arranjo $\mathrm{A}_{3}$ e velocidade de $5,1 \mathrm{~km} / \mathrm{h}$.

*, ** - Ambos trabalhando à $300 \mathrm{lbf} / \mathrm{pol}^{2}$.

O maior número de bicos de pulverização no tratamento 2 , em número de trinta e cinco, distribuídos em ramais superior e inferior de pulverização $\left(A_{3}\right)$, e a maior penetração da pulverização no interior da copa das plantas utilizando-se este arranjo de bicos (Tabela 18) são fatores que podem ter contribuído para a ocorrência desta tendência, ou seja, em se obter maior eficiência de controle deste ácaro-praga, comparativamente ao tratamento 1 .

Ainda o fato deste ácaro permanecer com maior freqüência em ramos e frutos posicionados mais internamente à copa pode tê-lo deixado mais suscetível ao contato com as gotas pulverizadas com o arranjo de bicos $\mathrm{A}_{3}$ (bicos JA-2). Este arranjo de bicos promoveu a obtenção de melhores índices de penetração da pulverização na copa de plantas cítricas (Tabela 18).

\subsubsection{Experimento 5 - Controle do ácaro da falsa ferrugem ( $P$. oleivora)}

O número médio de eriofídeos nos diferentes tratamentos, com 1 dia antes, e 1, 3, 7, 14, 28 e 56 dias após a aplicação do acaricida azociclotin (Peropal 
250PM) utilizando-se o turboatomizador Arbus 2000/Export são mostrados nas Tabelas 23 e 24, respectivamente, para as avaliações realizadas nas superficies adaxial e abaxial das folhas em citros.

Tabela 23. Número médio de Phyllocoptruta oleivora na superficie adaxial das folhas antes (-) e após (+) a aplicação do acaricida azociclotin com o turboatomizador Arbus 2000/ Export sob diferentes condições operacionais. São Pedro, SP. Agosto a outubro/ 1995.

\begin{tabular}{|c|c|c|c|c|c|c|c|c|}
\hline \multicolumn{2}{|c|}{ Tratamento $^{*}$} & \multicolumn{7}{|c|}{ Dias após a aplicação } \\
\hline $\mathbf{N}^{\mathbf{0}}$. & Arranjo /Veloc. & $\mathbf{- 1}$ & $\mathbf{1}$ & $\mathbf{3}$ & $\mathbf{7}$ & $\mathbf{1 4}$ & $\mathbf{2 8}$ & $\mathbf{5 6}$ \\
\hline 1 & $\mathrm{~A}_{3} / 3,6 \mathrm{~km} / \mathrm{h}$ & $4,80 \mathrm{a}$ & $0,00 \mathrm{~b}$ & $0,00 \mathrm{~b}$ & $0,00 \mathrm{~b}$ & $0,00 \mathrm{~b}$ & $0,00 \mathrm{~b}$ & $0,20 \mathrm{~b}$ \\
2 & $\mathrm{~A}_{3} / 5,1 \mathrm{~km} / \mathrm{h}$ & $5,60 \mathrm{a}$ & $0,20 \mathrm{~b}$ & $0,00 \mathrm{~b}$ & $0,00 \mathrm{~b}$ & $0,00 \mathrm{~b}$ & $0,00 \mathrm{~b}$ & $0,60 \mathrm{~b}$ \\
3 & $\mathrm{~A}_{2} / 3,6 \mathrm{~km} / \mathrm{h}$ & $4,80 \mathrm{a}$ & $0,20 \mathrm{~b}$ & $0,00 \mathrm{~b}$ & $0,00 \mathrm{~b}$ & $0,00 \mathrm{~b}$ & $0,00 \mathrm{~b}$ & $0,40 \mathrm{~b}$ \\
4 & $\mathrm{~A}_{2} / 5,1 \mathrm{~km} / \mathrm{h}$ & $3,20 \mathrm{a}$ & $0,20 \mathrm{~b}$ & $0,00 \mathrm{~b}$ & $0,00 \mathrm{~b}$ & $0,00 \mathrm{~b}$ & $0,00 \mathrm{~b}$ & $0,80 \mathrm{~b}$ \\
5 & Testemunha & $6,40 \mathrm{a}$ & $6,40 \mathrm{a}$ & $6,00 \mathrm{a}$ & $7,00 \mathrm{a}$ & $4,20 \mathrm{a}$ & $4,40 \mathrm{a}$ & $3,60 \mathrm{a}$ \\
\hline \multicolumn{2}{|c|}{ CV $(\%)$} & 22,52 & 14,95 & 12,43 & 41,48 & 29,19 & 25,35 & 25,85 \\
& DMS $5 \%$ & 4,433 & 1,912 & 1,732 & 5,579 & 3,146 & 2,975 & 2,360 \\
\hline
\end{tabular}

* a pressão de trabalho em todos tratamentos foi de $300 \mathrm{lbf} / \mathrm{pol}^{2}$.

Obs. : Médias seguidas pela mesma letra, dentro da mesma coluna, não diferem entre si pelo teste de Tukey ao nível de 5\%. Dados transformados em $\sqrt{ } x+1$.

Pelos resultados obtidos e apresentados nas Tabelas 23 e 24 , pode-se verificar que não houve diferenças significativas entre os tratamentos acaricidas no controle do ácaro da falsa ferrugem até a última avaliação (56 dias). Porém, todos os tratamentos que receberam a aplicação do produto azociclotin apresentaram números médios significativamente menores de ácaros em relação ao obtido na testemunha, em todo o período de avaliação, procedendo-se as avaliaçø̃es em ambas as superficies foliar.

Ainda pode-se observar que em todo o período de avaliação, o número médio de ácaros na superfície adaxial das folhas sempre foi superior ao encontrado na 
superficie abaxial e, na maior parte das vezes, superando em dobro aos presentes nesta superficie numa área equivalente a $1 \mathrm{~cm}^{2}$ (Tabelas 23 e 24).

Tabela 24. Número médio de Phyllocoptruta oleivora na superficie abaxial das folhas antes (-) e após (+) a aplicação do acaricida azociclotin com o turboatomizador Arbus 2000/ Export sob diferentes condições operacionais. São Pedro, SP. Agosto a outubro/ 1995.

\begin{tabular}{|c|c|c|c|c|c|c|c|c|}
\hline \multicolumn{2}{|c|}{ Tratamento $^{*}$} & \multicolumn{7}{|c|}{ Dias após a aplicação } \\
\hline $\mathbf{N}^{\mathrm{o}}$. & Arranjo / Veloc. & $\mathbf{- 1}$ & $\mathbf{1}$ & $\mathbf{3}$ & $\mathbf{7}$ & $\mathbf{1 4}$ & $\mathbf{2 8}$ & $\mathbf{5 6}$ \\
\hline $\mathrm{l}$ & $\mathrm{A}_{3} / 3,6 \mathrm{~km} / \mathrm{h}$ & $1,40 \mathrm{a}$ & $0,00 \mathrm{~b}$ & $0,00 \mathrm{~b}$ & $0,00 \mathrm{~b}$ & $0,00 \mathrm{~b}$ & $0,00 \mathrm{~b}$ & $0,20 \mathrm{~b}$ \\
2 & $\mathrm{~A}_{3} / 5,1 \mathrm{~km} / \mathrm{h}$ & $2,80 \mathrm{a}$ & $0,00 \mathrm{~b}$ & $0,00 \mathrm{~b}$ & $0,00 \mathrm{~b}$ & $0,00 \mathrm{~b}$ & $0,00 \mathrm{~b}$ & $0,60 \mathrm{ab}$ \\
3 & $\mathrm{~A}_{2} / 3,6 \mathrm{~km} / \mathrm{h}$ & $2,00 \mathrm{a}$ & $0,20 \mathrm{~b}$ & $0,00 \mathrm{~b}$ & $0,00 \mathrm{~b}$ & $0,00 \mathrm{~b}$ & $0,00 \mathrm{~b}$ & $0,20 \mathrm{~b}$ \\
4 & $\mathrm{~A}_{2} / 5,1 \mathrm{~km} / \mathrm{h}$ & $3,60 \mathrm{a}$ & $0,00 \mathrm{~b}$ & $0,00 \mathrm{~b}$ & $0,00 \mathrm{~b}$ & $0,00 \mathrm{~b}$ & $0,20 \mathrm{~b}$ & $0,40 \mathrm{~b}$ \\
5 & Testemunha & $2,00 \mathrm{a}$ & $2,80 \mathrm{a}$ & $3,40 \mathrm{a}$ & $3,20 \mathrm{a}$ & $1,60 \mathrm{a}$ & $1,60 \mathrm{a}$ & $1,40 \mathrm{a}$ \\
\hline \multicolumn{2}{|c|}{ CV $(\%)$} & 34,01 & 14,05 & 21,70 & 17,68 & 6,94 & 16,66 & 15,03 \\
& DMS $5 \%$ & 4,588 & 1,146 & 2,174 & 1,877 & 0,474 & 1,247 & 0,898 \\
\hline
\end{tabular}

* a pressão de trabalho em todos tratamentos foi de $300 \mathrm{lbf} / \mathrm{pol}^{2}$.

Obs. : Médias seguidas pela mesma letra, dentro da mesma coluna, não diferem entre si pelo teste de Tukey ao nivel de 5\%. Dados transformados em $\sqrt{x}+1$.

Mesmo não havendo diferenças estatísticas entre os tratamentos em teste, houve uma tendência para a obtenção de maior porcentagem de eficiência no controle deste ácaro quando o produto foi pulverizado à $300 \mathrm{lbf} / \mathrm{pol}^{2}$ com o arranjo de bicos $\mathrm{A}_{3}$ (bicos JA-2) e, em menor velocidade de deslocamento $(3,6 \mathrm{~km} / \mathrm{h})$, quando avaliou-se a superficie adaxial das folhas no primeiro dia após a aplicação (Tabela 25).

Aos 3, 7, 14 e 28 dias da aplicação do produto não foram observadas diferenças na eficiência de controle entre os tratamentos testados, exceto aos 28 dias, quando a avaliação na superficie abaxial das folhas revelou um menor percentual de 
controle do ácaro da falsa ferrugem $(92,6 \%)$ para o tratamento 4 (arranjo $\mathrm{A}_{2}$ e velocidade de $5,1 \mathrm{~km} / \mathrm{h})$.

Tabela 25. Eficiência média (\%) de controle de Phyllocoptruta oleivora, nas superficies adaxial e abaxial das folhas, até 56 dias da aplicação do produto azociclotin. São Pedro, SP. Agosto a outubro/ 1995.

\begin{tabular}{|c|c|c|c|c|c|c|c|c|c|c|c|c|}
\hline Trat. & \multicolumn{4}{|c|}{ Dias após a aplicação (sup. adaxial) } & \multicolumn{5}{c|}{ Dias após a aplicação (sup. abaxial) } \\
\cline { 2 - 11 } & $\mathbf{1}$ & $\mathbf{3}$ & $\mathbf{7}$ & $\mathbf{1 4}$ & $\mathbf{2 8}$ & $\mathbf{5 6}$ & $\mathbf{1}$ & $\mathbf{3}$ & $\mathbf{7}$ & $\mathbf{1 4}$ & $\mathbf{2 8}$ & $\mathbf{5 6}$ \\
\hline 1 & 100,0 & 100,0 & 100,0 & 100,0 & 100,0 & 91,6 & 100,0 & 100,0 & 100,0 & 100,0 & 100,0 & 79,4 \\
2 & 96,8 & 100,0 & 100,0 & 100,0 & 100,0 & 79,8 & 100,0 & 100,0 & 100,0 & 100,0 & 100,0 & 70,1 \\
3 & 96,0 & 100,0 & 100,0 & 100,0 & 100,0 & 83,6 & 93,2 & 100,0 & 100,0 & 100,0 & 100,0 & 86,6 \\
4 & 94,1 & 100,0 & 100,0 & 100,0 & 100,0 & 47,7 & 100,0 & 100,0 & 100,0 & 100,0 & 92,6 & 82,9 \\
Test. & - & - & - & - & - & - & - & - & - & - & - & - \\
\hline
\end{tabular}

A redução bastante acentuada na eficiência de controle aos 56 dias devese, em parte, ao menor número deles presente na testemunha neste periodo, proporcionalmente à população existente na testemunha antes da aplicação $(6,40$ e 2,00 em média, na avaliação prévia para a superficie adaxial e abaxial, respectivamente) o que pode ser comprovado pela fórmula de Henderson \& Tilton (NAKANO et al., 1981). Desconsiderando esta particularidade, mesmo assim, aos 56 dias foram constatadas menores eficiências de controle quando comparada às obtidas nas avaliações antecedentes a este período. Isto, provavelmente se deve aos menores niveis de resíduos presente nas folhas aos 56 dias após a aplicação deste acaricida.

Para as condições experimentais, a pulverização de menores volumes de calda (arranjo de bicos $A_{3}$, na velocidade de $5,1 \mathrm{~km} / \mathrm{h}$ e à $300 \mathrm{lbf} / \mathrm{pol}^{2}$ ) neste caso, de 6,8 litros/planta (tratamento 2), proporcionou uma economia substancial em tempo e volume de calda aplicado. Entretanto, menores níveis de resíduos podem ter influenciado na obtenção de menores eficiências de controle e, dessa forma, havendo a necessidade de maior número de pulverizações no pomar. 


\section{CONCLUSÕES}

Baseado nos dados obtidos nas condições do presente estudo podem ser extraídas as seguintes conclusões:

- Os depósitos médios de calda nas folhas variam com o volume de aplicação, velocidade de deslocamento, arranjo de bicos e posição delas na copa em relação à direção da pulverização. A combinação de menores velocidades de deslocamento, arranjo com maior número de bicos e maior pressão de trabalho propiciam melhores distribuição, deposição e penetração das pulverizações com o turboatomizador Arbus 2000/Export em citros.

- As velocidades de 3,6 e $5,1 \mathrm{~km} / \mathrm{h}$ são adequadas para a aplicação de defensivos na citricultura com os turboatomizadores Arbus 2000/Export e Arbus 2000/850, independente da pressão de trabalho e arranjo de bicos.

- O arranjo de bicos $\mathrm{A}_{3}$ (35 bicos JA-2, distribuídos em ramais superior e inferior de pulverização) mostra-se adequado para a aplicação de defensivos em citros à $300 \mathrm{lbf} / \mathrm{pol}^{2}$. 
- Variações nas condições operacionais do turboatomizador Arbus 2000 / Export não mostram diferenças no controle das espécies de ácaros-pragas nesta cultura com o acaricida azociclotin.

- Não há diferenças no controle de ácaros com o produto azociclotin para pulverizações realizadas à $300 \mathrm{lbf} / \mathrm{pol}^{2}$ com os equipamentos Arbus 2000/Export e Arbus 2000/850 deslocando-se nas menores velocidades em teste $(3,6$ e $5,1 \mathrm{~km} / \mathrm{h})$.

. O produto azociclotin, na dosagem comercialmente recomendada $(100 \mathrm{~g}$ de p.c./100 litros d'água), mostra-se eficiente no controle dos ácaros Phyllocoptruta oleivora e Brevipalpus phoenicis por 30 dias, e Panonychus citri por 16 dias da aplicação, independente da combinação dos fatores pressão, velocidade e arranjo de bicos.

- O acaricida azociclotin, pulverizado na base de $75 \%$ da dosagem comercialmente recomendada com o turboatomizador Arbus 2000/Export equipado com o arranjo $\mathrm{A}_{3}$ (35 bicos JA-2) proporciona níveis de controle de Panonychus citri equivalentes aos obtidos com $100 \%$ da dosagem recomendada, com o mesmo equipamento de pulverização. 


\section{REFERÊNCIAS BIBLIOGRÁFICAS:}

AKESSON, N. M. ; YATES, W. E. Pesticide application equipment and techniques. Rome: FAO, 1979. 257 p. (FAO Agricultural Bulletin, 38).

ANDREI, E. coord. Compêndio de defensivos agrícolas. São Paulo: Andrei, 1996. p. 338.

ANTONIN, P.; FELLAY, D.; MITTAZ, C. Pulvérisation à bas volume en arboriculture: quatre années d'expérimentation. Revue suisse Vitic., Arboric., Hortic., v. 19, n.5, p. $275-81,1987$.

ANTUNIASSI, U. R.; VELINI, E. D.; MARTINS, D. Spray deposition and drift evaluation of air-carrier peach orchard sprayers. In: INTERNATIONAL CONFERENCE ON AGRICUltural ENGINEERING, Madrid, 1996. Paper, 96A-136. Madrid: AgEng, september, 1996. v.1, p. 1-7. 
BULLOCK, R.C.; BROOKS, R.F.; WHITNEY, J.D. A method of evaluating pesticide application equipment for Florida citrus. Journal of Economic Entomology, v.61, n.6, p. $1511-4,1968$.

BYASS, J.B. Equipment and methods for orchard spray application research. II. The geometry of apple trees. Journal of Agricultural Engineering Research, v.13, n. 4 , p. $358-69,1968$.

BYERS, R.E. Tree-row-volume spraying rate calculator for apples. Hortscience, v.22, n.3, p. 506-7, 1987.

CARMAN, G.E. Spraying procedures for pest control on citrus. In: CIBA-GEIGY AGROCHEMICALS, ed. Citrus. Basle: Ciba-Geigy agrochemicals, 1975. p. 2834. (Technical Monograph, 4).

CARMAN, G.E.; IWATA, Y.; GUNTHER, F.A. Pesticide deposition on citrus orchard soil resulting from spray drift and runoff. Bulletin of Environmental Contamination and Toxicology, v.18, n.6, p. 706-10, 1977.

CARMAN, G.E.; JEPPSON, L.R. Low volume applications to citrus trees: method for evaluation of spray droplet distributions. Journal of Economic Entomology, v.67, n.3, p. 397-402, 1974.

CARPENTER, T.G.; REICHARD, D.L.; KHAN, A.S. Spray deposition from a rowcrop airblast sprayer. Transactions of the ASAE, v.26, n.2, p. 338-42, 1983. 
CATI. Citros: recomendações para o controle das principais pragas e doenças em pomares do Estado de São Paulo 1990/91. 4.ed. Campinas: CATI, 1991. 55p. (Boletim Técnico, 165).

CROSS, J.V.; BERRIE, A.M. Efficacy of reduced volume and reduced dose rate spray programmes in apple orchards. Crop Protection, v.9, n.3, p. 207-17, june, 1990.

DERKSEN, R. C.; BRETH, D. I. Orchard air - carrier sprayer application accuracy and spray coverage evaluations. Applied Engineering in Agriculture, St. Joseph, v.10, n. 4 , p. $463-70,1994$.

DERKSEN, R. C.; GRAY, R. L. Deposition and air speed patterns of air-carrier apple orchard sprayer. Transactions of the ASAE, v.38, n.1, p. 5-11, 1995.

EDWARDS, G.J.; THOMPSON, W.L.; KING, U.R.; JUTRAS, P.J. Optical determination of spray coverage. Transactions of the ASAE, v.4, p. 206-7, 1961.

FRANKEL, H.; GROSS, Y.; AUSTERWEIL, M.; NAHIR, D.; NEUBAUER, I. Red scale control in citrus with a peripheral small-volume sprayer. Hassadeh, v. 57, n. 8, p. 463-8, 1976. (Hebraico).

GILES, D.K.; DELWICHE, M.J.; DODD, R.B. Control of orchard spraying based on electronic sensing of spray target characteristics. ASAE Paper, 87=1069. St. Joseph: ASAE, june / july, 1987. 
GILES, D. K. ; DELWICHE, M. J. ; DODD, R. B. Sprayer control by sensing orchard crop characteristics: orchard architecture and spray liquid savings. Journal of Agricultural Engineering Research, v.43, n.4, p. 271-89, 1989.

HALL, F. R.; REICHARD, D. L.; KRUEGER, H. R. Effects of spray volume and nozzle pressure on orchard spray deposits. Journal of Economic Entomology, v.74, n.4, p.461-5, august, 1981.

HIMEL, C. M. The fluorescent particle spray droplet tracer method. Journal of Economic Entomology, v.62, n.4, p. 912-6, august, 1969.

JUSTE, F.; SANCHEZ, S.; IBANEZ, R.; VAL, L.; GARCIA, C. Measurement of spray deposition and efficiency of pesticide application in citrus orchards. Journal of Agricultural Engineering Research, v.46, p. 187-96, 1990.

MATTHEWS, G. A. Chemicals and equipment: determination of droplet size. PANS, v.21, n.2, p. 213-25, june, 1975.

MATUO, T. Desenvolvimento de um pulverizador intermitente operado fotoeletricamente para tratamento de pomares de citros. Jaboticabal, 1988. 167p. Tese Livre Docência - Faculdade de Ciências Agrárias e Veterinária, Universidade Estadual Paulista.

MATUO, T. Técnicas de pulverização de pomares de citros; Análise e perspectivas. Laranja, v.5, p. 115-29, 1984.

MATUO, T. Técnicas de aplicação de defensivos agrícolas. Jaboticabal: Funep, 1990. $139 \mathrm{p}$. 
McCOY, C. W. ; LYE, B. H. ; SALYANI, M. Effect of spray volume on the residual control of citrus rust mite. Citrus \& Vegetable Magazine, v.53, n.5, p. 23, 64-5, january, 1990.

MORGAN, N. G. Minimizing pesticide waste in orchard spraying. Outlook on Agriculture, v. 10, p. 342-4, 1981.

MORIYA, S.; SHIBUYA, M. Spray deposit on apple trees by low volume application. Journal of Pesticide Science, v.9, n.2, p. 293-7, may, 1984.

MURARO, R. P.; HURNER, G. T.; OSWALT, T. W. Budgeting costs and returns: Central Florida citrus production. Univ. of Florida: IFAS, 1988. (Economic Information Report, 248).

NAKANO, O.; SILVEIRA NETO, S.; ZUCCHI, R. A. Entomologia econômica. São Paulo: Nobel, 1981. 314p.

NOGUEIRA, H. C. Avaliação da uniformidade de deposição e perdas de calda na utilização de um pulverizador desenvolvido para aplicação de herbicidas em ferrovias. Botucatu, 1996. 72p. Dissertação (Mestrado) - Faculdade de Ciências Agronômicas, Universidade Estadual Paulista.

NORBDO, E. Effects of nozzles size, travel speed and assistance on deposition on artificial vertical and horizontal targets in laboratory experiment. Crop Protection, v. 11, n.3, p. 272-8, 1992.

OLIVEIRA, C.A.L. de. Máquina de varredura de ácaro "Modelo Jaboticabal". Anais da Sociedade Entomológica do Brasil, v. 12, n.2, p. 299-303, 1983. 
PALLADINI, L.A. Efeito de condições operacionais de um turboatomizador na cobertura de folhas de citros. Jaboticabal, 1990. 93p. Dissertação (Mestrado) - Faculdade de Ciências Agrárias e Veterinária, Universidade Estadual Paulista.

PALLADINI, L. A. Efeitos de diferentes condições operacionais de turboatomizador na cobertura das folhas de macieira. Caçador: EMPASC - Estação Experimental de Caçador, 1991. p. 133-51: Relatório técnico de pesquisa 1990/91.

PEREGRINE, D. J· DOUGHTON, N. E.; SOUTHCOMBE, E. S. E. The influence of application volume on the efficacy of clofentezine used early season for the control of Panonychus ulmi (Koch) on apples. In: BRITISH CROP PROTECTION CONFERENCE - PESTS AND DISEASES, Brighton, 1986. Proceedings. Brighton: BCPC, 1986. p. 307-14.

RANDALL, J M. The relationships between air volume and pressure on spray distribution in fruit trees. Journal of Agricultural Engineering Research, v. 16, n. 1, p. 131, 1971.

SALYANI, M. Droplet size effect on spray deposition efficiency. ASAE Paper, 871536. St. Joseph: ASAE, december, 1987.

SALYANI, M. Spray deposition and drift from airblast sprayers used in citrus applications. Citrus Industry, v.76, n. 1, p. 35-9, january, 1995.

SALYANI, M. ; McCOY, C. W. Spray droplet size effect on mortality of citrus rust mite. In: HAZEN, J. L. ; HOVDE, D. A. ed. Pesticide formulations and application systems: International aspects. Philadelphia: ASTM, 1989. v.9, p. 262-73. 
SALYANI, M. ; WHITNEY, J. D. Effect of oscillators on deposition characteristics of an airblast sprayer. Transactions of the ASAE, v.34, n.4, p. 1618-22, july / august, 1991.

SALYANI, M.; WHITNEY, J. D. Evaluation of methodologies for field studies of spray deposition. Transactions of the ASAE, v. 31, n.2, p. 390-5, 1988.

SALYANI, M. ; WHITNEY, J. D. Ground speed effect on spray deposition inside citrus trees. Transactions of the ASAE, v.33, n.2, p. 361-6, march / april, 1990.

SARTORI, S.; HONDA, A. I. Estudo de pulverização a baixo volume em citros com atomizador de bocais oscilantes. Pompéia: Jacto, s.d. 20p. (mimeografado).

SHARP, R.B. A rapid method of spray deposit measurement and its use in new apple orchards. In: BRITISH INSECTICIDE AND FUNGICIDE CONFERENCE, 7, Brighton, 1973. Proceedings. Brighton: BCPC, 1973. p. 637-41.

STAFFORD, E. M.; BYASS, J. B.; AKESSON, N. B. A fluorescent pigment measure spray coverage. Journal of Economic Entomology, v.63, n.3, p. 769-76, 1970.

TRAVIS, J. W.; SKROCH, W. A.; SUTTON, T. B. Effect of canopy density on pesticide deposition and distribution in apple trees. Plant Disease, v.71, n.7, p. 613-5, july, 1987a. 
TRAVIS, J. W. ; SKROCH, W. A. ; SUTTON, T. B. Effects of travel speed, application volume, and nozzle arrangement on deposition and distribution of pesticides in apple trees. Plant Disease, v.71, n. 7, p. 606-12, july, 1987b.

VAN EE, G. R.; LEDEBUHR, R. L.; POTTER, H. S. Air curtain increases spraying efficiency. Agricultural Engineering, v.66, n.7, p. 15-7, july, 1985.

VELINI, E. D.; ANTUNIASSI, U. R.; MARTINS, D.; TRINDADE, M. L. B. ; SILVA, M. A. S. Utilização da condutividade elétrica para a avaliação do depósito da calda de pulverização em alvos ou folhas. In: CONGRESSO BRASILEIRO DA CIÊNCIA DAS PLANTAS DANINHAS, 20., Florianópolis, 1995. Resumos. Florianópolis: SBCPD, 1995. p. 427-9, julho.

WHITNEY, J.; SALYANI, M. Deposition characteristics of two air-carrier sprayers in citrus trees. Transactions of the ASAE, v.34, n. 1, p. 47-50, january / february, 1991.

WHITNEY, J.; BROOKS, R. F.; BULLOCK, R. C. Pesticide application methods for citrus in Florida. Proceedings of the International Society of Citriculture, p. 1637, 1978 . 